RPP-RPT-45825, Rev. 0

\title{
Tank Space Alternatives Analysis Report
}

D. A. Turner and P. S. Schaus et. al.

Washington River Protection Solutions LCC, A E M Consulting LLC

Richland, WA 99352

U.S. Department of Energy Contract DE-AC27-08RV14800

$\begin{array}{llll}\text { EDT/ECN: } & \text { DRF } & \text { UC: NA } & \\ \text { Cost Center: } & \text { 2GB00 } & \text { Charge Code: } & 200700 \\ \text { B\&R Code: } & \text { NA } & \text { Total Pages: } & 74\end{array}$

Key Words: tank, space, waste, retreival, DST, double-shell, alternatives, options, storage, decision,

Abstract: This report adresses the projected shortfall of double-shell tank (DST) space starting in 2018. Using a multi-variant methodology, a total of eight near-term options and 17 long-term options for recovering DST space were evaluated. These include 11 options that were previously evaluated in RPP 7702, Tank Space Options Report (Rev. 1). Based on the results of this evaluation, two near-term and three long-term options have been identified as being sufficient to overcome the shortfall of DST space projected to occur between 2018 and 2025.

TRADEMARK DISCLAIMER. Reference herein to any specific commercial product, process, or service by trade name, trademark, manufacturer, or otherwise, does not necessarily constitute or imply its endorsement, recommendation, or favoring by the United States Government or any agency thereof or its contractors or subcontractors.
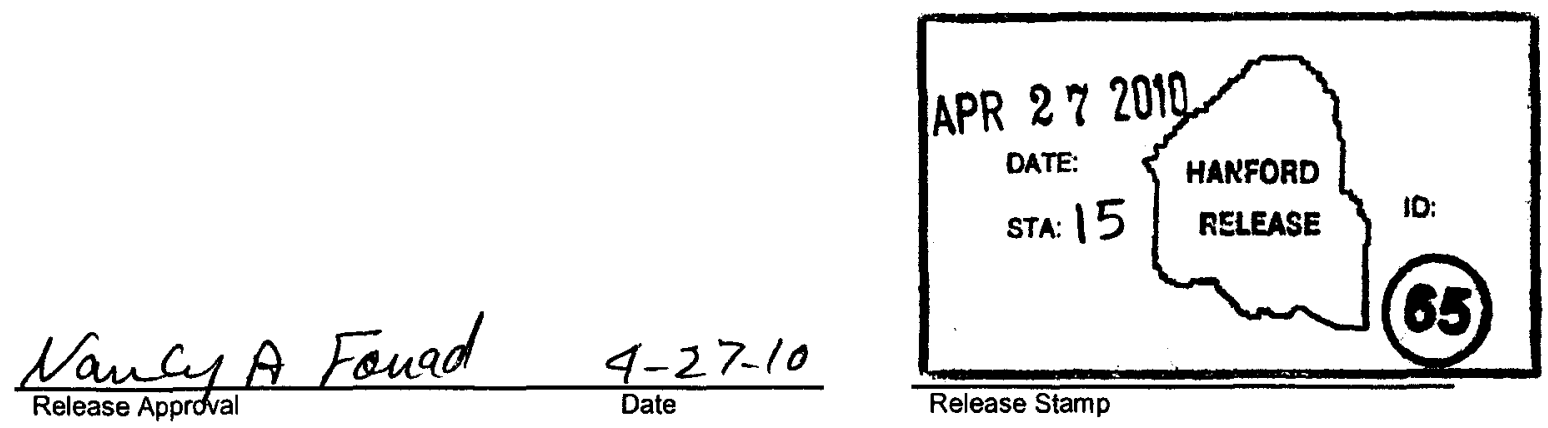

\section{Approved For Public Release}


RPP-RPT-45825

Revision 0

\section{Tank Space Alternatives Analysis Report}

Prepared for the U.S. Department of Energy

Assistant Secretary for Environmental Management

Contractor for the U.S. Department of Energy

Office of River Protection under Contract DE-AC27-08RV14800

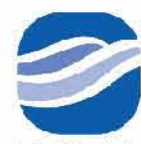

washington river

protection solutions

P.O. Box 850

Richland, Washington 


\section{Tank Space Alternatives Analysis Report}

\section{Author}

D. A. Turner

N. W. Kirch

D. J. Washenfelder

Washington River Protection Solutions, LLC

\section{Author}

P. S. Schaus

D. D. Wodrich

S. A. Wiegman

A E M Consulting, LLC

Date Published

April 9, 2010

Prepared for the U.S. Department of Energy

Assistant Secretary for Environmental Management

Gontractor for the U.S. Department of Energy

Office of River Protection under Contract DE-AC27-08RV14800

\section{washington river}

protection solutions

P.O. Box 850

Richland, Washington 


\section{TRADEMARK DISCLAIMER}

Reference herein to any specific commercial product, process, or service by trade name, trademark, manufacturer, or otherwise, does not necessarily constitute or imply its endorsement, recommendation, or favoring by the United States Government or any agency thereof or its contractors or subcontractors.

This report has been reproduced from the best available copy.

Printed in the United States of America

\section{washington river protectionsolutions}

Contractor for the U.S. Department of Energy

Office of River Protection under Contract DE-AC27-08RV14800 


\section{EXECUTIVE SUMMARY}

The River Protection Project (RPP) System Plan (ORP-11242, Rev. 4) identified the need to address the projected shortfall of double-shell tank (DST) space starting in 2018. This shortfall could occur even sooner, if the current initiative to change the buoyant displacement gas release event (BDGRE) criteria for storing supernatant over settled solids is not successful. The need for DST space is driven by the requirement to continue retrieving waste from the single-shell tanks (SST) and at the same time to effectively support the delivery of waste feed to the Waste Treatment and Immobilization Plant (WTP). Recognizing that this issue needed to be addressed, the Tank Operations Contractor (TOC) commissioned a five-member team, the Tank Space Decision Support Board (DSB), to evaluate options that could mitigate the projected shortfall and to provide a set of recommended options for potential implementation.

Using a multi-variant methodology for its evaluation, the DSB evaluated a total of eight nearterm options (options that could be implemented between 2011 and 2015) and 17 long-term options (options that could potentially be implemented between 2016 and 2020). These included 11 options that were previously evaluated in RPP-7702, Tank Space Options Report (Rev. 1).

Based on the results of this evaluation, the DSB identified two near-term and three long-term options as being sufficient to overcome the shortfall of DST space projected to occur between 2018 and 2025. The options recommended by the DSB for implementation are:

\section{Near-Term Options (2011- 2015)}

- Recommended Option 1: Raising the allowable waste level in nine non-aging waste tanks would provide as much as $940 \mathrm{kgal}$ of additional tank space.

- Recommended Option 2: Concentrating the waste in 15 DSTs to a specific gravity (SpG) of $1.43 \mathrm{~g} / \mathrm{ml}$ at the $242-\mathrm{A}$ Evaporator would provide as much as $3,500 \mathrm{kgal}$ of additional tank space.

\section{Long-Term Options (2016 - 2020)}

- Recommended Option 3: Using four of the six planned Waste Retrieval Facility (WRF) tanks would create an additional $600 \mathrm{kgal}$ of tank space.

- Recommended Option 4: Using the DST space currently reserved as emergency space would make an additional 1,260 kgal of tank space available.

- Recommended Option 5: Implementing a revised SST retrieval sequence that would require DST space ranging from $2,170 \mathrm{kgal}$ (22 sludge tanks) to $4,240 \mathrm{kgal}$ (22 tanks, including all $\mathrm{A} / \mathrm{AX}$ tanks), compared to the $11,500 \mathrm{kgal}$ of tank space required for the 22-tank retrieval sequence shown in the RPP System Plan (Rev. 4), Table D-1 between 2016 and 2025.

Figure ES-1 shows the approximate time period in which these options would be implemented. 


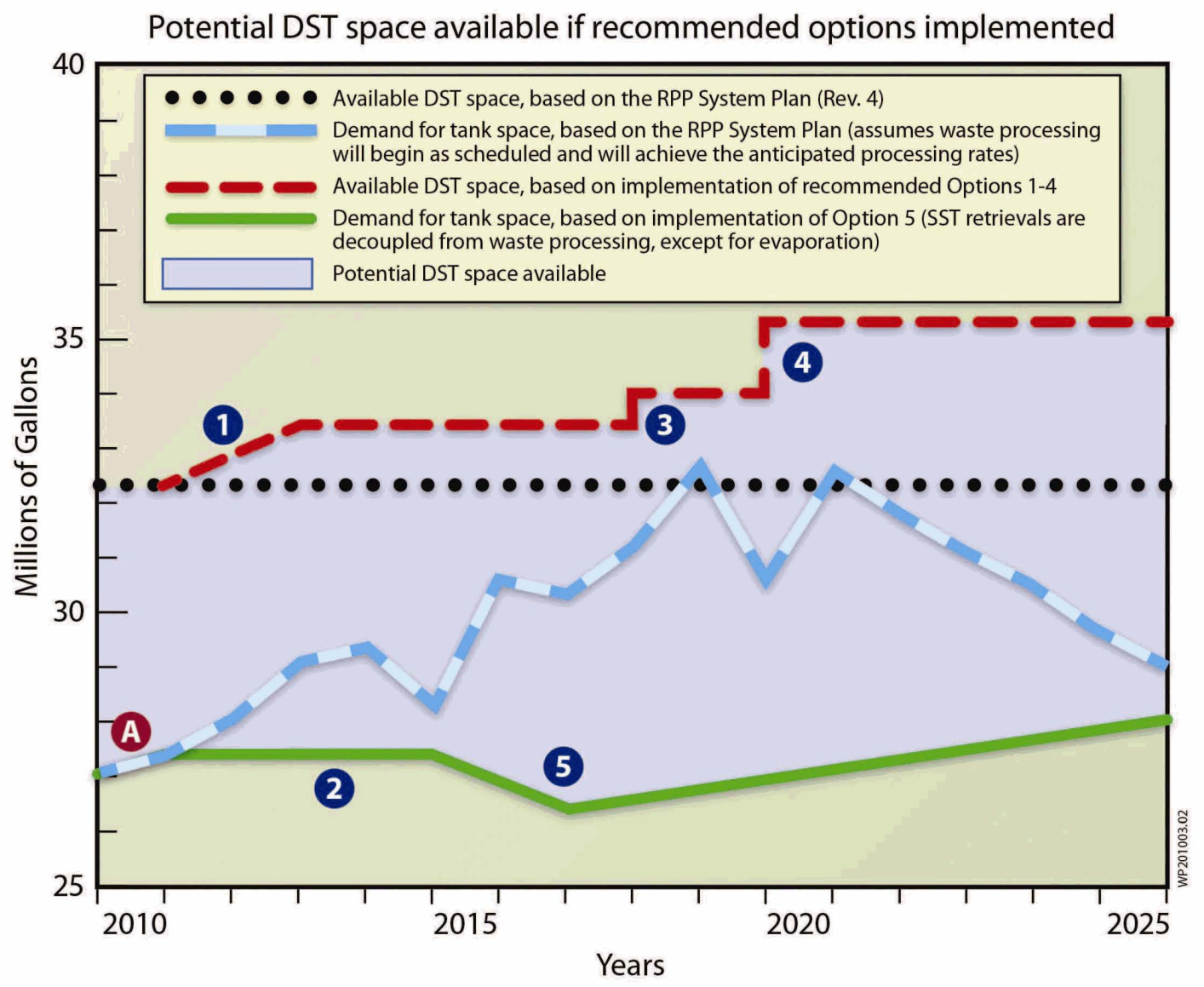

Figure ES-1. Potential Double-Shell Tank Space Available if Recommended Options are Implemented.

\section{Proposed options to increase DST capacity:}

(1) 2011 - 2015: Raise waste level in nine non-aging waste tanks

3 2018: Use four of six tanks in WRF

4 2020: Use DST emergency space

Change in DST space available, if proposed options implemented

A 2010 - 2014: Complete C Farm waste retrievals (included in RPP System Plan)

2 2011-2015: Concentrate waste in 15 DSTs at 242-A Evaporator

(5) 2016-2025: Retrieve SST waste per sludge tanks only retrieval sequence

${ }^{\text {a }}$ This represents a 9,500 kgal reduction in required DST space and decouples SST retrievals from the processing of waste during this period of time, except through evaporation. 
The advantages and disadvantages of implementing the recommended options relative to the current baseline as defined in the RPP System Plan (ORP-11242, Rev. 4) are described below.

\section{Advantages of implementing recommended options}

- Allows uninterrupted waste retrieval from at least 22 SSTs to continue through 2025 (compared with the RPP System Plan retrieval sequence for 22 SSTs that requires multiple shutdowns of retrieval systems after 2018, awaiting WTP to remove waste inventory from the DST system)

- Decouples SST waste retrieval from waste processing (other than evaporation campaigns) through 2025

- Improves the potential to provide DST space in support of the waste feed delivery mission

- Provides additional inventory of sludge waste as high-level waste feed to WTP

- Expands initiatives that are currently on-going (e.g., additional evaporation campaigns, raising waste levels in additional tank farms).

\section{Disadvantages of implementing recommended options}

- Requires two to three additional evaporator runs per year from 2011 through 2015

- Requires early operation of 200 East WRF to support retrievals from B-complex SSTs

- Reduces the inventory of saltcake waste as low-activity waste feed to WTP.

In the event that recommended options 1 through 5 do not yield the predicted DST space, the implementation of other space options identified by the DSB could be considered, including:

- Using sound SSTs for waste staging

- Raising waste levels in the aging waste DSTs

- Using tank space in DSTs classified as restricted-use tanks

- Using wiped-film evaporation at-tank to further concentrate waste, thereby freeing up additional tank space.

A summary of the scores of the short- and long-term options and alternatives and the proposed implementation are provided in Table ES-1. 
Table ES-1. Summary of Option Scores and Proposed Implementation. (2 pages)
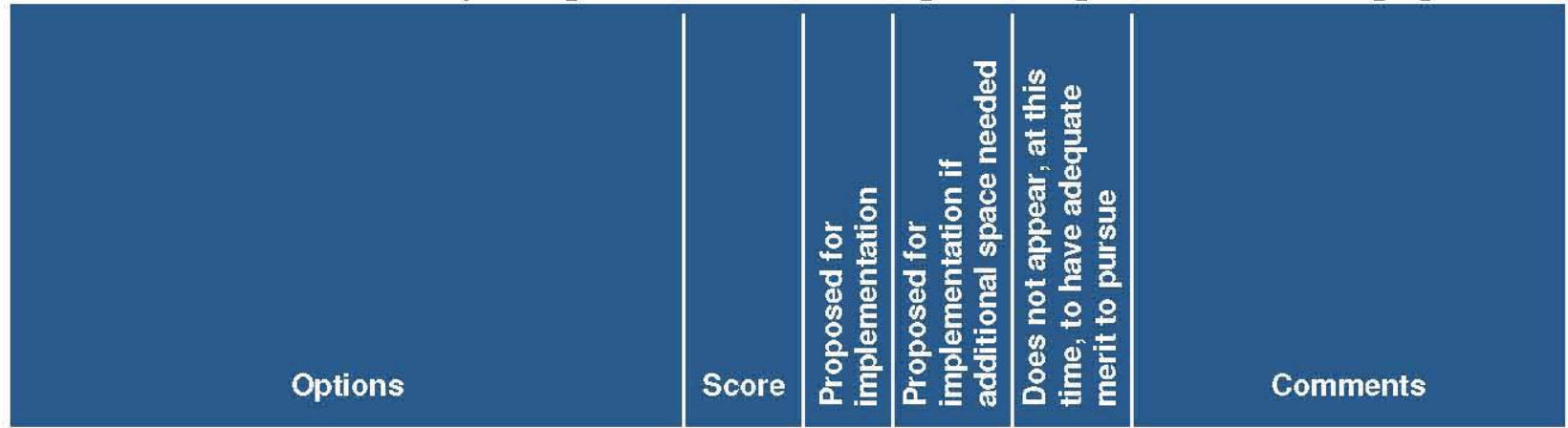

Near-Term Options

Raise waste level in nine non-aging DSTs

Concentrate waste in 15 DSTs at

242-A Evaporator to $1.43 \mathrm{~g} / \mathrm{ml}$

Raise waste level in three aging waste DSTs

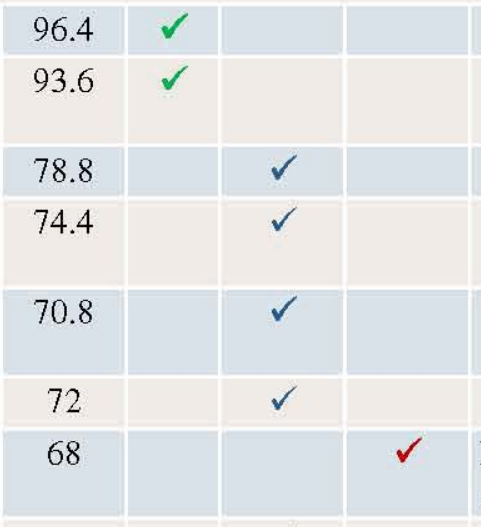

Not pursued because evaporation rate is low

Stage waste in sound SSTs

65.2

Tanks must be declared sound before considering this option

\section{Long-Term Options}

Revise SST retrieval logic and sequence

Decouples SST retrievals from waste processing

\section{Use receiver tanks in new facilities}

Accelerate construction of 200 East WRF

Expand capacity/accelerate construction of 200 East WRF

Utilize receiver tanks in a mix/blend facility

\section{2}

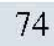

60.8

Utilize receiver tanks in Aluminum Removal

Facility

Accelerate startup and utilize receiver tanks in WTP

\section{Alternatives to Using DSTs for Emergency Storage}

Use sound SSTs for emergency space

Use DST annulus for leak collection and recycle

Use grout vault for emergency storage

Use modified grout vault for emergency storage
72.8

77.6

42

62
Implemented only if needed

Not pursued as other better options identified

Not pursued as other better options identified 
Table ES-1. Summary of Option Scores and Proposed Implementation. (2 pages)

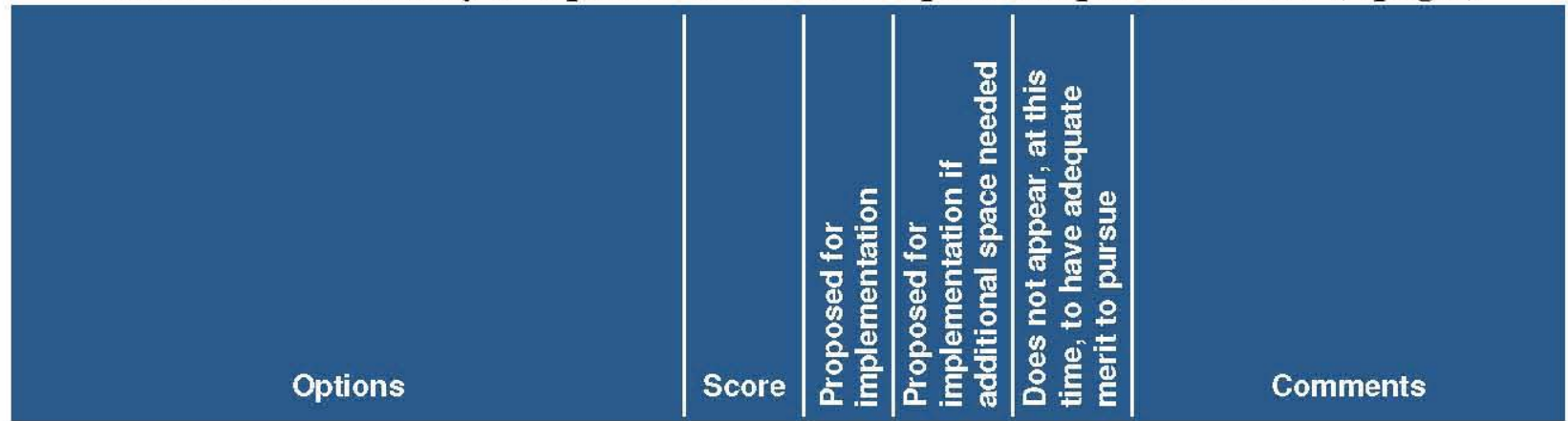

\section{Alternatives for Using WFE}

\begin{tabular}{|c|c|c|c|c|c|}
\hline $\begin{array}{l}\text { Use WFE at-tank to concentrate waste to } \\
1.5 \mathrm{~g} / \mathrm{ml}\end{array}$ & 58.4 & & $\checkmark$ & & $\begin{array}{l}\text { Also provides back-up to } \\
\text { 242-A Evaporator }\end{array}$ \\
\hline $\begin{array}{l}\text { Use WFE at-tank to concentrate waste to } \\
1.7 \mathrm{~g} / \mathrm{ml} \text { (damp saltcake) }\end{array}$ & 49.6 & & & $\checkmark$ & $\begin{array}{l}\text { Method to transfer } \\
\text { concentrated salts to tank not } \\
\text { developed }\end{array}$ \\
\hline $\begin{array}{l}\text { Pump-off liquid/fill with saltcake in BDGRE } \\
\text { tanks }\end{array}$ & 63.6 & & & $\checkmark$ & $\begin{array}{l}\text { While this option scored } \\
\text { higher, it would need to use } \\
\text { the WFE, which is not fully } \\
\text { developed }\end{array}$ \\
\hline \multicolumn{6}{|l|}{ New storage facility alternatives } \\
\hline $\begin{array}{l}\text { Use compliant bladder in lined basin to store } \\
\text { pretreated waste }\end{array}$ & 36.8 & & & $\checkmark$ & \\
\hline Use small modular tanks & 42.4 & & & $\checkmark$ & \\
\hline Build 4 new DSTs & 50 & & $\checkmark$ & & \\
\hline Build one large DST & 70 & & & $\checkmark$ & \\
\hline \multicolumn{2}{|c|}{$\begin{array}{ll}\text { BDGRE } & =\text { buoyant displacement gas release event. } \\
\mathrm{CC} & =\text { complexant concentrate. } \\
\mathrm{DST} & =\text { double-shell tank. }\end{array}$} & $\begin{array}{l}\text { WFE } \\
\text { WRF } \\
\text { WTP }\end{array}$ & $\begin{array}{l}= \\
= \\
=\end{array}$ & $\begin{array}{l}\text { wiped-fi } \\
\text { Waste R } \\
\text { Waste T } \\
\text { Plant. }\end{array}$ & $\begin{array}{l}\text { a evaporator. } \\
\text { rieval Facility. } \\
\text { atment and Immobilization }\end{array}$ \\
\hline
\end{tabular}

The DSB specifically focused on identifying and evaluating options that would generate tank space in the DST system and would make beneficial use of that space. The U.S. Department of Energy Office of River Protection and WRPS management will need to balance the recommendations provided in this report with other programmatic initiatives and constraints. 


\section{CONTENTS}

EXECUTIVE SUMMARY .ES-1

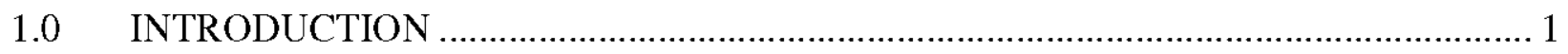

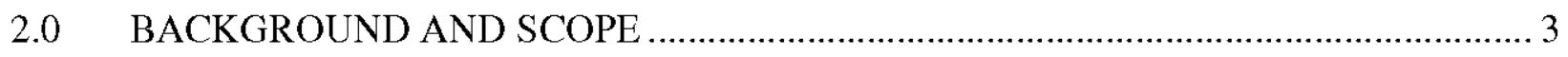

$3.0 \quad$ ALTERNATIVE ANALYSIS METHODOLOGY .............................................. 4

$3.1 \quad$ Evaluation Criteria and Goals ...................................................................... 4

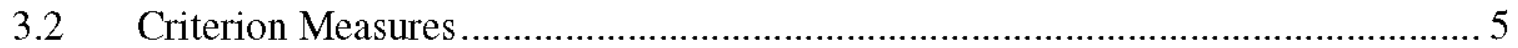

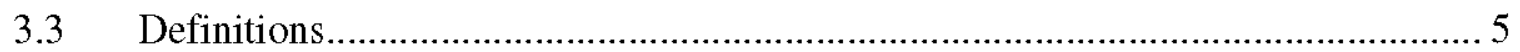

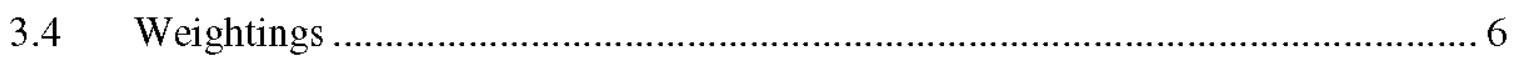

4.0 DESCRIPTIONS OF TANK SPACE OPTIONS ..................................................... 7

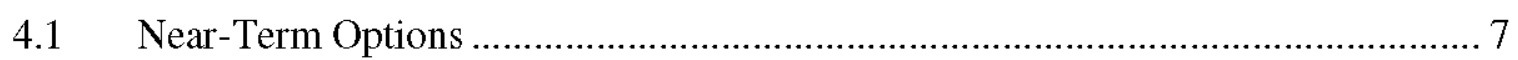

4.1.1 Raise Waste Levels in Nine Non-Aging Waste Tanks .............................. 7

4.1.2 Concentrate Waste to $1.43 \mathrm{~g} / \mathrm{ml}$ in 15 Tanks .........................................

4.1.3 Raise Waste Levels in Three Aging Waste Tanks ...................................9

4.1.4 Raise Waste Level/Concentrate Waste in Tank AY-102 ..........................9

4.1.5 Install Mixer Pumps and Use Restricted Space in Group A Tanks ...........10

4.1.6 Use Restricted Space in Complex Concentrate Tanks..............................11

4.1.7 Evaporate In-Tank Using Warm Dry Air ..............................................11

4.1.8 Stage Sludge Waste in Sound Single-Shell Tanks..................................12

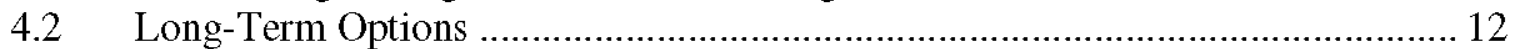

4.2.1 Alternative Single-Shell Tank Retrieval Sequence...................................12

4.2.2 Use Receiver Tanks in Planned Facilities.................................................16

4.2.3 Alternatives to Using Double-Shell Tanks for Emergency Storage ...........18

4.2.4 Alternatives for Using Wiped-Film Evaporation....................................20

4.2.5 New Storage Facility Alternatives ..............................................22

5.0 ALTERNATIVES ANALYSIS OF TANK SPACE OPTIONS ................................ 24

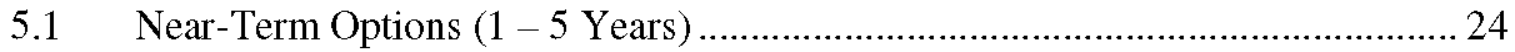

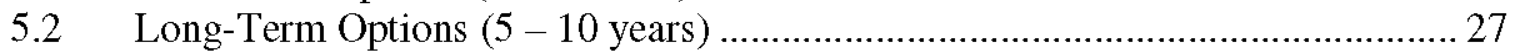

5.2.1 Alternative Retrieval Sequence .............................................................28

5.2.2 Use Receiver Tanks in Planned Facilities..............................................29

5.2.3 Alternatives to Using Double-Shell Tanks for Emergency Storage ...........30

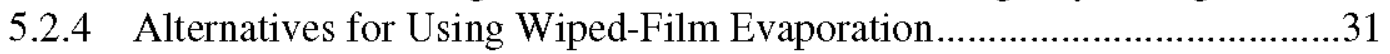

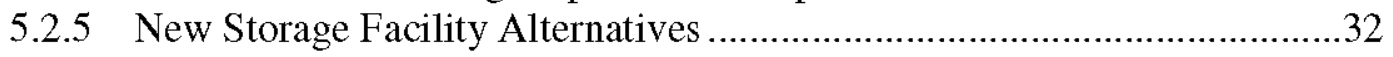

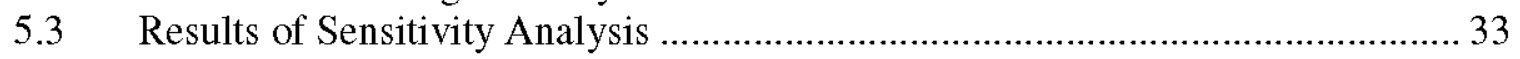

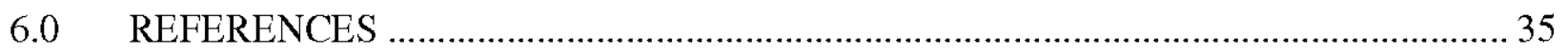




\section{APPENDICES}

Appendix A. Decision Criteria, Measures, and Definitions for Evaluating Double-Shell Tank Space Options ............................................................................... A-i

Appendix B. Double-Shell Tank Space Options Scoring - Near-Term Options ..................... B-i

Appendix C. Double-Shell Tank Space Options Scoring - Long-Term Options .................. C-i

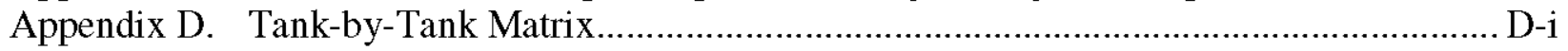

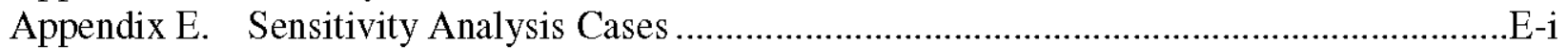

Appendix F. Summary of Decision Support Board Meetings .................................................

Appendix G. Decision Support Board Member Bios ......................................................... G-i 


\section{LIST OF FIGURES}

Figure 4-1. Time Averaged Demand for Double-Shell Tank Space (2016-2025). ...................16

Figure 5-1. Sensitivity Cases - Near-Term Options.................................................................33

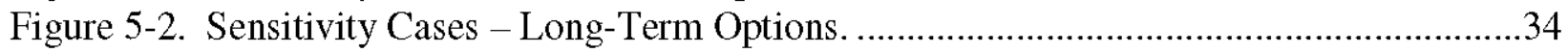

\section{LIST OF TABLES}

Table 4-1. Increased Volume of Non-Aging Waste Tanks by Raising Allowable Waste Levels.

Table 4-2. Recovered Tank Volume by Increasing Specific Gravity to $1.43 \mathrm{~g} / \mathrm{ml}$.

Table 4-3. Increased Volume of Three Aging Waste Tanks by Raising Allowable Waste Levels

Table 4-4. Increased Volume of Tank Space in Group A (Buoyant Displacement Gas Release Event) Tanks

Table 4-5. Increased Volume of Tank Space in Group A (Buoyant Displacement Gas Release Event) Tanks

Table 4-6. River Protection Project System Plan (Table D-1) Retrieval Sequence for Single-Shell Tanks (2016 - 2025).

Table 4-7. Alternative Single-Shell Tank Retrieval Sequence (2016 - 2025)

Table 4-8. Alternative Single-Shell Tank Retrieval Sequence with All 10 A/AX Tanks $(2016-2025)$

Table 5-1. Summary of Near-Term Options Weighted Scoring.

Table 5-2. Summary of Long-Term Options Weighted Scoring. (2 pages) 


\section{LIST OF TERMS}

$\mathrm{AB}$

ARF

BDGRE

$\mathrm{CC}$

CH-TRU

DOE

DNFSB

DSB

DST

HAB

HLW

LAW

LDR

ORP

RCRA

RPP

$\mathrm{SpG}$

SST

TF

TOC

TRL

TRU

WFE

WRF

WRPS

WTP

authorization basis

Aluminum Removal Facility

buoyant displacement gas release event

complexant concentrate

contact-handled transuranic

U.S. Department of Energy

Defense Nuclear Facilities Safety Board

Decision Support Board

double-shell tank

Hanford Advisory Board

high-level waste

low-activity waste

land disposal restrictions

Office of River Protection

Resource Conservation and Recovery Act

River Protection Project

specific gravity

single-shell tank

tank farm

Tank Operations Contractor

technology readiness level

transuranic

wiped-film evaporator

Waste Retrieval Facility

Washington River Protection Solutions, LLC

Waste Treatment and Immobilization Plant 


\subsection{INTRODUCTION}

The River Protection Project (RPP) System Plan (ORP-11242, Rev. 4) documents the technical and programmatic baseline for the RPP. One of the RPP System Plan's major purposes is to identify and "define the issues that must be resolved in order to ensure successful completion of the RPP mission." One issue in particular that requires near-term attention is the projected shortfall of double-shell tank (DST) space, starting in 2018. This shortfall potentially impacts the ability to continue retrieval of waste from the single-shell tanks (SST) and to effectively support the delivery of waste feed to the Waste Treatment and Immobilization Plant (WTP).

This document (the Tank Space Alternatives Analysis Report) describes the results of the evaluation of a number of options that could potentially mitigate the projected shortfall of tank space in the DST system. The alternatives analysis report also recommends a preferred set of options, once the current baseline tank space initiatives as described in the RPP System Plan have been fully implemented and utilized (e.g., raising the fill level in all AP Farm tanks). Three types of options were evaluated:

1. Options that would improve the utilization of existing tanks (e.g., increased fill heights in additional DSTs, further concentrating waste at the 242-A Evaporator) could typically be implemented in the near-term (next $1-5$ years) and would provide distributed tank space within the existing DST system.

2. Options that would typically require the design and construction of a new storage facility (e.g., Waste Retrieval Facility [WRF]) or modification to an existing facility (e.g., staging waste in a sound SST) could be implemented in the longer term (5 - 10 years) and would provide waste storage capacity outside of the existing DST system.

3. Options that would provide an alternative approach to the tank retrieval sequence shown in Table D-1 of the RPP System Plan (Rev. 4) and would potentially select a significantly different set of candidate SSTs for retrieval after completion of the C Farm retrievals, starting in 2016 through 2025.

The Tank Operations Contractor (TOC), Washington River Protection Solutions (WRPS), manages this activity on behalf of the U.S. Department of Energy (DOE) Office of River Protection (ORP). WRPS management impaneled a five-person Decision Support Board (DSB), comprised of three independent subcontractors and two members of WRPS technical staff, to perform this alternatives analysis (i.e., to evaluate the tank space options).

Several options to increase DST space were previously identified in RPP-7702, Tank Space Options Report, and were preliminarily evaluated for their potential to be implemented. As an initial step to this analysis, several new options were identified for inclusion in the evaluation of alternatives and for opportunities to further enhance some of the options in RPP-7702.

Each tank space option was evaluated using a multi-variant methodology that assigned measures, definitions, and weightings for each of the selected evaluation criteria. This methodology is described in RPP-PLAN-45168, Tank Space Options Decision Plan. The Decision Plan describes the process for identifying, evaluating, and comparing options that might be considered to store retrieved SST wastes and/or to support the waste feed delivery mission and for selecting and recommending the preferred options. 
The DSB specifically focused on identifying and evaluating options that would generate tank space in the DST system and would make beneficial use of that space. The U.S. Department of Energy Office of River Protection and WRPS management will need to balance the recommendations provided in this report with other programmatic initiatives and constraints. 


\subsection{BACKGROUND AND SCOPE}

There are approximately 57 million gallons (Mgal) of highly radioactive nuclear wastes resulting from the processing of irradiated fuels that are currently being stored in a total of 149 SSTs and 28 DSTs in the 200 Areas at Hanford. To continue to reduce the risk of waste leaking from the SSTs, one of the near-term cleanup initiatives at Hanford is to continue emptying SSTs and transferring waste to the DST system. However, the amount of SST waste that can be transferred is constrained by the limited space in the DST system until the WTP, which will treat and package the waste for disposal, becomes fully operational.

Given the current SST retrieval sequence and schedule, as defined in the RPP System Plan (ORP-11242, Rev. 4), it has been estimated that the DST system will not be able to support RPP's programmatic needs and goals, including continued retrieval of SST waste, between 2018 and 2025. This shortfall in available DST space could occur even earlier, if the current initiative to revise the criteria for limiting the depth of supernatants that can be stored on high-shear strength settled solids is not successful. The existing criteria used to prevent making new waste configurations that could exhibit buoyant displacement gas release events (BDGRE) are based on the behavior observed in low-shear strength waste (typical of saltcake waste) in the six DSTs that have historically had BDGRE-related concerns. If these same criteria continue to be applied to the DSTs receiving the sludge wastes from C-Farm, it is estimated that as much as 1,000 to $2,000 \mathrm{kgal}$ of tank space may no longer be available.

Based on information found in Table D-1 of the RPP System Plan (Rev. 4), it is estimated that approximately $11,500 \mathrm{kgal}$ of DST space are needed to store the waste volume generated by the 22 SSTs scheduled for retrieval to the DST system between 2016 and $2025 .^{1}$

The scope of this alternatives analysis is to:

- Identify additional options not included in RPP-7702

- Evaluate each of the tank space options using a predetermined set of weighted evaluation criteria, in accordance with RPP-PLAN-45168

- Recommend to WRPS management a set of options that provide tank space for the RPP technical and programmatic needs.

This alternatives analysis report is structured as follows:

- Section 3.0 describes the methodology used for performing the evaluation of options

- Section 4.0 describes each of the evaluated options

- Section 5.0 documents the results of the evaluations

- Section 6.0 provides references of the key documents that were used for technical and programmatic information and background.

Appendices A-E provide the detailed results of the evaluations. Appendix F and Appendix G provide DSB meeting information and the qualifications of the DSB participants, respectively.

\footnotetext{
${ }^{1}$ According to the RPP System Plan, the waste from 11 additional SSTs in B Farm and T Farm are also scheduled to be retrieved for direct packaging during this same time period and are not addressed in this report.
} 


\subsection{ALTERNATIVE ANALYSIS METHODOLOGY}

The methodology used for evaluating the tank space options consisted of the following steps:

1. Identifying the evaluation criteria and goals

2. Developing two or more measures for each criterion

3. Defining each measure on a scale of 1 to 5

4. Establishing weighting factors for each of the criteria and parsing the weighting factor for each criterion between its measures

5. Evaluating each tank space option (based on available information) in relation to the identified criteria and measures

6. Combining those tank space options that are highly rated to provide tank space in support of the RPP mission

7. Documenting the tank space options evaluation and the recommended options in an alternatives analysis report

8. Presenting to WRPS management the recommended tank space options consistent with the alternatives analysis report.

The goals and measures for each of the five evaluation criteria are provided in Appendix A. Measures were developed in a manner that shows to what extent their associated criterion is met. Weighting factors (Appendix B) were then assigned to each measure commensurate with the relative importance.

The DSB evaluated and scored each tank space option against the measures discussed in Section 3.2. Each measure was given a rating of 1 to 5 , where " 5 " represents the best performance and " 1 " the worst performance against the measure. Based on the total points, rankings and ratings for each tank space option were developed. The DSB evaluated the data and determined the preferred tank space option, or the optimum combination of options.

\subsection{EVALUATION CRITERIA AND GOALS}

The following evaluation criteria and goals were selected for the analysis:

- Safety/regulatory compliance/stakeholder - to ensure that the tank farm authorization basis can accommodate the recommended options; to ensure compliance with environmental laws and regulation and DOE Orders; to ensure acceptance by other stakeholders (e.g., Hanford Advisory Board, Defense Nuclear Facilities Safety Board) and the Tribal Nations.

- Technical feasibility - to maximize technical confidence in the implementation of a tank space option

- Operability and maintainability - to ensure that a tank space option can be operated and maintained

- Cost and schedule - to optimize costs for a tank space option; to provide an implementation schedule that meets the needs for additional tank space 
- Impact on waste feed delivery mission - to ensure that the waste feed delivery mission can be supported by the deployment of an option.

The evaluation criteria, measures, and definitions are provided in Appendix A.

\subsection{CRITERION MEASURES}

For each of the evaluation criteria identified in Section 3.1, two or more measures were developed to help evaluate their respective criterion.

For the safety/regulatory compliance/stakeholder acceptance criterion, the measures were:

- Extent to which the existing authorization basis for tank farm operations will require modification

- The difficulty in achieving regulatory agency approval of modifications to existing environmental permits or issuance of new environmental permits

- Stakeholder and Tribal Nations acceptance.

For technical feasibility, the measures were:

- Estimated volume of tank space created

- Technical maturity.

For operability and maintainability, the measures were:

- Ability for facility/process to be operated and maintained

- Acceptability of secondary waste (if any) for disposal (this measure was not used in the final evaluations because it was found not to be a discriminator).

For implementation cost and schedule, the measures were:

- Estimated total cost, including design, procurement, installation, and operations

- Estimated cost per gallon of tank space created

- Project/activity in existing or planned facility

- Implementation schedule, including development and demonstration, design, procurement, installation, and startup.

For the impact to waste feed delivery mission, the four measures were:

- Impact to mixing/blending function

- Impact to sampling/characterization/certification function

- Impact to WTP pretreatment function

- Impact on retrieving or returning waste to a form that can be processed.

\subsection{DEFINITIONS}

Each of the measures listed in Section 3.2 is defined on a scale of 1 to 5, with a score of " 5 " being considered the best. For example, the measure "Ability for facility/process to be operated and maintained" is defined as being a " 5 " if the anticipated facility, operations, and/or processes required to support the proposed tank space option are similar to an existing tank farm facility, 
operation, and/or process. However, this same measure would be rated as a " 1 " if the anticipated facility, operations, and/or processes are new to the tank farms and would therefore require significant additional training of operating personnel, new procedures, etc.

\subsection{WEIGHTINGS}

The relative weightings assigned to each criterion are the result of consensus estimates by the members of the DSB as to their relative importance. Previous experience has shown that programmatic factors, such as cost and schedule, are typically more of a discriminator than other important criteria, such as regulatory compliance and stakeholder acceptance. This is caused by the relatively larger differences that are perceived to exist among the options when they are evaluated for cost and schedule. Conversely, an activity will typically not be undertaken if it is perceived to have little chance of obtaining regulatory approval or achieving stakeholder acceptance. 


\subsection{DESCRIPTIONS OF TANK SPACE OPTIONS}

\subsection{NEAR-TERM OPTIONS}

\subsubsection{Raise Waste Levels in Nine Non-Aging Waste Tanks}

Increasing the allowable waste levels in the non-aging DSTs can provide additional distributed capacity in support of continued retrieval of SST waste and/or support to the waste feed delivery mission. Levels have already been increased to 454 in., or 1,250 kgal, in Tanks AP-103 and AP-108, with the allowable levels in the remaining six AP Farm tanks scheduled to be raised in 2010. This alternatives analysis evaluated the impact of increasing the allowable waste levels in Tanks AN-101, AN-106, AW-102, AW-103, AW-104, AW-105, AW-106, SY-101, and SY-102. Other non-aging waste DSTs were not included in this option because of existing restrictions (hot commissioning feed for WTP [Section 4.1.4], Group A tanks [Section 4.1.5], and complexant concentrate tanks [Section 4.1.6]).

The option to raise the allowable level of waste in non-aging DSTs was previously evaluated in RPP-7702. The DSB agreed with the selection of tanks identified in that report, but slightly decreased the estimate of recovered volume from $990 \mathrm{kgal}$ to $940 \mathrm{kgal}$, based on improved information (Table 4-1).

Table 4-1. Increased Volume of Non-Aging Waste Tanks by Raising Allowable Waste Levels.

\begin{tabular}{|c|c|c|c|}
\hline Tank \# & Volume increase, kgal & Tank \# & Volume increase, kgal \\
\hline AN-101 & 104.5 & AW-105 & 104.5 \\
\hline AN-106 & 104.5 & AW-106 & 104.5 \\
\hline $\mathrm{AW}-102^{\mathrm{a}}$ & 104.5 & SY-101 & 104.5 \\
\hline AW-103 & 104.5 & SY-102 & 104.5 \\
\hline AW-104 & 104.5 & Total & 940.5 \\
\hline
\end{tabular}

a The normal operating capacity of Tank AW-102 is 409 in., rather than 416 in., to provide room for a dump and flush from the 242-A Evaporator.

The current operating capacity of the non-aging waste tanks is $1,140 \mathrm{kgal}$, which is equivalent to a level of $416 \mathrm{in}$. of waste in the tanks. To-date, structural analysis of the tanks shows there would be no impact on the integrity of the tanks from an increase in waste level (RPP-28968, Hanford Double-Shell Tank Thermal and Seismic Project - Summary of Combined Thermal and Operating with Seismic Analysis, and RPP-RPT-32237, Hanford Double-Shell Tank Thermal and Seismic Project - Increased Liquid Level Analysis for 241-AP Tank Farm). An increase in waste level to $454 \mathrm{in}$. in the tanks would still be $6 \mathrm{in}$. below the 460 -in. level of double containment for the annulus tank and would increase the operating capacity for each of these tanks to $1,250 \mathrm{kgal}$. 
The cost of this option was estimated to be $\$ 5.3$ million, primarily to cover documentation modifications, including waste level permits for each farm, and operating and engineering documents. No capital equipment is required, but limited modifications would also be needed to the instrumentation. This option would require approximately three years to complete.

\subsubsection{Concentrate Waste to $1.43 \mathrm{~g} / \mathrm{ml}$ in 15 Tanks}

The option of concentrating waste assumes that the 242-A Evaporator will be used. The nominal limit of specific gravity for tank waste evaporated at the $242-\mathrm{A}$ Evaporator is $1.43 \mathrm{~g} / \mathrm{ml}$. The DSB identified 15 tanks not currently in the planning baseline in which the waste can be further concentrated using the 242-A Evaporator. By increasing the density of waste in these 15 tanks to $1.43 \mathrm{~g} / \mathrm{ml}$, a total of up to $3,500 \mathrm{kgal}$ of DST space could potentially be recovered (Table 4-2).

Table 4-2. Recovered Tank Volume by Increasing Specific Gravity to $1.43 \mathrm{~g} / \mathrm{ml}$.

\begin{tabular}{|c|c|c|c|}
\hline Tank \# & Volume recovered, kgal & Tank \# & Volume recovered, kgal \\
\hline AN-101 & 266 & AP-108 & 26 \\
\hline AN-106 & 268 & AW-103 & 340 \\
\hline AP-101 & 78 & AW-104 & 132 \\
\hline AP-102 & 147 & AW-105 & 140 \\
\hline AP-103 & 138 & AY-101 & 450 \\
\hline AP-104 & 20 & SY-101 & 594 \\
\hline AP-105 & 72 & SY-102 & 254 \\
\hline AP-106 & 581 & Total & $\mathbf{3 , 5 0 6}$ \\
\hline
\end{tabular}

The option to concentrate waste from selected DSTs to a specific gravity of $1.43 \mathrm{~g} / \mathrm{ml}$ was previously evaluated in RPP-7702. However, the DSB revised the estimated number of tanks, and the resulting volume of recovered tank space, based on improved information that it developed for each tank.

The estimated cost of this option, which includes sampling and analyzing the tank waste, performing compatibility assessments, revising procedures, making cross-site transfers from the SY Farm, performing evaporator campaigns above the existing baseline, and transferring waste into Tank AW-102 and from Tank AW-106 back to the DST system, is \$23 million. This option would require two additional evaporator campaigns per year, and would require six years to complete.

Increasing the specific gravity ( $\mathrm{SpG}$ ) of Tank AZ-102 supernatant is currently in the baseline, and therefore was not included in this analysis. Tank AZ-101 supernatant is currently above the ${ }^{137} \mathrm{Cs}$ source term limit for the 242-A Evaporator and would have to be blended with supernatant from other tanks before it could be evaporated. Based on the difficulty of blending/diluting this supernatant, increasing the SpG of Tank AZ-101 supernatant was not evaluated. 


\subsubsection{Raise Waste Levels in Three Aging Waste Tanks}

The aging waste tanks in AY and AZ Farms were designed and built with side fill lines that penetrate the primary containment at the $370 \mathrm{in}$. level, and therefore currently restrict the allowable waste level in these tanks to an operating limit of $364 \mathrm{in}$. (1,000 kgal). To raise the waste level in three of these tanks (AY-101, AZ-101 and AZ-102) to 454 in. (1,250 kgal) would require that the sidewall penetrations be sealed to maintain primary containment. If the sidewall penetrations could be successfully sealed, almost $750 \mathrm{kgal}$ of additional distributed tank space would become available (Table 4-3).

\section{Table 4-3. Increased Volume of Three Aging Waste Tanks by Raising Allowable Waste Levels}

\begin{tabular}{|c|c|c|c|}
\hline Tank \# & Volume increased, kgal & Tank \# & Volume increased, kgal \\
\hline $\mathrm{AY}-101^{\mathrm{a}}$ & 247.5 & AZ-102 & 247.5 \\
\hline AZ-101 & 247.5 & Total & 742.5 \\
\hline
\end{tabular}

a There were previous concerns regarding the integrity of the Tank AY-101 primary wall, due to evidence of minor surface corrosion and moisture on the outside of the primary wall (see RPP-13361, 2003, Tank 241-AY-101 Fitness for Service, Rev. 0, CH2M HILL Hanford Group, Inc., Richland, Washington). Additional testing may be required to verify that Tank AY-101 could support the level rise.

The option to raise the allowable level of waste in three of the aging waste DSTs (AY-101, AZ-101, and AZ-102) was previously identified in RPP-7702, but was not further evaluated. The DSB concluded that this option had sufficient merit to evaluate it as part of this alternatives analysis.

The DSB estimated that the cost of developing and implementing this option would be approximately \$15 million, and would include both the cost for sealing the sidewall penetrations in these three tanks and the documentation modifications, including waste level permits for both farms, and operating and engineering documents. Limited modifications would also be needed to the instrumentation. This option would require approximately three years to complete.

\subsubsection{Raise Waste Level/Concentrate Waste in Tank AY-102}

Tank AY-102 has been set aside and its contents planned as the first feed to the WTP. While the DSB recognized that the waste in Tank AY-102 has been certified and designated for transfer to the WTP in support of hot commissioning, it concluded that there is sufficient time to recertify the contents of this tank if additional waste is added and/or its supernatant is further concentrated. Therefore, the DSB included this tank as one of the new options to evaluate as part of this alternatives analysis.

By raising the allowable waste level in Tank AY-102 to 454 in. (similar to the other three aging waste tanks described in Section 4.1.3), approximately $250 \mathrm{kgal}$ of additional tank space is gained. This increased level would require that the side fill penetration into the primary containment be sealed. Concentrating the supernatant in Tank AY-102 to $1.43 \mathrm{~g} / \mathrm{ml}$ would create an additional $215 \mathrm{kgal}$ of tank space, or a total of $465 \mathrm{kgal}$, if both raising the fill level and concentrating the supernatant are implemented. 
The DSB estimated that the cost of implementing this option would be approximately $\$ 15$ million. For concentrating the waste, costs would include sampling and analyzing the tank waste, performing compatibility assessments, performing evaporator campaigns above the existing baseline, and transferring waste into Tank AW-102 and from Tank AW-106 back to Tank AY-102 to be recertified for WTP hot commissioning feed. For raising the allowable waste level, the costs would include the cost for sealing the sidewall penetration in this tank, documentation modifications (including the waste level permit for Tank AY-102, and operating and engineering documents), and limited modifications to the instrumentation. There would also be costs associated with recertifying Tank AY-102 as hot commissioning feed for the WTP. Implementing this option would require approximately three to four years to complete.

\subsubsection{Install Mixer Pumps and Use Restricted Space in Group A Tanks}

This option proposes to use the restricted space in the Group A (BDGRE) tanks by first installing mixer pumps. The DSB concluded that all five Group A tanks should be evaluated because the allowable waste levels in these tanks could be raised and the currently restricted space used, if the BDGRE issue could be successfully addressed by mixing.

The use of the space in these tanks is currently restricted because BDGRE events could potentially occur. These events result in the episodic rollover of waste and the associated release of flammable hydrogen gases. The restricted BDGRE tanks associated with concerns for release of flammable gas are Tanks AN-103, AN-104, AN-105, AW-101, and SY-103. These episodic releases of the flammable gases could be mitigated by installing mixer pumps and periodically operating them in the Group A tanks. Pump installation and operation could potentially allow the remainder of the currently unused space in these five tanks to be filled, thereby creating more than 1,300 kgal of additional distributed tank space (Table 4-4).

Table 4-4. Increased Volume of Tank Space in Group A (Buoyant Displacement Gas Release Event) Tanks

\begin{tabular}{|c|c|c|c|}
\hline Tank \# & $\begin{array}{c}\text { Restricted volume } \\
\text { increase, kgal }\end{array}$ & $\begin{array}{c}\text { 454-in. level volume } \\
\text { increase, kgal }\end{array}$ & $\begin{array}{c}\text { Total volume } \\
\text { increase, kgal }\end{array}$ \\
\hline AN-103 & 200 & 104.5 & 304.5 \\
\hline AN-104 & 112 & 104.5 & 216.5 \\
\hline AN-105 & 36 & 104.5 & 140.5 \\
\hline AW-101 & 29 & 104.5 & 133.5 \\
\hline SY-103 & 422 & 104.5 & 526.5 \\
\hline Total & $\mathbf{7 9 9}$ & $\mathbf{5 2 2 . 5}$ & $\mathbf{1 , 3 2 1 . 5}$ \\
\hline
\end{tabular}

It should be noted that mixer pumps are already planned for future installation in these tanks to support the retrieval of the sludge waste. Therefore, initially this is an acceleration of cost, rather than a new cost to the project. However, because the design life of the mixer pumps is ten years, it was assumed that three of the pumps would be need to be replaced at a cost of $\$ 15 \mathrm{M}$ per pump. Additionally there would be costs associated with modifying the authorization basis from watch list-type controls to active mixing as the control mechanism, previously estimated to be 
$\$ 5$ million, and the ten years of additional operating costs, estimated by the DSB to be $\$ 5$ million per year. The total estimated cost for this option is approximately $\$ 100 \mathrm{M}$. The estimated construction time is approximately five years to complete pump installation and turnover for operation.

\subsubsection{Use Restricted Space in Complexant Concentrate Tanks}

The option to use the restricted space in the two complexant concentrate tanks (AN-102 and AN-107) was evaluated because the allowable waste levels in these tanks could be raised and the currently restricted space used, if the issues associated with these tanks could be successfully addressed.

Due to the presence of chemical complexants in the supernatant wastes, some of the transuranic (TRU) and strontium that are normally waste sludge constituents remain in the supernatant. As a result, the supernatant must first be chemically pretreated before it can be vitrified, so that the TRU and strontium constituents are not immobilized as part of the low-activity waste (LAW). If more supernatant waste is added to these two tanks, the volume of waste that will require future pretreatment increases proportionally. The total volume of waste currently stored in these two tanks is $2,138 \mathrm{kgal}$, of which $1,754 \mathrm{kgal}$ is supernatant. By increasing the allowable waste levels to $454 \mathrm{in}$. and using the currently restricted space, almost $400 \mathrm{kgal}$ of additional distributed tank space could potentially be made available (Table 4-5).

Table 4-5. Increased Volume of Tank Space in Complexant Concentrate Tanks

\begin{tabular}{|c|c|c|c|}
\hline Tank \# & $\begin{array}{c}\text { Restricted volume } \\
\text { increase, kgal }\end{array}$ & $\begin{array}{c}\text { 454-in. level volume } \\
\text { increase, kgal }\end{array}$ & $\begin{array}{c}\text { Total volume } \\
\text { increase, kgal }\end{array}$ \\
\hline AN-102 & 110 & 104.5 & 214.5 \\
\hline AN-107 & 71 & 104.5 & 175.5 \\
\hline Total & $\mathbf{1 8 1}$ & $\mathbf{2 0 9}$ & $\mathbf{3 9 0}$ \\
\hline
\end{tabular}

Using this additional tank space would potentially result in a $22 \%$ increase $(390 / 1,754 \times 100 \%)$ in the volume of complex concentrate waste requiring chemical pretreatment to remove the TRU and strontium constituents. The cost of implementing this option was estimated at $\$ 12.2$ million and could be implemented in one to two years.

\subsubsection{Evaporate In-Tank Using Warm Dry Air}

The option to evaporate waste in-tank using warm dry air was previously identified and evaluated in RPP-7702. The DSB used information developed for that report as the basis for further evaluating this option.

The option of evaporating tank waste using warm dry air would be considered as a supplement to evaporation conducted at the 242-A Evaporator, and its use was envisioned for only a limited number of tanks. The warm dry air would be sparged into the tank, where air would then cool to the waste temperature as it passes. With an airflow of $500 \mathrm{ft}^{3} / \mathrm{min}$, water would be removed (evaporated) at an estimated rate of $480 \mathrm{cc} / \mathrm{min}$, or about $66 \mathrm{kgal} / \mathrm{year}$ in each tank. A problem with this option is that while the air passes through the waste, the waste cools, thus reducing the 
amount of water being evaporated. The tank waste could be maintained at the desired temperature by adding a heater and mixer pump.

Because of the relatively low rate of tank space recovery, the potential added complexity of needing to heat and mix the waste to maintain its temperature, and the planned deployment of wiped-film evaporation technology at-tank (discussed in Section 4.2.4), the DSB concluded that this option did not warrant further evaluation.

\subsubsection{Stage Sludge Waste in Sound Single-Shell Tanks}

The option to stage sludge waste in sound SSTs was identified as an option in RPP-7702, but was not previously evaluated. In light of the current proposal to use sound SSTs in support of accelerated SST retrieval, the DSB concluded that this option should be evaluated as part of this alternatives analysis. This option does not include the effort to identify and establish that the SSTs are sound, only the effort to use the sound tanks.

The DSB estimated that there are approximately $650 \mathrm{kgal}$ of sludge that could be retrieved and staged in sound (i.e., non-leaking) SSTs. The proposed system of staging the sludge waste would require three sound SSTs as receiver tanks, one in 200 West and two in 200 East. As soon as sufficient DST space could be made available to accommodate the staged waste, it would be transferred from the sound SSTs to the DST system.

Because the cost of SST waste retrieval is already in the baseline, the estimated incremental cost of this option includes setting up the three SSTs as receivers ( $\$ 5$ million per tank), and pumping the sludge waste from the three SST receivers to the DST system (\$22 million per tank). Therefore, the total estimated cost of this option would be approximately $\$ 81$ million. Implementation of this option could be completed within five years, if this option is needed.

\subsection{LONG-TERM OPTIONS}

\subsubsection{Alternative Single-Shell Tank Retrieval Sequence}

Unlike the near-term and long-term tank space options that recover or create tank space as discussed above, this option evaluates one way of potentially using the space more efficiently. The baseline SST retrieval sequence is documented in Table D-1 of the RPP System Plan (Rev. 4). During the timeframe of interest for this alternatives analysis, 22 SSTs are listed as retrieval candidates between 2016 and 2025. These 22 tanks, located in four tank farms (A, AX, BY and SX), are listed in Table 4-6. Eleven of these SSTs contain large volumes of saltcake, ranging from $278 \mathrm{kgal}$ for Tank BY-102 to $431 \mathrm{kgal}$ for Tank SX-103. These large volumes of saltcake require significantly more post-evaporation DST storage volume, ranging from $757 \mathrm{kgal}$ for Tank BY-102 to 1,227 kgal for Tank SX-103, or an approximate threefold increase in DST tank volume. The total DST tank space required for these 22 retrievals is $11,635 \mathrm{kgal}$, of which $10,641 \mathrm{kgal}$ is required for the 11 saltcake tanks (the equivalent of almost nine DSTs).

Alternatively, by selecting 11 relatively low-volume and/or non-saltcake tanks from B/BY and $\mathrm{SX}$ Farms in place of the 11 high-volume/saltcake tanks (plus the 11 relatively low-volume and/or non-saltcake tanks shown in Table 4-6), the post-evaporation impact on DST space is reduced to $2,169 \mathrm{kgal}$, or the equivalent of approximately two DSTs, as shown in Table 4-7. 
Because there may be an RPP programmatic goal to complete the retrieval of A/AX tank farm, a second alternative would be to retrieve twelve low-volume sludge tanks from SX and B/BY farms, in addition to the ten $\mathrm{A} / \mathrm{AX}$ tanks. This retrieval sequence would have a post-evaporation impact on DST space of an estimated total of approximately 4,200 kgal, as shown in Table 4-8.

Table 4-6. River Protection Project System Plan (Table D-1)

Retrieval Sequence for Single-Shell Tanks (2016 - 2025).

\begin{tabular}{|c|c|c|c|c|c|c|c|c|}
\hline & Tank & $\begin{array}{l}\text { Sludge } \\
\text { volume }\end{array}$ & $\begin{array}{l}\text { Saltcake } \\
\text { volume }\end{array}$ & $\begin{array}{c}\text { Supernatant } \\
\text { volume }\end{array}$ & $\begin{array}{l}\text { DST volume } \\
\text { impact post- } \\
\text { evaporation }\end{array}$ & $\begin{array}{l}\text { Cumulative } \\
\text { impact to } \\
\text { SY Farm }\end{array}$ & $\begin{array}{l}\text { Cumulative } \\
\text { impact to } \\
\text { AY/AZ Farm }\end{array}$ & $\begin{array}{l}\text { Cumulative } \\
\text { impact to } \\
\text { DST system }\end{array}$ \\
\hline RPP-1 & AX-101 & 3 & 355 & 0 & 963 & & 963 & 963 \\
\hline RPP-2 & AX-103 & 8 & 99 & 0 & 240 & & 1,203 & 1,203 \\
\hline RPP-3 & A-106 & 50 & 29 & 0 & 173 & & 1,376 & 1,376 \\
\hline RPP-4 & AX-102 & 6 & 24 & 0 & 64 & & 1,440 & 1,440 \\
\hline RPP-5 & AX-104 & 7 & 0 & 0 & 11 & & 1,451 & 1,451 \\
\hline RPP-6 & A-102 & 0 & 37 & 3 & 91 & & 1,542 & 1,542 \\
\hline RPP-7 & A-103 & 2 & 372 & 4 & 782 & & 2,324 & 2,324 \\
\hline RPP-8 & A-104 & 28 & 0 & 0 & 56 & & 2,380 & 2,380 \\
\hline RPP-9 & A-105 & 37 & 0 & 0 & 92 & & 2,472 & 2,472 \\
\hline RPP-10 & A-101 & 3 & 317 & 0 & 785 & & 3,257 & 3,257 \\
\hline RPP-11 & BY-102 & 0 & 278 & 0 & 757 & & 4,014 & 4,014 \\
\hline RPP-12 & BY -110 & 43 & 323 & 0 & 928 & & 4,942 & 4,942 \\
\hline RPP-13 & BY-112 & 2 & 284 & 0 & 839 & & 5,781 & 5,781 \\
\hline RPP-14 & SX-105 & 63 & 312 & 0 & 1,041 & 1,041 & & 6,822 \\
\hline RPP-15 & SX-115 & 4 & 0 & 0 & 8 & 1,049 & & 6,830 \\
\hline RPP-16 & SX-113 & 19 & 0 & 0 & 24 & 1,073 & & 6,854 \\
\hline RPP-17 & BY-101 & 37 & 333 & 0 & 1,088 & & 6,869 & 7,942 \\
\hline RPP-18 & SX-112 & 75 & 0 & 0 & 128 & 1,201 & & 8,070 \\
\hline RPP-19 & SX-110 & 49 & 7 & 0 & 107 & 1,308 & & 8,177 \\
\hline RPP-20 & BY -103 & 9 & 405 & 0 & 1,159 & & 8,028 & 9,336 \\
\hline RPP-21 & BY-111 & 0 & 402 & 0 & 1,072 & & 9,100 & 10,408 \\
\hline RPP-22 & SX-103 & 78 & 431 & 0 & 1,227 & 2,535 & & 11,635 \\
\hline
\end{tabular}

Total volume of DST space required for baseline case $=\mathbf{1 1 , 6 3 5} \mathbf{k g a l}$.

DST $\quad=$ double-shell tank.

Table 4-7. Alternative Single-Shell Tank Retrieval Sequence (2016 - 2025) 
Retrievals from A/AX Farm Tanks to DSTs in 200 East

\begin{tabular}{|c|c|c|c|c|c|c|c|c|}
\hline ALT 1 & AX-104 & 7 & 0 & 0 & 11 & 11 & 11 \\
\hline ALT 2 & A-104 & 28 & 0 & 0 & 56 & 67 & 67 \\
\hline ALT 3 & AX-102 & 6 & 24 & 0 & 64 & 222 & 222 \\
\hline ALT 4 & A-102 & 0 & 37 & 3 & 91 & 314 & 314 \\
\hline ALT 5 & A-105 & 37 & 0 & 0 & 92 & 487 & 487 \\
\hline ALT 6 & A-106 & 50 & 29 & 0 & 173 & 727 & 727 \\
\hline
\end{tabular}

Retrievals from SX Farm Tanks to DSTs in 200 West

\begin{tabular}{|l|l|l|l|l|l|l|c|}
\hline ALT 8 & SX-115 & 4 & 0 & 0 & 8 & 8 & 735 \\
\hline ALT 9 & SX-113 & 19 & 0 & 0 & 24 & 32 & 759 \\
\hline ALT 10 & SX-110 & 49 & 7 & 0 & 107 & 139 & 866 \\
\hline ALT 11 & SX-112 & 75 & 0 & 0 & 128 & 267 & 994 \\
\hline ALT 12 & SX-107 & 94 & 0 & 0 & 147 & 414 & 1,141 \\
\hline ALT 13 & SX-108 & 74 & 0 & 0 & 175 & 589 & 1,316 \\
\hline
\end{tabular}

\section{Retrievals from B/BX Farm tanks to 200 East WRF and then to DSTs in 200 East}

\begin{tabular}{|c|c|c|c|c|c|c|c|}
\hline ALT 14 & B-102 & 0 & 28 & 4 & 66 & 793 & 1,382 \\
\hline ALT 15 & B-112 & 15 & 17 & 3 & 67 & 860 & 1,449 \\
\hline ALT 16 & BX-108 & 31 & 0 & 0 & 76 & 936 & 1,525 \\
\hline ALT 17 & BX-106 & 10 & 28 & 0 & 78 & 1,014 & 1,603 \\
\hline ALT 18 & BX-101 & 48 & 0 & 0 & 89 & 1,103 & 1,692 \\
\hline ALT 19 & BX-102 & 79 & 0 & 0 & 106 & 1,209 & 1,798 \\
\hline ALT 20 & B-103 & 1 & 55 & 0 & 116 & 1,325 & 1,914 \\
\hline ALT 21 & BX-103 & 62 & 0 & 13 & 118 & 1,443 & 2,032 \\
\hline ALT 22 & BX-104 & 97 & 0 & 3 & 137 & 1,580 & 2,169 \\
\hline
\end{tabular}

Total volume of DST space required for alternative case $=\mathbf{2 , 1 6 9} \mathbf{k g a l}$.

DST $=$ double-shell tank.

$\mathrm{WRF} \quad=$ Waste Retrieval Facility. 
Retrievals from A/AX Farm Tanks to DSTs in 200 East $^{\mathrm{a}}$

\begin{tabular}{|c|c|c|c|c|c|c|c|}
\hline ALT 1 & AX-104 & 7 & 0 & 0 & 11 & 11 & 11 \\
\hline ALT 2 & A-104 & 28 & 0 & 0 & 56 & 67 & 67 \\
\hline ALT 3 & AX-102 & 6 & 24 & 0 & 64 & 131 & 131 \\
\hline ALT 4 & A-102 & 0 & 37 & 3 & 91 & 222 & 222 \\
\hline ALT 5 & A-105 & 37 & 0 & 0 & 92 & 314 & 314 \\
\hline ALT 6 & A-106 & 50 & 29 & 0 & 173 & 487 & 487 \\
\hline ALT 7 & AX-103 & 8 & 99 & 0 & 240 & 727 & 727 \\
\hline ALT 8 & A-103 & 2 & 372 & 4 & 782 & 1,509 & 1,509 \\
\hline ALT 9 & A-101 & 3 & 317 & 0 & 785 & 2,294 & 2,294 \\
\hline ALT 10 & AX-101 & 3 & 355 & 0 & 963 & 3,257 & 3,257 \\
\hline
\end{tabular}

\section{Retrievals from SX Farm Tanks to DSTs in 200 West}

\begin{tabular}{|l|l|l|l|l|c|c|c|}
\hline ALT 11 & SX-115 & 4 & 0 & 0 & 8 & 8 & 3,565 \\
\hline ALT 12 & SX-113 & 19 & 0 & 0 & 24 & 32 & 3,289 \\
\hline ALT 13 & SX-110 & 49 & 7 & 0 & 107 & 139 & 3,396 \\
\hline ALT 14 & SX-112 & 75 & 0 & 0 & 128 & 267 & 3,524 \\
\hline
\end{tabular}

\section{Retrievals from B/BX Farm tanks to 200 East WRF and then to DSTs in 200 East}

\begin{tabular}{|c|c|c|c|c|c|c|c|}
\hline ALT 15 & B-102 & 0 & 28 & 4 & 66 & 3,323 & 3,590 \\
\hline ALT 16 & B-112 & 15 & 17 & 3 & 67 & 3,390 & 3,657 \\
\hline ALT 17 & BX-108 & 31 & 0 & 0 & 76 & 3,466 & 3,733 \\
\hline ALT 18 & BX-106 & 10 & 28 & 0 & 78 & 3,544 & 3,811 \\
\hline ALT 19 & BX-101 & 48 & 0 & 0 & 89 & 3,633 & 3,900 \\
\hline ALT 20 & BX-102 & 79 & 0 & 0 & 106 & 3,739 & 4,006 \\
\hline ALT 21 & B-103 & 1 & 55 & 0 & 116 & 3,855 & 4,122 \\
\hline ALT 22 & BX-103 & 62 & 0 & 13 & 118 & 3,973 & 4,240 \\
\hline
\end{tabular}

Total volume of DST space required for case that includes retrieval of all $\mathrm{A} / \mathrm{AX}$ tanks $=\mathbf{4 , 2 4 0} \mathbf{k g a l}$.

a Tanks SX-107, SX-108, and BX-104 are replaced by A-101, A-103, and AX-101 in this alternative retrieval sequence.

DST $=$ double-shell tank.

WRF $\quad$ Waste Retrieval Facility. 
Figure 4-1 graphically portrays the significant differences in post-evaporation demand for DST space that each of these three 22-tank retrieval sequences requires, assuming that no waste processing (except for evaporation) occurs.

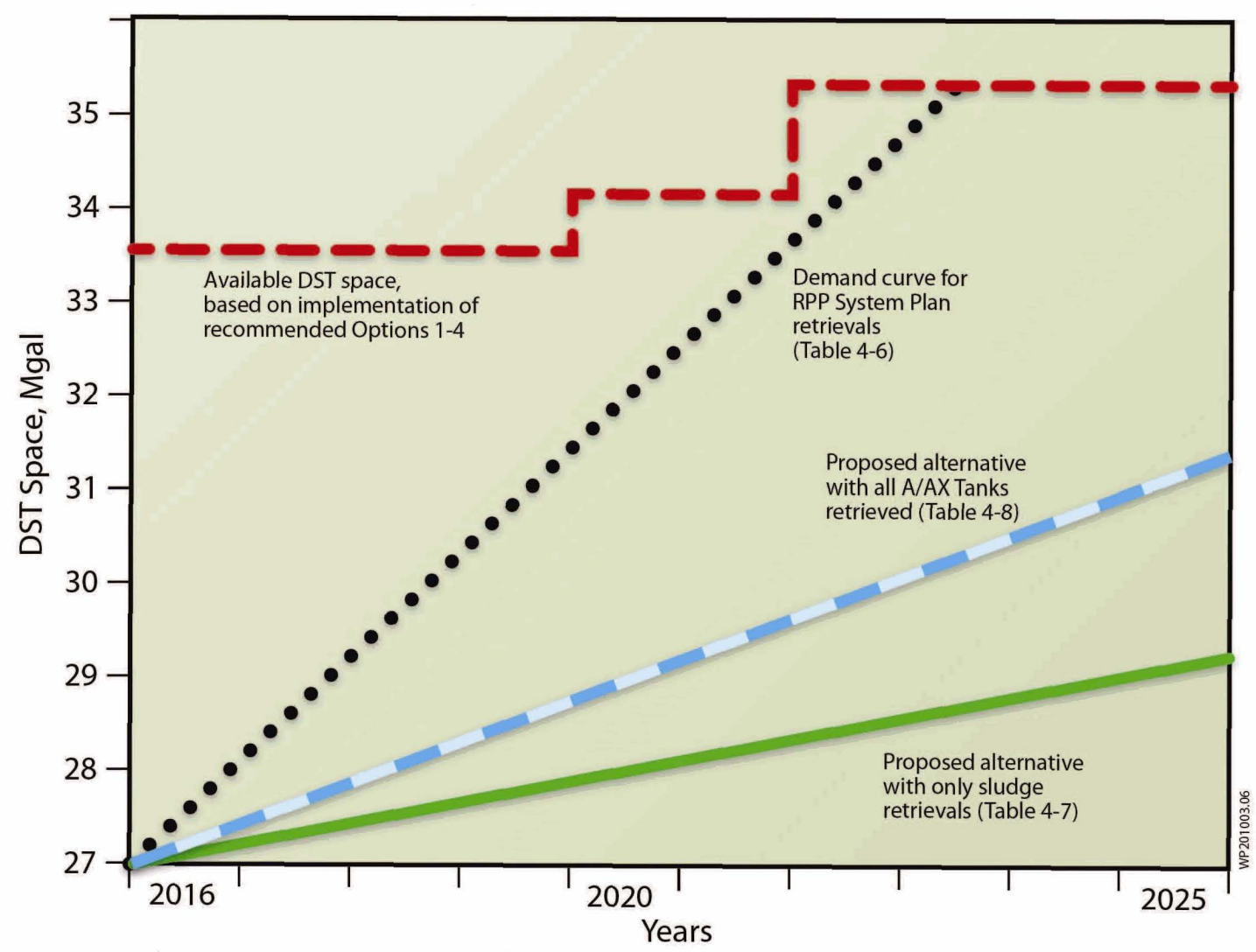

Assumes no waste processing occurs (except evaporation)

Figure 4-1. Time Averaged Demand for Double-Shell Tank Space (2016-2025).

\subsubsection{Use Receiver Tanks in Planned Facilities}

\subsubsection{Accelerate Construction of 200 East Waste Retrieval Facility}

The option to accelerate construction of the 200 East WRF was previously evaluated in RPP-7702. However, the DSB revised the estimated volume of created tank space based on an improved understanding of its potential functions and operation, as described in the draft 200 East Area WRF Mission Analysis Report.

The WRF storage tanks would be needed between 2018 and 2025 to support waste retrievals from the BY tanks that are in the current baseline (ORP-11242, Rev. 4, Table D-1), and to alleviate some of the DST tank space shortfall anticipated to occur in this time period. To accelerate the construction of the 200 East WRF, the baseline cost of $\$ 127.4$ million for a sixtank facility would be accelerated three to seven years earlier than in the current budget guidance. The tank space obtained for waste storage would be $600 \mathrm{kgal}$ (using only four of the six 150-kgal tanks, rather than all six as suggested in RPP-7702), so that limited retrieval could be conducted. 
Because the WRF is currently in the baseline, the cost associated with accelerating its design and construction was not included in this analysis. Assuming that design of the WRF could start no sooner than 2012, this facility could be completed by 2017 to 2019 (in five to seven years).

\subsubsection{Expand Capacity/Accelerate Construction of 200 East Waste Retrieval Facility}

The option to accelerate construction of the 200 East WRF and increase the size of its tanks was previously evaluated in RPP-7702. The DSB chose to evaluate this option separately from the "Accelerate Construction of 200 East Waste Retrieval Facility," because it concluded that the increased tank size could potentially provide additional benefits to the waste feed delivery mission and additional storage capacity for waste retrieved from the SSTs. The DSB also determined that only one of the planned WRFs was needed during this time (rather than two as previously evaluated in RPP-7702), because there are no 200 West retrievals that require a WRF in the current baseline.

Increasing the storage capacity of the tanks for the WRF would require modifications, including expanding the size of the building to enable the installation of additional storage capacity and increasing the capacity of the storage tanks to $300 \mathrm{kgal}$. The DSB again assumed that only four of the six $300-\mathrm{kgal}$ tanks would be available as alternative waste storage capacity, or a total of $1,200 \mathrm{kgal}$.

The incremental cost to accelerate the construction and expand the capacity of the facility is estimated to be $\$ 69$ million. Assuming that design of the WRF could start no sooner than 2012, this facility could be completed by 2017 to 2019 (in five to seven years).

\subsubsection{Utilize Receiver Tanks in Mix/Blend Facility}

Potential use of the receiver tanks in a mix/blend facility was previously evaluated in RPP-7702. The DSB used information developed for that report as the basis for evaluating this option.

The mix/blend facility is envisioned to be a new facility that would be constructed for the primary purposes of improved mixing of sludge waste before it is sent to the WTP and blending sludge waste to reduce the number of high-level waste (HLW) glass canisters produced. ${ }^{2}$ A significant reduction in the number of HLW canisters would potentially shorten the RPP mission duration and reduce the cost of transportation to and disposal at a national repository.

The mix/blend facility would consist of six $500 \mathrm{kgal}$ tanks that would receive waste transferred from the existing DST system. The facility would be a multi-purpose set of tanks that would provide several functions in addition to mixing and blending, including (but not limited to) waste characterization and certification and waste pretreatment (e.g., filtration of supernatant). For purposes of this alternatives analysis, the tanks were evaluated for their potential use as storage for tank waste retrieved from the SSTs.

The cost of using the tanks in a mix/blend facility was not estimated for this analysis, but was assumed to be minimal, assuming the facility is built. Assuming that design of the mix/blend facility could start no sooner than 2014, this facility would be completed no sooner than 2021 (seven years).

\footnotetext{
${ }^{2}$ This facility is being considered as part of an integrated WRF, and may not be separate.
} 


\subsubsection{Utilize Receiver Tanks in Aluminum Removal Facility}

Because the Aluminum Removal Facility (ARF) was only recently added to RPP baseline, the potential use of its receiver tanks was not previously evaluated. However, the DSB assumed that information from RPP-7702 developed for a mix/blend facility would serve as an appropriate basis for evaluating this option.

The ARF is envisioned to be a new facility consisting of six 500-kgal tanks whose primary purpose would be to chemically pretreat the waste sludge so that its aluminum content is leached into solution. Removing aluminum from the sludge in the ARF would mitigate the impacts on the waste treatment mission due to the expected need to add large quantities of sodium hydroxide to the waste to keep aluminum in solution.

For purposes of this alternatives analysis, the tanks were evaluated for their potential use as storage for tank waste retrieved from the SSTs.

Because the ARF is currently in the baseline, the cost associated with accelerating its design and construction was not included in this analysis. Assuming that design of the ARF could start no sooner than 2014, this facility could be completed no sooner than 2021 (seven years).

\subsubsection{Accelerate Startup and Utilize Low-Activity Waste Receiver Tanks in Waste Treatment and Immobilization Plant Pretreatment Facility}

The option that would accelerate the startup of the LAW receiver tanks in the WTP Pretreatment Facility was not previously evaluated in RPP-7702. While the DSB recognized that there would be significant challenges associated with any proposal to accelerate the startup of even a limited portion of WTP, it concluded that the cost of acceleration, while not quantified, could potentially be less than constructing new tanks. Therefore, the DSB included it as one of the new options to evaluate as part of this alternatives analysis.

While the LAW receiver tanks in the WTP Pretreatment Facility have a capacity of 1,500 kgal, the DSB concluded that if their use was to be accelerated for the purpose of waste storage prior to WTP startup, it would be limited to the $1,000 \mathrm{kgal}$ of LAW. Because the cost of WTP Pretreatment Facility startup is already in the baseline, the incremental cost associated with operating these tanks for two years prior to WTP startup was estimated to be less than $\$ 10$ million per year.

\subsubsection{Alternatives to Using Double-Shell Tanks for Emergency Storage}

DOE M 435.1-1, Radioactive Waste Management Manual, requires that "spare capacity with adequate capabilities shall be maintained to receive the largest volume of waste contained in any one storage vessel." Hanford maintains 1,265 kgal of emergency storage space in the DST system to meet this requirement. This option proposes to use this emergency space under certain conditions. Those conditions would include a method to store the waste from a DST leak, not implement this option until the WTP was started up or nearly ready to start up, and there were no other storage options available. At such time, using the emergency storage space to continue retrieving SST waste might be a lower risk than leaving the waste in unsound SSTs, because the likelihood of a DST leaking during the short time period that emergency space will not be available should be low. Four methods to store waste resulting from a DST leak were evaluated. 


\subsubsection{Use Sound Single-Shell Tanks for Emergency Storage}

The option to use sound SSTs for emergency storage in the unlikely event that a DST would start to leak was not previously evaluated in RPP-7702. However, the DSB concluded that this option was sufficiently viable to justify its evaluation.

Two 1-Mgal AX Farm SSTs are proposed to provide the emergency space. In the time period that this option would be implemented, the waste in these tanks would have been retrieved, and the tanks qualified for potential reuse. The AX tanks have a secondary leak detection and collection system provided by laterals beneath the primary tank to drain any leakage to an exterior collection well where it can be pumped out. Two AX tanks are required to provide the $1,265 \mathrm{kgal}$ of emergency space. Hose-in-hose surface lines would provide waste transfer capability.

The cost for this option has not been estimated, but an allowance of $\$ 20$ million is assumed to cover the cost to implement and to evaporate $2 \mathrm{Mgal}$ of water, if water is added to the tanks in preparation for their use as emergency space.

\subsubsection{Waive Emergency Storage Requirement - Use Double-Shell Tank Annulus for Leak Collection and Pump/Recycle}

The option to waive the requirement for emergency storage space and to use the DST annulus for leak collection and then to pump the leaked waste out of the annulus and back into the tank was not previously evaluated in RPP-7702. However, the DSB concluded that this option was sufficiently viable to justify including its evaluation.

If a DST leaks during the time the emergency space is used for other purposes, the leaking tank would remain in service and any waste that leaks into the annulus would be pumped back into the tank. It is anticipated that any leak would likely be the result of corrosion and would be small. By pumping the waste back into the tank, the hydrostatic head on the secondary liner and the area of the secondary liner exposed to the waste is expected to be small. The DSTs also have lateral grooves beneath the secondary liner that drain to a collection well, in the event that the secondary liner would leak. An allowance of $\$ 1$ million is assumed to cover the cost of acquiring a waiver to the DOE M 435.1-1 emergency space requirement and a backup annulus pump, if required.

\subsubsection{Use Unmodified Grout Vault for Emergency Storage}

This option uses one of the four unused grout vaults ${ }^{3}$ for emergency storage in the unlikely event that a DST would start to leak. This option was previously evaluated in RPP-7702. The vaults are rectangular, below-ground, concrete structures, with a sprayed-on asphalt liner and a capacity of $1,600 \mathrm{kgal}$. The interior dimensions are $50.5 \mathrm{ft}$ wide by $123.5 \mathrm{ft}$ long by $34 \mathrm{ft} \mathrm{high}$. The concrete vaults are encased in a one-meter-thick asphalt barrier. There is a drainage net and a high-density polyethylene layer between the exterior concrete wall and the asphalt that drains to a lined, gravel-filled catch basin equipped with a leachate collection sump and pump.

\footnotetext{
${ }^{3}$ The mission for which these vaults were constructed was cancelled in the 1990s.
} 
The original purpose of these vaults was for disposing low-level waste in a grout waste form that met hazardous waste land disposal restrictions (LDR) treatment standards. Tank waste does not meet LDR treatment standards. As constructed, it may not be possible to show the vaults have an adequate secondary containment system for storing tank waste.

Use of the vaults would include hydrostatic testing with water, installation of approximately $2,500 \mathrm{ft}$ of hose-in-hose transfer lines, installation of a portable exhauster, a new leachate sump pump, and obtaining permits, preparing procedures, etc. When previously considered, the implementation cost was estimated at $\$ 8$ million; and if the vault is used, an additional $\$ 22$ million is needed to close it.

\subsubsection{Modify Grout Vaults and Use for Emergency Storage}

The option to use modified grout vaults for emergency storage in the unlikely event that a DST would start to leak was previously evaluated in RPP-7702. Steel tanks would be constructed inside two of the vaults to contain the waste, while the vaults provide secondary containment. It is assumed that two vaults would be needed to provide adequate space to construct (or install) the tanks. Installation would require removing the vault cover blocks, and the vault liner may need to be replaced as a result of damage during tank construction. It is assumed that a rectangular tank with a capacity of $\sim 700 \mathrm{kgal}$ is constructed in each vault. When previously considered, the implementation cost was estimated at $\$ 12$ million, with an additional cost of $\$ 11$ million for closure if the tanks are used. This estimate for tank construction appears low and rather than $\$ 23$ million, the total cost is more likely to be $\$ 50$ to 100 million.

\subsubsection{Alternatives for Using Wiped-Film Evaporation}

\subsubsection{Concentrate Waste at-Tank to $1.50 \mathrm{~g} / \mathrm{ml}$ Using Wiped-Film Evaporation}

A skid-mounted, wiped-film evaporator (WFE) would be placed near or on top of a tank riser, where the liquid waste would be concentrated and returned to the tank. Given the evaporation rate of $2.5 \mathrm{gal} / \mathrm{min}$ and an estimated total operating efficiency of $75 \%$ (as provided by the WFE Project), the estimated volume of tank space that could potentially be recovered is approximately 1 Mgal per year for each $50 \mathrm{ft}^{2}$ WFE system in operation.

The option to concentrate waste at-tank to a SpG of $1.50 \mathrm{~g} / \mathrm{ml}$ using the wiped-film evaporation technology was previously evaluated in RPP-7702. The DSB used information developed for that report and additional information provided by the WFE Project as the basis for evaluating this option.

To evaluate this option, the DSB assumed that waste had previously been concentrated to a SpG of $1.43 \mathrm{~g} / \mathrm{ml}$, either in the 242-A Evaporator or by wiped-film evaporation. This assumption allowed the DSB to estimate the incremental increase in DST space that would potentially be recovered by concentrating waste beyond its current nominal limit to some intermediate concentration, but less than the typical density of saltcake found in the SSTs (estimated to be $1.7 \mathrm{~g} / \mathrm{ml})$.

The total estimated cost for three operating units would be approximately $\$ 100$ million and would include sampling and analyzing the tank waste, performing compatibility assessments, 
revising procedures, and procuring and operating the WFE system. The design and construction of the process equipment for this option is estimated to be five years.

\subsubsection{Concentrate Waste at-Tank to Damp Saltcake Using Wiped-Film Evaporation}

The option to concentrate waste at-tank to damp saltcake using the wiped-film evaporation technology was previously evaluated in RPP-7702. The DSB used information developed for that report and additional information provided by the WFE Project as the basis for evaluating this option.

The concentration of the tank waste to damp saltcake is assumed to have a SpG of approximately $1.70 \mathrm{~g} / \mathrm{ml}$. To estimate the incremental volume of recovered DST space that would be generated if this option were implemented, it was assumed that the waste had previously been concentrated to a SpG of $1.50 \mathrm{~g} / \mathrm{ml}$ (see Section 4.2.4.1). The WFE system would continue to run until damp saltcake, similar to that currently found in the interim stabilized SSTs, is produced. The additional volume of recovered tank space is estimated to be $2,850 \mathrm{kgal}$.

The cost to sample and analyze tanks, perform compatibility assessments, revise procedures, evaluate the drying and consolidation characteristics of damp saltcake, procure three WFE systems, operate the drying equipment, and perform waste transfers is estimated at $\$ 150$ million. The design and construction of the process equipment for this option is estimated to be five years. Design changes to the WFE system discussed in Section 4.2.4.1 would be required to enable transfer of the damp saltcake from the WFE to the DST.

\subsubsection{Pump Off Liquid Fraction of Group A Tanks/Backfill with Saltcake from Wiped-Film Evaporation}

The option to concentrate supernatant waste retrieved from other tanks to damp saltcake using the wiped-film evaporation technology, and then backfill the BDGRE tanks with the saltcake was not previously evaluated in RPP-7702. However, the DSB was able to use information previously developed for that report and additional information provided by the WFE Project as the basis for evaluating this option.

The WFE system would be operated in a manner similar to that described in Section 4.2.4.2, except that it would be located specifically at the BDGRE tanks. Supernatant would be pumped from other tanks and evaporated using the wiped-film evaporation process. The resulting damp saltcake would then be used to backfill the volume of tank space remaining in the BDGRE tanks after its supernatant has either been pumped out or has been converted to damp saltcake using the wiped-film evaporation process.

Assuming that the BDGRE tank supernatants have been pumped off, the total void space created in these five tanks is approximately $4,000 \mathrm{kgal}$. If we further assume that the supernatant being pumped to the WFE system has already been evaporated to $1.43 \mathrm{~g} / \mathrm{ml}$, a reduction of $\sim 38 \%$ would occur in volume of this supernatant when it is now evaporated to damp saltcake. This would result in as much as $2,500 \mathrm{kgal}$ of DST space being recovered in the tanks from which the supernatant was pumped. However, damp saltcake "growth" has been previously observed and might occur after it has been used to backfill these tanks. A conservative estimate of $25 \%$ "growth" was used to reduce the estimated volume of recovered DST space to $\sim 1,800 \mathrm{kgal}$. 
The cost to sample and analyze tanks, perform compatibility assessments, revise procedures, evaluate the drying and consolidation characteristics of damp saltcake, procure three WFE systems, operate the drying equipment, and perform waste transfers is estimated at $\$ 150$ million. The design and construction of the process equipment for this option is estimated to be five years.

\subsubsection{New Storage Facility Alternatives}

\subsubsection{Use Compliant Bladder in Lined Basin to Store Pretreated Waste}

The use of a compliant bladder in a lined basin for storage of pretreated waste was previously evaluated in RPP-7702. The DSB used information developed for that report as the basis for evaluating this option.

This option would store pretreated supernatant waste in a regulatory-compliant bladder placed in a lined open-air basin (similar to the Liquid Effluent Retention Facility) with a leak detection system. Each lined basin is estimated to provide an additional 1,000 kgal of storage capacity. The bladder would be the primary containment, while the lined basin would provide secondary containment. The waste would require pretreatment to filter out the solids and to remove the cesium to low levels of radioactivity because of limited shielding and potential damage to the bladder.

The bladder containment system would be designed, constructed, tested, and turned over to operations at an estimated cost of $\$ 111$ million. This estimate includes permitting and regulatory approval; bladder/basin design, procurement, and construction; a 5-gpm system for removing solids and cesium; capability to retrieve the waste from the bladder; and startup and testing. The estimated duration for completing design and construction of the bladder system is seven years.

\subsubsection{Use Small Modular Tanks}

The use of small modular tanks was previously evaluated in RPP-7702. The DSB used information developed for that report as the basis for evaluating this option.

To use small modular tanks, a facility to contain the modular tanks would first need to be constructed. Conceptually, the modular tank storage facility would consist of a concrete pad at-grade with an open concrete vault below grade. The modular storage facility would consist of a concrete slab, precast concrete culverts with a steel liner and leak detection, cover blocks for the culverts, a crane for moving the waste liners, and a Butler building to provide weather protection. Each modular tank would have a storage capacity of $\sim 2,000$ gal and would be placed in a steel-walled culvert that would act as secondary containment. The modular storage facility would be designed to hold 500 modular tanks for a total storage capacity of $\sim 1,000 \mathrm{kgal}$.

The waste could be condensed to dry solids or wet saltcake, but would require re-liquification to transfer the liquid from the tanks and to a mix/blend tank. The estimated cost for the modular storage facility design, construction, and turnover to operations and for the cost of the 500 stainless steel tanks was approximately $\$ 29$ million. There would also be additional costs for transferring the waste to the WTP and for disposal of the 500 contaminated tanks. The time to implement this option is estimated to take four years, once it has become an approved project. 


\subsubsection{Build Large Tank for Low-Activity Waste Storage}

As an alternative to constructing four 1.25 Mgal DSTs, the DSB concluded that there might be some economies-of-scale by building one $5 \mathrm{Mgal}$ tank. This option was not previously evaluated in RPP-7702. While it is recognized that there is an overall desire not to build additional tanks that would potentially be used only for the storage function, there might be some merit in building one additional storage tank that could store very large quantities of supernatant.

\subsubsection{Build New Double-Shell Tanks}

The construction of new double-shell tanks was previously evaluated in RPP-7702. Information developed for that report was used as the basis for evaluating this option. Construction of four new DSTs would provide 5,000 kgal of additional storage capacity, or 1,250 kgal for each additional new tank. Several DST farms have been previously designed and constructed at Hanford, and are currently being operated. New tanks would be built to Washington Administrative Code requirements for double-walled tanks and would include a continuous leak detection system.

The approximate cost of each new DST has been previously estimated at $\$ 88$ million, or approximately $\$ 350$ million for four DSTs. Construction and operation of any new tanks would also impose additional closure costs, which were not included in this estimate. It is estimated that this option would take approximately seven years to complete, two years to obtain authorization for the necessary funding and five years for design and construction. 


\subsection{ALTERNATIVES ANALYSIS OF TANK SPACE OPTIONS}

The tank space options were evaluated and scored using five criteria and 14 measures and weighting, as described in Appendix A. Several general uncertainties that could potentially affect multiple options became evident during the evaluations, including:

- Characterization data have an uncertain degree of accuracy as sampling and analysis have been done for different reasons over time, and the Best Basis Inventory has been established as a reasonable estimate based on assembled data. Accuracy will vary among tanks.

- Evaporator operation is required at a more intense level, along with multiple transfers for some options. Work processes are not in place for more intense operation.

- SST retrieval sequence criteria have a significant effect on volumes of waste that need to be handled in the critical period. Criteria should be carefully evaluated for mission optimization. Retrieval sequences that include a preponderance of saltcake waste during the critical space period will result in far fewer completed tank retrievals than if sludge tanks are emphasized because of the difference in as-retrieved waste volumes that would be stored in the recovered DST space.

- Utilization of tank space in new facilities built for various waste feed delivery purposes can be a challenge to the original facility purpose-temporary use as DST storage could complicate the authorization basis, the operating permit, or create complex isolation boundaries between the storage and other components of the facility.

\subsection{NEAR-TERM OPTIONS (1 - 5 YEARS)}

Eight options that could potentially be implemented within the next five years were evaluated, and include:

1. Raising the allowable waste levels in nine AN, AW, and SY Farm non-aging waste tanks

2. Concentrating waste in 15 tanks to a SpG of $1.43 \mathrm{~g} / \mathrm{ml}$ using the 242-A Evaporator

3. Raising the waste levels in three of the aging waste tanks (AY-101, AZ-101, AZ-102)

4. Raising the waste level and concentrating the waste to a $\mathrm{SpG}$ of $1.43 \mathrm{~g} / \mathrm{ml}$ in the hot commissioning tank for WTP (Tank AY-102)

5. Using the restricted space in the Group A tanks by installing mixer pumps (Tanks AN-103, AN-104, AN-105, AW-101, and SY-103)

6. Using the restricted space in the complexant concentrate tanks (AN-102 and AN-107)

7. Concentrating waste by using warm dry air in-tank to evaporate water

8. Temporarily staging sludge waste in sound SSTs.

The near-term option scores ranged from a high of 96.4 for the option "Raise allowable waste levels in nine non-aging waste tanks," to a low of 65.2 for "Stage sludge waste in sound SSTs." The total weighted scores for each near-term option are summarized in Table 5-1. Detailed scoring for each option is provided in Appendix B. 
Table 5-1. Summary of Near-Term Options Weighted Scoring.

\begin{tabular}{|l|c|}
\hline \multicolumn{1}{|c|}{ Near-Term Option } & $\begin{array}{c}\text { Total Weighted } \\
\text { Score }\end{array}$ \\
\hline Raise allowable waste levels in nine AN, AW and SY Farm non-aging waste tanks & 96.4 \\
\hline Concentrate waste in 15 tanks to a SpG of $1.43 \mathrm{~g} / \mathrm{ml}$ & 93.6 \\
\hline Raise the waste levels in three of the aging waste tanks & 78.8 \\
\hline Raise waste level/concentrate waste in Tank AY-102 & 74.4 \\
\hline Use the restricted space in the Group A tanks by installing mixer pumps & 70.8 \\
\hline Use the restricted space in the complexant concentrate tanks & 72 \\
\hline Concentrate waste by using warm dry air in-tank & 68 \\
\hline Stage sludge waste in sound SSTs & 65.2 \\
\hline
\end{tabular}

\section{Raise Allowable Waste Levels in Nine Non-Aging Waste Tanks}

Because this option rated high when evaluated against all of the criteria, it received the highest score of any of the options (96.4). This is a continuation of successful activities to utilize the full DST capacity. Significant precedent has already occurred with the initiative to raise waste levels in the AP Farm tanks. As result, operational, technical, and safety/regulatory issues were judged to be minimal. Potentially $\sim 940 \mathrm{kgal}$ of tank space could be recovered. There are no significant uncertainties associated with this option.

\section{Concentrate Waste to $1.43 \mathrm{~g} / \mathrm{ml}$ in Selected Tanks}

This option was also highly rated, receiving a score of 93.6 , because it too is a continuation of successful activities to utilize the full DST capacity. Although the processes are well developed, there may be potential operational challenges because a large number of waste transfers and several additional 242-A Evaporator campaigns are required to recover the space, and it may not be cost-effective to concentrate the waste in some tanks due to the volume of recovered space being relatively small. However, as much as $\sim 3,500 \mathrm{kgal}$ of tank space could be recovered if this option is fully implemented.

\section{Raise Levels in Three Aging Waste DSTs}

Although raising the allowable waste level in the non-aging waste tanks was highly rated, this option scored lower (78.8) than either of the previous two options, primarily due to the uncertainties associated with the design of these tanks. The aging waste tanks have fill lines in the side that are not double-contained at the penetration of the tank. To raise the waste level in these tanks, their sidewall penetration would need to be sealed. This modification has not been previously engineered and would need to be done remotely.

\section{Raise Waste Level and Concentrate Waste in Tank AY-102}

Although Tank AY-102 is also an aging waste tank, this option scored slightly lower (74.4) than the option to raise the waste level in the other aging waste tanks, because the waste in this tank 
has been designated as the hot commissioning feed for the WTP. In addition to the technical challenges associated with sealing the side fill-line penetration, the composition of the waste would be changed once additional waste was added. This would require that the tank be resampled, and that the LAW and HLW glass reformulated and qualified. While there would appear to be sufficient time to complete these activities, it could potentially impact the WTP start-up schedule.

\section{Install Mixer Pumps and Use Restricted Space in Group A Tanks}

This option scored slightly lower (70.8) than the two previous options because of the safety concerns associated with the Group A tanks and operational concerns associated with the mixer pumps that would need to be installed to mitigate BDGRE. Although the use of mixer pumps is already planned for these tanks as part of the waste feed delivery strategy, implementation of this option would require accelerating their installation and operation. The mixer pumps would be used to actively mitigate the BDGRE potential by periodically mixing the waste to release retained gas after the restricted space has been filled with the waste. Historical experience has shown that:

- Mixing can cause slurry growth and crust due to gas bubbles rising to the surface and solidifying.

- Mixer pumps must be maintained and rotated regularly; bearings, seals, etc. can become a maintenance issue for extended periods of operation.

\section{Use Restricted Capacity in Complexant Concentrate Tanks}

Although this option scored slightly higher (72) than the previous option that also evaluated using restricted tank space, it was recognized that there would be a significant future impact if the unused tank space in Tanks AN-102 and AN-107 was available for waste storage. The issue with using this space is that the volume of supernatant requiring future chemical pretreatment to precipitate the TRU and strontium would be increased. If the allowable level of waste in these tanks is raised to $454 \mathrm{in}$. (1,250 kgal), it would increase the recovered volume to $\sim 350 \mathrm{kgal}$, the volume of supernatant requiring pretreatment would increase by $\sim 20 \%$. Because volume of recovered tank space is relatively small, future implementation of this option would likely be low priority.

\section{Evaporate In-Tank Using Warm Dry Air}

This option scored low (68) because historical experience has shown that the effectiveness of this alternative is severely limited. The waste tends to solidify at the heat source and the evaporation rate is slow. This option was not evaluated further.

\section{Stage Sludge Waste in Sound Single-Shell Tanks}

While WRPS has an on-going initiative that proposes to use sound SSTs for staging retrieved waste in an effort to accelerate SST retrievals, the DSB concluded that there are significant regulatory and stakeholder risks associated with this option. Scoring of this option (65.2) reflects those concerns. Although recent information on the potential integrity of tanks has been generated, based on successful containment of liquids during retrieval and the ability to inspect 
the tank liners, SSTs were previously declared unfit for use and significant uncertainties related to demonstrating that sound tanks exist remain:

- SSTs do not meet the regulatory requirement for double containment

- $\quad$ SSTs must be shown to be structurally sound with no leaks

- Stakeholder and regulatory acceptance will require a convincing technical basis and clear understanding of the mission benefits.

Additionally it was assumed that no saltcake wastes would be retrieved into these tanks, and only $\sim 650 \mathrm{kgal}$ of sludge that would potentially be retrieved and staged were identified. This would require three sound SSTs costing an estimated $\$ 81$ million to implement. On a cost per gallon of waste retrieved, this became one of the more expensive options evaluated.

\subsection{LONG-TERM OPTIONS (5 - 10 YEARS)}

A total of 17 long-term options were evaluated that could potentially be implemented in the next 5 - 10 years to create tank space in support of continued retrieval of SST waste and/or more effectively and efficiently providing waste feed to the WTP. The DSB evaluated each option and scored them using the five criteria and 14 measures described in Appendix A. Based on the scoring assigned to each option and the weightings applied to each measure, the overall weighted scores ranged from a high of 94 for "Revise SST retrieval logic and sequence," to a low of 36.8 for "Use compliant bladder in lined basin to store pretreated waste." The total weighted scores for the long-term options are summarized in Table 5-2. Detailed scoring for each option is provided in Appendix B.

Table 5-2. Summary of Long-Term Options Weighted Scoring. (2 pages)

\begin{tabular}{|l|c|}
\hline \multicolumn{1}{|c|}{ Long-Term Option } & $\begin{array}{c}\text { Total Weighted } \\
\text { Score }\end{array}$ \\
\hline Revise SST retrieval logic and sequence & 94 \\
\hline Use receiver tanks in planned facilities & \\
\hline Accelerate construction of 200 East WRF & 83.2 \\
\hline Expand capacity/accelerate construction of 200 East WRF & 74 \\
\hline Utilize receiver tanks in a mix/blend facility & 60.8 \\
\hline Utilize receiver tanks in the Aluminum Removal Facility & 64 \\
\hline Accelerate startup and utilize LAW receiver tanks in WTP Pretreatment Facility & 78.8 \\
\hline Alternatives to using DSTs for emergency storage & \\
\hline Use sound SSTs for emergency storage & 72.8 \\
\hline Waive emergency storage requirement/use DST annulus space for leak & 77.6 \\
\hline collection and pump/recycle & 42 \\
\hline Use unmodified grout vault for emergency storage & 62 \\
\hline Modify grout vaults and use for emergency storage & \\
\hline
\end{tabular}


Table 5-2. Summary of Long-Term Options Weighted Scoring. (2 pages)

\begin{tabular}{|c|c|c|c|c|}
\hline \multicolumn{4}{|c|}{ Long-Term Option } & $\begin{array}{l}\text { Total Weighted } \\
\text { Score }\end{array}$ \\
\hline \multicolumn{5}{|c|}{ Alternatives for using wiped-film evaporation } \\
\hline \multicolumn{4}{|c|}{ Concentrate waste at-tank to $1.50 \mathrm{~g} / \mathrm{ml}$ using WFE } & 58.4 \\
\hline \multicolumn{4}{|c|}{ Concentrate waste at-tank to damp saltcake using WFE } & 49.6 \\
\hline \multicolumn{4}{|c|}{ Pump-off liquid fraction of Group A tanks/backfill with saltcake from WFE } & 63.6 \\
\hline \multicolumn{5}{|c|}{ New storage facility alternatives } \\
\hline \multicolumn{4}{|c|}{ Use compliant bladder in lined basin to store pretreated waste } & 36.8 \\
\hline \multicolumn{4}{|c|}{ Use small modular tanks } & 42.4 \\
\hline \multicolumn{4}{|c|}{ Build large tanks for LAW storage } & 50 \\
\hline \multicolumn{4}{|c|}{ Build new DSTs } & 70 \\
\hline $\begin{array}{l}\text { DST } \\
\text { LAW } \\
\text { SST }\end{array}$ & $\begin{array}{l}=\text { double-shell tank. } \\
=\text { low-activity waste. } \\
=\text { single-shell tank. }\end{array}$ & $\begin{array}{l}\text { WFE } \\
\text { WRF } \\
\text { WTP }\end{array}$ & $\begin{array}{l}=\text { wiped-film evaporator. } \\
=\text { Waste Retrieval Facilit } \\
=\text { Waste Treatment and I }\end{array}$ & ilization Plant. \\
\hline
\end{tabular}

For purposes of its evaluation, the DSB divided the long-term options into five groups, which are described in the subsections that follow.

\subsubsection{Alternative Retrieval Sequence}

The current baseline retrieval sequence between 2016 and 2025, as shown in Table D-1 of the RPP System Plan (ORP-11242, Rev. 4), requires a significant volume of DST space, approaching the equivalent of ten DSTs. With the predicted shortfall of DST space during this time (Figure 5-5 of the RPP System Plan), a re-sequencing of tank retrievals appears to be prudent. By identifying SSTs that contain low volumes of waste and/or sludge waste, the same number of tanks (22) can be retrieved with as much as $80 \%$ reduction in required DST space. Retrievals would be focused in A/AX, B/BX, and SX Farms, as shown in Table 4-7 (Section 4.2.1). Note that the retrieval sequence is grouped by tank farm and is not necessarily the order in which they would be retrieved. However, both the baseline case and the alternative case assume that an early deployment and operation of the 200 East WRF is necessary to support the B Farm complex retrievals.

Modeling of the baseline retrieval sequence shows that on several occasions, the volume of retrieved waste exceeds the available DST space and/or requires the use of DST space otherwise reserved as emergency space. In addition, several of the retrievals that are scheduled to occur during this timeframe (e.g., Tanks BY-110, BY-112, SX-105) are performed quite inefficiently, because retrieval activities periodically must be shutdown to wait for tank space to become available, either by transferring waste to the WTP, or by completing an evaporator campaign. For example, the modeling predicts that the duration of an earlier retrieval (Tank A-103 containing $379 \mathrm{kgal}$ of saltcake waste) would be 193 days, compared to the 2,301 days predicted 
for Tank BY-110, which has a similar volume of saltcake waste (366 kgal) but is retrieved late in the modeled sequence.

While the alternative retrieval sequence proposed in Table 4-7 (Section 4.2.1) is an optimized example of how much the volume of required DST space can be reduced, any tank space that is recovered or created during the timeframe $(2016-2025)$ is of great value and needs to be carefully managed. This becomes even more apparent if the WTP startup is delayed and/or its processing throughput rates are not achieved as quickly as anticipated. DOE-ORP and the TOC should carefully weigh what the priorities for waste retrieval are for that time period, and then determine a retrieval sequence consistent with those criteria.

The SST retrieval sequence can have a significant impact on DST tank space requirements, primarily due to the significant increase in the post-evaporation as-stored volume of retrieved saltcake wastes as compared to sludge waste. The principal uncertainties include:

- Optimizing waste feed for WTP

- Retrieval system capability for retrieving waste from tanks that have been declared leakers and/or have hard waste heels

- Operational issues such as tank farm interferences, available transfer lines, and receiver tanks

- Risk reduction and various perceptions of risk.

\subsubsection{Use Receiver Tanks in Planned Facilities}

This group of options includes:

- Accelerate construction of the 200 East WRF

- Expand capacity/accelerate construction of the 200 East WRF

- Utilize receiver tanks in a mix/blend facility

- Utilize receiver tanks in the ARF

- Accelerate startup and utilize LAW receiver tanks in WTP Pretreatment Facility.

The 200 East WRF option scored well (83.2) when compared to most of the other long-term options because the need for this planned facility appears to be generally accepted and its eventual design and construction relatively well-assured. There are no other compliant tanks near the B/BX/BY Farm complex in 200 East that could be used to support waste retrieval.

The mix/blend and aluminum removal facilities are in their early planning stages and are envisioned to serve multiple waste feed delivery needs. Whether they are part of the final waste feed delivery system is not yet known. If the design and construction of one or more of these facilities were accelerated, the receiver tanks could be used for increasing the compliant storage capacity. Uncertainties include:

- The facilities are not yet designed and it is not known what capacity might be available or how it would be accessed. Waste stored in the facility would need to be compatible with the early commissioning needs of that facility.

- Early storage of waste in these facilities carries the risk that this use will disrupt construction and acceptance of the remainder of the facility. 
- Acquiring these facilities in the planned timeframe is uncertain and may not be available for waste storage when needed during the early years of the program.

These uncertainties will be mitigated as the waste feed delivery program matures and facility needs are finalized. They can be considered as potential assets for future planning.

The option to use tank capacity in the WTP Pretreatment Facility LAW receiver tanks as potential waste storage has several uncertainties associated with it, including:

- Hot startup and operation of a portion of a facility that may still be under construction

- Overall schedule uncertainties related to the startup of the WTP Pretreatment Facility

- Additional effort to isolate uncontaminated systems and structures, and ongoing construction activities from contaminated receiver tanks

- Assuring that the stored waste type and quantity would meet WTP waste acceptance criteria

- Acquiring a partial permit to operate one portion of an integrated facility early; partial facility utilization will also require a unique authorization basis modification.

\subsubsection{Alternatives to Using Double-Shell Tanks for Emergency Storage}

Four alternatives to using DST space for emergency storage in the unlikely event of a DST leak were evaluated. The weighted scoring for the four options that could potentially be used to replace DST space currently reserved to meet the emergency space requirement (see Section 4.2.3) ranged from a high score of 77.6 for the option that would use the DST annulus for leak collection to a low score of 42 for the unmodified grout vault option. These options were evaluated assuming that none of them would be considered until such time as the WTP startup was either imminent or had already begun, and that there was no other remaining DST space to continue retrieval of waste from SSTs. Uncertainties associated with these options include:

- Using sound SSTs for emergency storage - Primary uncertainties are demonstrating and maintaining tank integrity and obtaining needed regulatory and stakeholder approvals because these tanks do not meet the double-containment requirement. Depending on the outcome of the current initiative to use sound SSTs as staging tanks in support of accelerating SST retrievals, the designation of sound SSTs as emergency storage space in the event of a DST leak could become more viable.

- Waiving the emergency storage requirement and using DST annulus space for leak collection and pump/recycle - Primary uncertainty is gaining the acceptance and approvals required to waive the emergency requirement. However, the infrastructure, equipment, and personnel currently exist to support this option.

- Using an unmodified grout vault for emergency storage - Multiple uncertainties for this option include gaining public acceptance and regulatory approval and its operability as a storage facility based on the design of the vaults as non-retrievable disposal facilities for non-LDR, low-level grouted waste.

- Modifying grout vaults for emergency storage - This alternative would require construction of new tanks inside the grout vaults. Adapting them as storage facilities for 
hazardous radioactive wastes would require significant modifications to their structure and/or major concessions from the regulators.

\subsubsection{Alternatives for Using Wiped-Film Evaporation}

Assuming its successful full-scale demonstration, using the wiped-film evaporation technology to concentrate waste at-tank to a SpG greater than $1.43 \mathrm{~g} / \mathrm{ml}$ (the current nominal limit for wastes concentrated at the 242-A Evaporator), the following options were evaluated:

- Concentrate waste at-tank to $1.50 \mathrm{~g} / \mathrm{ml}$ using WFE - The WFE system is currently under development and its technology, availability, and operability are not yet mature. Authorization to operate the system would require significant modification to the documented safety analysis. The cost to provide and operate the WFE, and the "transportability" of the system to other DSTs, is uncertain.

- Concentrate waste at-tank to damp saltcake using WFE - In addition to the uncertainties noted above, the capability to dry the salts to $1.7 \mathrm{~g} / \mathrm{ml}$ and convey the salts to the tank has not been demonstrated.

- Pump-off liquid fraction of Group A tanks/backfill with saltcake from WFE - This alternative allows the tank to be filled with solids by controlling the depth of supernatant above the solids below the BDGRE energy ratio limit. All WFE uncertainties discussed above apply to the option.

The WFE system is currently envisioned as primarily a back-up to the 242-A Evaporator, in the event that the 242-A Evaporator might experience operational difficulties. The WFE system is also an alternative for evaporating wastes in the SY Farm tanks, thereby reducing some of the logistical challenges of transferring SY Farm tank waste cross-site and then having to find space in the 200 East tanks for the concentrated wastes. However, this technology also has long-term promise for its potential capability to concentrate wastes beyond the maximum SpG that is generally accepted as the 242-A Evaporator limit.

By evaporating waste at-tank, as the wiped-film evaporation technology would allow, neither of these limitations would prevent the waste from being concentrated to a SpG in excess of the current $1.43 \mathrm{~g} / \mathrm{ml}$ limit. The impact of wiped-film evaporation technology, assuming that it could concentrate wastes at-tank to $1.50 \mathrm{~g} / \mathrm{ml}$, would result in an approximate reduction in waste volume of $\sim 15 \%$ over wastes from that concentrated to $1.43 \mathrm{~g} / \mathrm{ml}$.

In addition, the possibility of evaporating supernatant waste to damp saltcake wastes, nominally with a SpG of $1.7 \mathrm{~g} / \mathrm{ml}$, is of interest. The wiped-film evaporation technology was evaluated for its potential applicability to achieving this option. Further concentration of waste from $1.43 \mathrm{~g} / \mathrm{ml}$ to that of damp saltcake would result in a $\sim 35 \%$ reduction in waste volume. The equipment configuration currently being designed for demonstration and full-scale deployment would require significant modification to transfer relatively solid saltcake, rather than concentrated liquid supernatant.

The same limitations as those described above would apply to the potential deployment of the wiped-film evaporation technology to provide damp saltcake that could be used to backfill the recovered tank space in the Group A tanks, once the supernatant in those tanks is transferred to other DSTs or concentrated in place. Additional regulatory challenges associated with 
performing any activity that might potentially disturb the acceptable storage conditions that currently exist in those tanks would need to be overcome. There would also be logistical challenges of transferring supernatant wastes from non-Group A tanks so that the resulting saltcake could be backfilled into the Group A tanks.

\subsubsection{New Storage Facility Alternatives}

The DSB evaluated four options that were based on design, construction, and operation of new facilities with the sole purpose of storing tank waste. In general, this group of options was rated the lowest because they are "one-dimensional," in that they have no other purpose than to store tank waste, and because there is the consideration that building and operating more storage tanks only adds to the future decontamination and decommissioning liability. While the option to build new DSTs is the best understood and the most mature of the four options evaluated, it is politically unpopular and would be quite difficult to justify, unless the existing DST system became inoperable and/or there were significant delays in the startup and operation of the WTP. The four options include:

- Use compliant bladder in lined basin to store pretreated waste - This technique has no application history for this type of Hanford waste and has uncertainties such as weathering and maintenance of the liner, the requirement to store waste with low radioactive source term for worker safety, and retrieval and eventual closure. It is assumed that the waste would require pretreatment to reduce the radionuclide content before it could be stored.

- Use small modular tanks - By this alternative, tank waste would be retrieved and dried and stored aboveground in multiple small tanks pending treatment in a RCRA-compliant manner. Uncertainties include:

- Permitting and licensing an aboveground storage facility when the Hanford precedent has been primarily to use underground storage structures. However, there are precedents for the concept at Hanford for $100 \mathrm{~K}$ Basin sludge storage at 221-T and consideration of contact-handled transuranic (CH-TRU) waste storage.

- Storing dried waste in small volume tanks that later must be processed in the WTP raises issues concerning transferring the waste into the WTP feed system and disposing of the contaminated tanks.

- Regulators and stakeholders have been asked to consider a similar concept for CH-TRU waste in which the tanks would be shipped off-site and disposed by placing the tank of waste in the disposal site. However, high-level radioactive waste that requires remote handling has significant uncertainty.

- Build large tanks for LAW storage - Construction of new tanks and facilities not planned as part of the mission baseline are likely to divert resources from planned activities. Tanks larger than existing facilities also have significant design, site, and decommissioning challenges.

- Build new DSTs - This alternative would provide new facilities that need to be sited and decommissioned and are not part of the baseline. While providing compliant storage, they would divert resources from the retrieval and treatment mission. 


\subsection{RESULTS OF SENSITIVITY ANALYSIS}

To determine if the scores in both the near-term and long-term option matrices were consistent and not overly influenced by one of the selected criterion, a sensitivity analysis was performed. Three sensitivity cases were selected and developed in an effort to potentially segregate option(s) that might be favored as a result of changing the relative weightings:

- Sensitivity Case 1 - The weighting for the cost and schedule criterion was increased from $33 \%$ to $50 \%$, and the remaining $50 \%$ was proportionally divided among the other four criteria.

- Sensitivity Case 2 - The weighting for the waste feed delivery mission criterion was reduced from $15 \%$ to $0 \%$ (i.e., eliminated the scores associated with waste feed delivery and proportionally divided the weightings among the remaining four criteria using a base score of 85).

- Sensitivity Case 3 - The weighting for the cost and schedule criterion was increased from $33 \%$ to $100 \%$, and the other four criteria were reduced to $0 \%$.

Figure 5-1 shows the results of the three sensitivity cases for each of the near-term tank space options. Each of the sensitivity cases tended to follow the same scoring trend as the originally scored rankings. Based on these three cases, it would appear that none of the five selected criteria unduly influenced the scoring of the near-term options.

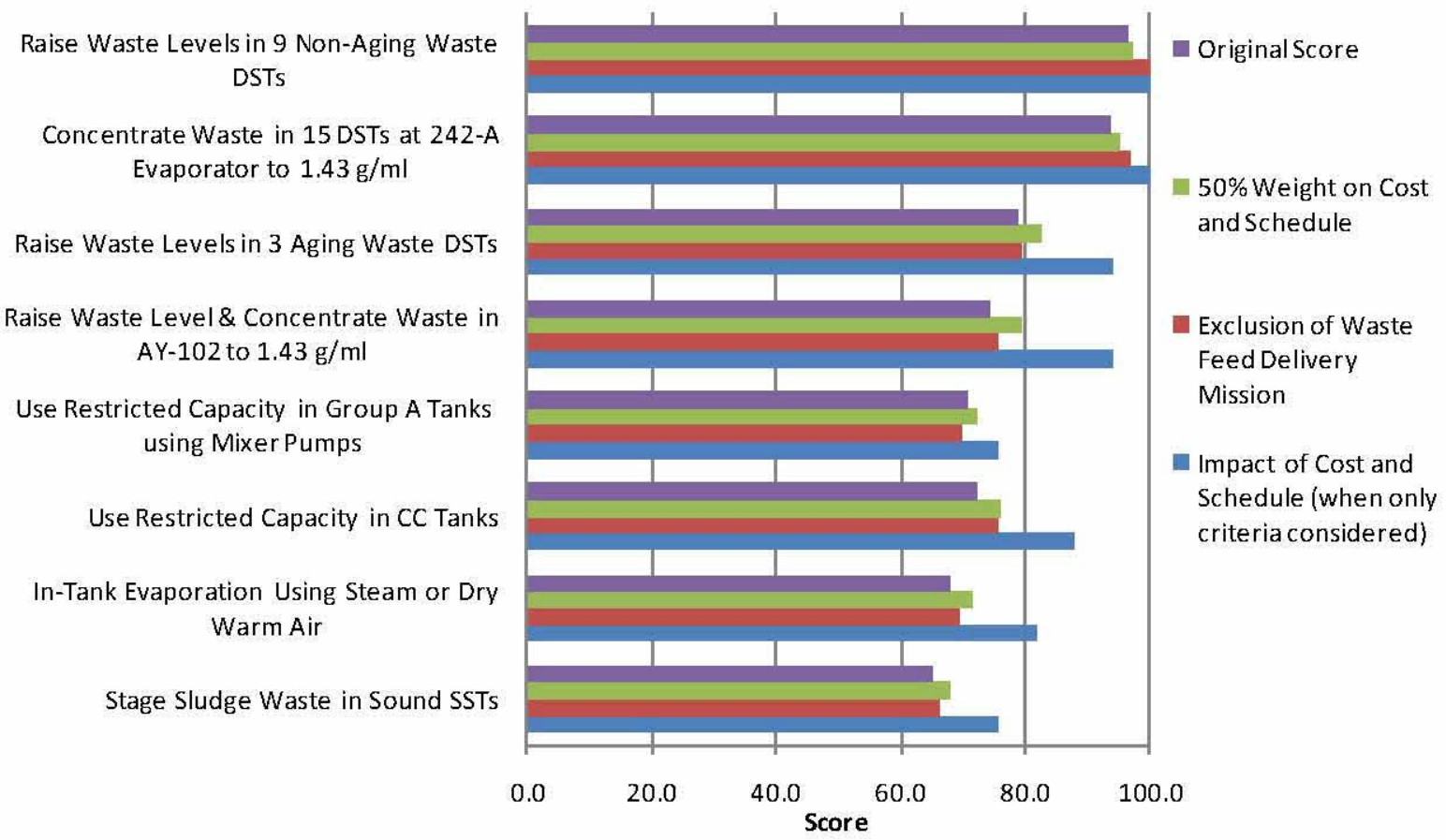

Figure 5-1. Sensitivity Cases - Near-Term Options. 
Figure 5-2 shows the results of the three sensitivity cases for each of the long-term tank space options. With the exception of sensitivity case 1 for the "Build/operate four new DSTs" option, Sensitivity cases 1 and 2 tended to follow the same scoring trend as the original score. Due to its relatively high implementation cost, the $50 \%$ weighting on cost and schedule brought down the score for the "Build/operate four new DSTs" option below those of other options. For sensitivity case 3, which measured the full impact of cost and schedule, scoring results were magnified depending on whether a new facility was being constructed (at a relatively high cost and long schedule), or an existing facility was being used (at a relatively low cost and short schedule). Albeit magnified, the scoring trend for sensitivity case 3 mostly followed the trend of the original scores.

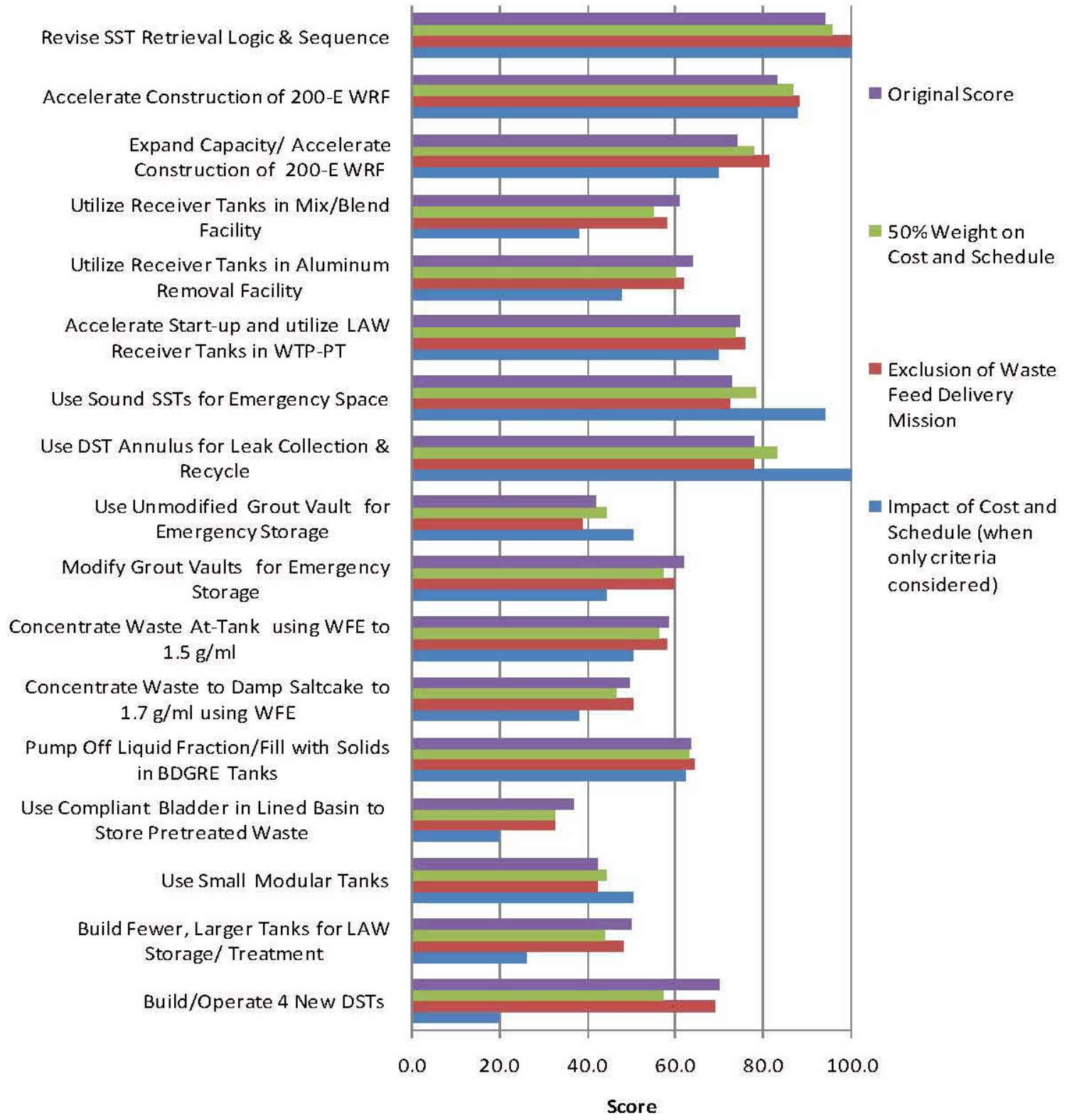

Figure 5-2. Sensitivity Cases - Long-Term Options. 


\subsection{REFERENCES}

42 USC 6901, et seq., Resource Conservation and Recovery Act of 1976 (RCRA).

DOE M 435.1-1, 2007, Radioactive Waste Management Manual, Change 1, Office of Environmental Management, U.S. Department of Energy, Washington, D.C.

ORP-11242, 2009, River Protection Project System Plan, Rev. 4, Washington River Protection Solutions, LLC, Richland, Washington.

RPP-7702, 2009, Tank Space Options Report, Rev. 1, Washington River Protection Solutions, LLC, Richland, Washington.

RPP-13361, 2003, Tank 241-AY-101 Fitness for Service, Rev. 0, CH2M HILL Hanford Group, Inc., Richland, Washington.

RPP-28968, 2010, Hanford Double-Shell Tank Thermal and Seismic Project-Summary of Combined Thermal and Operating with Seismic Analysis, Rev. 0, Washington River Protection Solutions, LLC, Richland, Washington.

RPP-PLAN-45168, 2010, Tank Space Options Decision Plan, Rev. 0, Washington River Protection Solutions, LLC, Richland, Washington.

RPP-RPT-32237, 2009, Hanford Double-Shell Tank Thermal and Seismic Project - Increased Liquid Level Analysis for 241-AP Tank Farm, Rev. 1, Washington River Protection Solutions, LLC, Richland, Washington. 


\section{APPENDIX A}

\section{DECISION CRITERIA, MEASURES, AND}

DEFINITIONS FOR EVALUATING DOUBLE-SHELL TANK SPACE OPTIONS 


\section{Decision Criteria, Measures, and Definitions for Evaluating Tank Space Options. ( 2 pages)}

Criterion

Safety/Regulatory

Compliance/

Stakeholder

Acceptance

Technical

feasibility

Operability and maintainability

Cost and schedule
Measure

Extent to which existing $\mathrm{AB}$ for $\mathrm{TF}$ operations will require modification

Regulatory agency approval of modifications to existing environmental permit(s), or issuance of new environmental permit(s)

Stakeholder (e.g., HAB, DNFSB) and Tribal Nations acceptance

Estimated volume of tank space created

Technical maturity

Ability for facility/process to be operated and maintained

Estimated total cost (including development and demonstration, design, procurement, installation/startup, operating cost through 2025)

Estimated cost per gallon of tank space created

Project/activity in existing or planned facility

\section{Definition}

$5=$ Minimal modifications to $\mathrm{AB}$ are required

3 = Moderate modifications to $\mathrm{AB}$ are required

$1=$ Significant modifications to $\mathrm{AB}$ are required

5 = High probability of achieving approval/issuance on a schedule supporting implementation of option

3 = Moderate probability of achieving approval/issuance on a schedule supporting implementation of option

1 = Low probability of achieving approval/issuance on a schedule supporting implementation of option

$5=$ High probability of achieving stakeholder acceptance

3 = Moderate probability of achieving stakeholder acceptance

1 = Low probability of achieving stakeholder acceptance

5 = Estimated volume is $>1,500 \mathrm{kgal}$ (slightly more than one DST equivalent)

3 = Estimated volume is $500-1,500 \mathrm{kgal}$

1 = Estimated volume is $<500 \mathrm{kgal}$ (slightly less than one-half of DST equivalent)

$5=$ TRL is judged to be 6 or greater

$3=$ TRL is judged to be 4 or 5

$1=$ TRL is judged to be 3 or less

5 = Easily operated/maintained

3 = Moderately difficult to operate/maintain, but possible

1 = Quite difficult or impossible to operate/maintain

5 = Estimated total cost is $\angle \$ 25 \mathrm{M}$ (U.S. dollars)

3 = Estimated total cost is $\$ 25-\$ 100 \mathrm{M}$ (U.S. dollars)

$1=$ Estimated total cost is $>\$ 100 \mathrm{M}$ (U.S. dollars)

5 = Estimated cost per gallon of created tank space is $<\$ 10 /$ gal

3 = Estimated cost per gallon of created tank space is $\$ 10-\$ 50 / \mathrm{gal}$

$1=$ Estimated cost per gallon of created tank space is $>\$ 50 / \mathrm{gal}$

$5=$ Project/activity performed in existing facility

3 = Project/activity performed in planned (baseline) facility

$1=$ Project/activity requires new facility not in baseline 


\section{Decision Criteria, Measures, and Definitions for Evaluating Tank Space Options. ( 2 pages)}

\begin{tabular}{|c|c|c|}
\hline Criterion & Measure & Def \\
\hline $\begin{array}{l}\text { Cost and schedule } \\
\text { (continued) }\end{array}$ & $\begin{array}{l}\text { Implementation schedule } \\
\text { (including development and } \\
\text { demonstration, design, } \\
\text { procurement, installation/startup) }\end{array}$ & $\begin{array}{l}5=\text { Tank space could become available by } 2015 \\
3=\text { Tank space could become available between } 2015 \text { and } \\
2020 \\
1=\text { Tank space could become available after } 2020\end{array}$ \\
\hline \multirow[t]{4}{*}{$\begin{array}{l}\text { Impact on waste } \\
\text { feed delivery } \\
\text { mission }\end{array}$} & Impact on mix/blend function & $\begin{array}{l}5=\text { Overall positive impact on mix/blend function } \\
3=\text { No impact on } \mathrm{mix} / \mathrm{blend} \text { function } \\
1=\text { Negatively impacts mix/blend function }\end{array}$ \\
\hline & $\begin{array}{l}\text { on } \\
\text { characterize/certify }\end{array}$ & $\begin{aligned} 5= & \text { Overall positive impact on sample/characterize/certify } \\
& \text { function } \\
3= & \text { No impact on sample/characterize/certify function } \\
1= & \text { Negatively impacts sample/characterize/certify } \\
& \text { function }\end{aligned}$ \\
\hline & $\begin{array}{l}\text { Impact on WTP pretreatment } \\
\text { function }\end{array}$ & $\begin{array}{l}5=\text { Overall positive impact on WTP pretreatment function } \\
3=\text { No impact on WTP pretreatment function } \\
1=\text { Negatively impacts WTP pretreatment function }\end{array}$ \\
\hline & $\begin{array}{l}\text { Impact on returning waste to } \\
\text { processable form }\end{array}$ & $\begin{aligned} 5 & =\text { Waste is easily returned to processable form } \\
3= & \text { Waste is returned to processable form, but with } \\
& \text { moderate difficulty } \\
1= & \text { Waste is returned to processable form with significant } \\
& \text { difficulty }\end{aligned}$ \\
\hline $\begin{array}{ll}\mathrm{AB} & =\text { auth } \\
\mathrm{DNFSB} & =\text { Defe } \\
\mathrm{DST} & =\text { doub } \\
\mathrm{HAB} & =\text { Hanf }\end{array}$ & $\begin{array}{l}\text {-shell tank. } \\
\text { rd Advisory Board. }\end{array}$ & $\begin{array}{ll}\text { TF } & =\text { tank farm. } \\
\text { TRL } & =\text { technology readiness level. } \\
\text { WTP } & =\text { Waste Treatment and Immobilization } \\
& \text { Plant. }\end{array}$ \\
\hline
\end{tabular}




\section{APPENDIX B}

DOUBLE-SHELL TANK SPACE OPTIONS SCORING NEAR-TERM OPTIONS 
Near-Term Options

\begin{tabular}{|c|c|c|c|c|c|c|c|c|c|c|c|c|c|c|c|c|c|c|}
\hline \multirow[b]{3}{*}{ Criteria } & \multirow[b]{3}{*}{ Measures } & \multirow[b]{3}{*}{$\begin{array}{l}\text { Weighting } \\
\text { factor }\end{array}$} & \multirow{2}{*}{\multicolumn{2}{|c|}{$\begin{array}{c}\text { Raise waste levels in } \\
9 \text { non-aging waste } \\
\text { DSTs }\end{array}$}} & \multirow{2}{*}{\multicolumn{2}{|c|}{$\begin{array}{c}\begin{array}{c}\text { Concentrate waste } \\
\text { in } 15 \text { DSTs at } \\
242-\mathrm{A} \text { Evaporator } \\
\text { to } 1.43 \mathrm{~g} / \mathrm{ml}^{2}\end{array} \\
(4.1 .2)\end{array}$}} & \multirow{2}{*}{\multicolumn{2}{|c|}{\begin{tabular}{|c|}
$\begin{array}{c}\text { Raise waste levels } \\
\text { in } 3 \text { aging waste } \\
\text { DSTs }^{\text {3 }}\end{array}$ \\
(4.1.3) \\
\end{tabular}}} & \multirow{2}{*}{\multicolumn{2}{|c|}{ 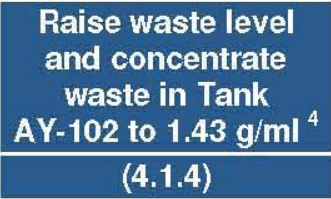 }} & \multirow{2}{*}{\multicolumn{2}{|c|}{$\begin{array}{c}\begin{array}{c}\text { Use restricted } \\
\text { capacity in Group A } \\
\text { tanks using mixer } \\
\text { pumps }\end{array} \\
(4.1 .5)\end{array}$}} & \multirow{2}{*}{\multicolumn{2}{|c|}{$\begin{array}{c}\begin{array}{c}\text { Use restricted } \\
\text { capacity in } \mathrm{CC} \\
\text { tanks }^{6}\end{array} \\
(4.1 .6)\end{array}$}} & \multirow{2}{*}{\multicolumn{2}{|c|}{$\begin{array}{c}\begin{array}{c}\text { In-tank evaporation } \\
\text { using dry warm } \\
\text { air }\end{array} \\
\text { (4.1.7) } \\
\end{array}$}} & \multirow{2}{*}{\multicolumn{2}{|c|}{$\begin{array}{c}\begin{array}{c}\text { Stage sludge waste } \\
\text { in sound SSTs }\end{array} \\
(4.1 .8)\end{array}$}} \\
\hline & & & & & & & & & & & & & & & & & & \\
\hline & & & $\begin{array}{l}\text { Raw } \\
\text { score }\end{array}$ & $\begin{array}{l}\text { Weighted } \\
\text { score }^{10}\end{array}$ & \begin{tabular}{|l|} 
Raw \\
score
\end{tabular} & $\begin{array}{c}\text { Weighted } \\
\text { score }\end{array}$ & $\begin{array}{l}\text { Raw } \\
\text { score }\end{array}$ & $\begin{array}{c}\text { Weighted } \\
\text { score }\end{array}$ & $\begin{array}{l}\text { Raw } \\
\text { score }\end{array}$ & $\begin{array}{l}\text { Weighted } \\
\text { score }\end{array}$ & $\begin{array}{l}\text { Raw } \\
\text { score }\end{array}$ & $\begin{array}{c}\text { Weighted } \\
\text { score }\end{array}$ & \begin{tabular}{|l|l|} 
Raw \\
score
\end{tabular} & $\begin{array}{l}\text { Weighted } \\
\text { score }\end{array}$ & $\begin{array}{l}\text { Raw } \\
\text { score }\end{array}$ & $\begin{array}{l}\text { Weighted } \\
\text { score }\end{array}$ & $\begin{array}{l}\text { Raw } \\
\text { score }\end{array}$ & $\begin{array}{l}\text { Weighted } \\
\text { score }\end{array}$ \\
\hline \multirow{3}{*}{$\begin{array}{l}\text { Safety/ } \\
\text { Regulatory } \\
\text { Compliance/ } \\
\text { Stakeholder } \\
\text { Acceptance }\end{array}$} & $\begin{array}{l}\text { Extent to which existing } \mathrm{AB} \text { for } \mathrm{TF} \text { operations } \\
\text { will require modification }\end{array}$ & 8 & 5 & 8 & 5 & 8 & 5 & 8 & 5 & 8 & 3 & 4.8 & 5 & 8 & 1 & 1.6 & 3 & 4.8 \\
\hline & $\begin{array}{l}\text { Regulatory agency approval of modifications to } \\
\text { existing environmental permit(s), or issuance of } \\
\text { new environmental permit(s) }\end{array}$ & 8 & 5 & 8 & 5 & 8 & 5 & 8 & 3 & 4.8 & 5 & 8 & 3 & 4.8 & 3 & 4.8 & 3 & 4.8 \\
\hline & $\begin{array}{l}\text { Stakeholder (e.g., HAB, DNFSB) and Tribal } \\
\text { Nations acceptance }\end{array}$ & 4 & 5 & 4 & 5 & 4 & 3 & 2.4 & 3 & 2.4 & 3 & 2.4 & 3 & 2.4 & 3 & 2.4 & 3 & 2.4 \\
\hline \multirow[t]{3}{*}{$\begin{array}{l}\text { Technical } \\
\text { Feasibility }\end{array}$} & Estimated volume of recovered tank space (kgal) & & 940 & & $\begin{array}{l}\text { up to } \\
3,500\end{array}$ & & 750 & & 450 & & 800 & & 390 & & 3,300 & & 650 & \\
\hline & & 15 & 5 & 15 & 5 & 15 & 3 & 9 & 3 & 9 & 3 & 9 & 1 & 3 & 3 & 9 & 3 & 9 \\
\hline & Technical maturity & 10 & 5 & 10 & 5 & 10 & 1 & 2 & 1 & 2 & 3 & 6 & 5 & 10 & 5 & 10 & 3 & 6 \\
\hline $\begin{array}{l}\text { Operability and } \\
\text { maintainability }\end{array}$ & $\begin{array}{l}\text { Ability for facility/process to be operated and } \\
\text { maintained }\end{array}$ & 7 & 5 & 7 & 3 & 4.2 & 5 & 7 & 5 & 7 & 3 & 4.2 & 5 & 7 & 3 & 4.2 & 3 & 4.2 \\
\hline \multirow{6}{*}{$\begin{array}{l}\text { Cost and } \\
\text { schedule }\end{array}$} & Total cost (including development and & & $\$ 5.3 \mathrm{M}$ & & $\$ 14 \mathrm{M}$ & & $\$ 15 \mathrm{M}$ & & $\$ 15 \mathrm{M}$ & & $\$ 100 \mathrm{M}$ & & $\$ 12.2 \mathrm{M}$ & & DNE & & $\$ 81 \mathrm{M}$ & \\
\hline & $\begin{array}{l}\text { demonstration, design, procurement, } \\
\text { installation/startup, operating cost through 2025) }\end{array}$ & 10 & 5 & 10 & 5 & 10 & 5 & 10 & 5 & 10 & 3 & 6 & 5 & 10 & 3 & 6 & 3 & 6 \\
\hline & Cost per gallon of tank space created & & $\$ 6.00$ & & $\$ 4.00$ & & $\$ 20.00$ & & $\$ 32.60$ & & $\$ 125$ & & $\$ 6.00$ & & DNE & & $\$ 125$ & \\
\hline & & 5 & 5 & 5 & 5 & 5 & 3 & 3 & 3 & 3 & 1 & 1 & 1 & 1 & 3 & 3 & 1 & 1 \\
\hline & Project/activity in existing or planned facility & 8 & 5 & 8 & 5 & 8 & 5 & 8 & 5 & 8 & 5 & 8 & 5 & 8 & 5 & 8 & 5 & 8 \\
\hline & $\begin{array}{l}\text { Implementation schedule (including development } \\
\text { and demonstration, design, procurement, } \\
\text { installation/startup) }\end{array}$ & 10 & 5 & 10 & 5 & 10 & 5 & 10 & 5 & 10 & 5 & 10 & 5 & 10 & 5 & 10 & 5 & 10 \\
\hline \multirow{5}{*}{$\begin{array}{l}\text { Impact on waste } \\
\text { feed delivery } \\
\text { mission }\end{array}$} & Impact on mix/blend function & 3 & 3 & 1.8 & 3 & 1.8 & 3 & 1.8 & 3 & 1.8 & 3 & 1.8 & 3 & 1.8 & 3 & 1.8 & 3 & 1.8 \\
\hline & Impact on sample/characterize/certify function & 3 & 3 & 1.8 & 3 & 1.8 & 3 & 1.8 & 1 & 0.6 & 3 & 1.8 & 3 & 1.8 & 3 & 1.8 & 3 & 1.8 \\
\hline & Impact on WTP pretreatment function & 3 & 3 & 1.8 & 3 & 1.8 & 3 & 1.8 & 3 & 1.8 & 3 & 1.8 & 1 & 0.6 & 3 & 1.8 & 3 & 1.8 \\
\hline & $\begin{array}{l}\text { Impact on retrieving or returning waste to } \\
\text { processable form }\end{array}$ & 6 & 5 & 6 & 5 & 6 & 5 & 6 & 5 & 6 & 5 & 6 & 3 & 3.6 & 3 & 3.6 & 3 & 3.6 \\
\hline & Total Score: & 100 & & 96.4 & & 93.6 & & 78.8 & & 74.4 & & 70.8 & & 72 & & 68 & & 65.2 \\
\hline
\end{tabular}

Non-aging waste tanks are AN, AW and SY Farms.

15 candidate DSTs for volume reduction; waste is concentrated to a nominal $1.43 \mathrm{~g} / \mathrm{ml}$ at $242-\mathrm{A}$ Evaporator.

Three aging waste tanks are AY-101, AZ-101, and AZ-102.

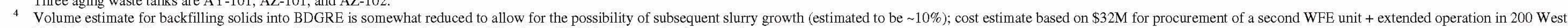
beyond initial demonstration + operation of second WFE in 200 East + design modification to WFE for damp saltcake operation

Group A tanks are AN-103, AN-104, AN-105, AW-101, and SY-103, cost estimate does not include cost of accelerating installation of mixer pumps, but does include the estimated cost of operating them for 10 additional years ( 5 pumps $\mathrm{x} \sim \$ 1 \mathrm{M} / \mathrm{year} \mathrm{x}$

10 years) $+\$ S M$ for $A B$ modifications.

anks are AN-102 and AN-107, per RPP-7702 (Tank Space Options Report, Rev. 1, Washington River Protection Solutions, LLC, Richland, Washington); \$5M per tank to raise level to 454 in. and \$1.2 to transfer/treat waste from

Warm air sparging assumes that same volume reduction can be achieved as at 242-A Evaporator; based on estimated $66 \mathrm{kgal} / \mathrm{year}$ evaporation rate (per RPP-7702), this option was not evaluated further because the rate of recovered space was so low (DNE).

8 Assumed the tank(s) are sound; cost estimate for staging sludge waste in

Raw score was selected by a consensus of the Decision Support Board.

Callation of the weighted score is performed by the equation: (Raw Score) $=$ (Weighting Factor) $*$ (Weighted Score) $/ 5$

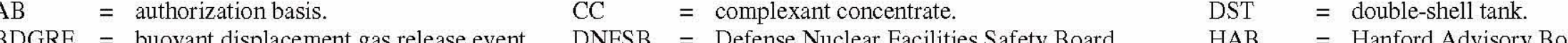

$\mathrm{HAB}=$ double-shell tank. $\quad \mathrm{SST}=$ single-shell tank

$\mathrm{WFE} \quad=$ wiped-film evaporator. 


\section{APPENDIX C}

\section{DST SPACE OPTIONS SCORING SPREADSHEET -} LONG-TERM OPTIONS 


\section{Long-Term Options}

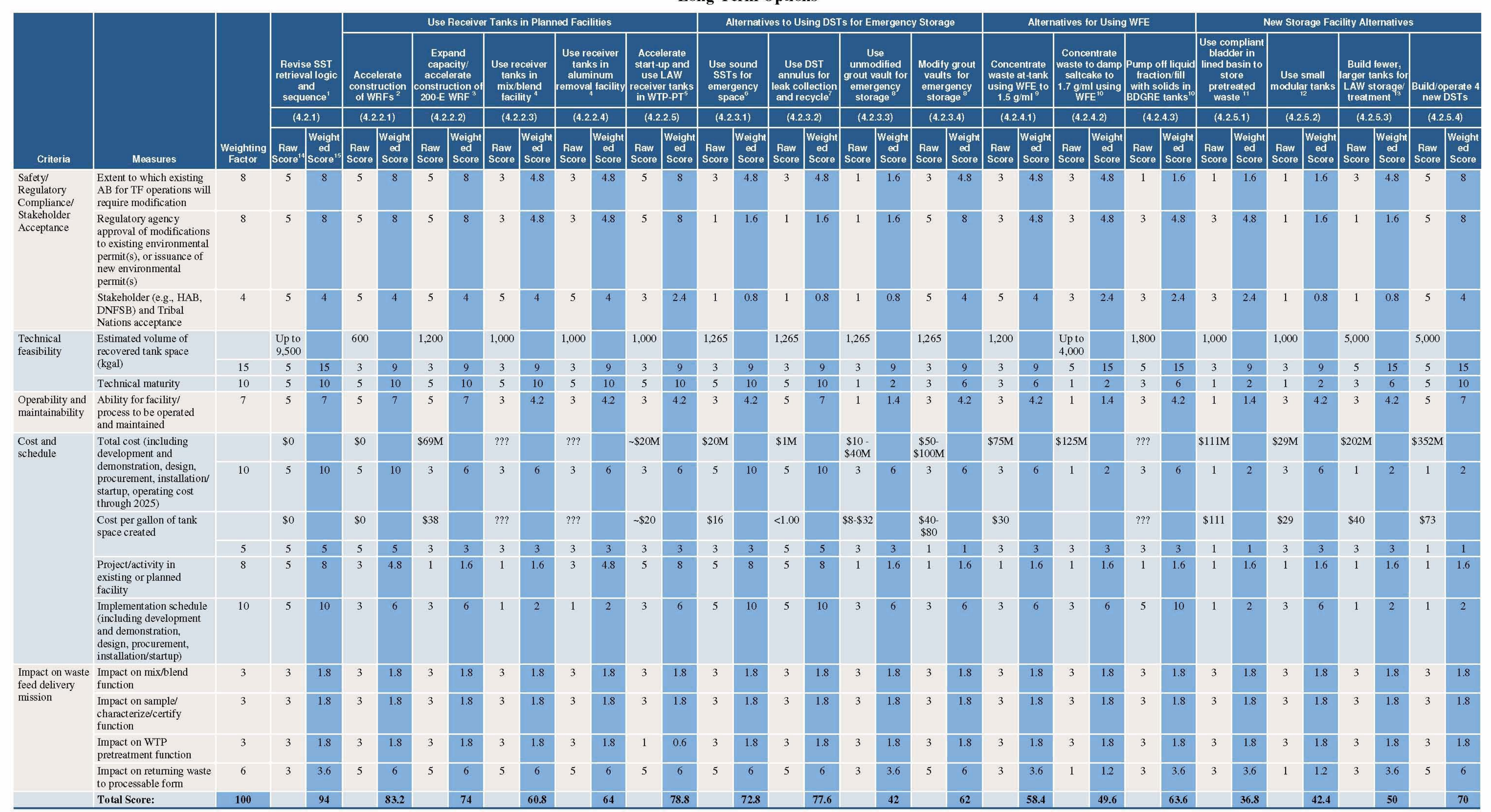


Because only the sequence of tank retrievals is being changed, there are no new or incremental costs associated with this option.

Costs associated with accelerating Waste Receiver Facility design and construction are not included.

Cost estimate for expand/accelerate WRFs assumes only incremental cost due to larger tanks; costs associated with acceleration are not included.

Uses two of six $500 \mathrm{kgal} \mathrm{tanks} \mathrm{-} \mathrm{only} \mathrm{receipt} \mathrm{function;} \mathrm{storage} \mathrm{function} \mathrm{is} \mathrm{technically} \mathrm{mature;} \mathrm{balance} \mathrm{of} \mathrm{plant} \mathrm{for} \mathrm{both} \mathrm{mix/blend} \mathrm{and} \mathrm{ARF} \mathrm{has} \mathrm{not} \mathrm{been} \mathrm{well} \mathrm{defined.}$

Costs associated with accelerating the startup of the LAW receipt tanks in WTP-PT are not included.

Cost estimate for using SST for emergency space includes $\$ 5 \mathrm{M}$ to set up two SSTs as a receiver + \$14M to subsequently pump contaminated water from SSTs and evaporate + \$1M for paperwork.

Waive emergency storage requirement would require that leaked liquid would be pumped from DST annulus and recycled into the DST primary containment; a redundant annulus pump would be required.

Range of cost and cost per gallon includes cost of retrieval from vaults and subsequent $D \& D$ in the event that they are used as emergency space.

Concentrate waste at-tank using WFE assumes that three WFE units will be procured, installed, and operated, two in 200 East and one in 200 West; estimated volume is difference between specific gravities 1.43 and 1.5 for supernatant.

${ }_{10}$ Concentrate waste to damp saltcake using WFE assumes damp saltcake has a SpG of $1.7 \mathrm{~g} / \mathrm{ml}$, or an additional $30-35 \%$ volume reduction from waste concentrated to $1.43 \mathrm{~g} / \mathrm{ml}$; three additional units for farms ( $\$ 32 \mathrm{M}$ each unit).

Cost estimate for compliant bladder in lined basin to store pretreated waste includes Cs ion removal and solids filtration of the supernatant.

Cost estimate for above-grade small modular tanks does not include cost of waste packaging; cost estimate based on CH-TRU waste packaging approach.

13 Cost of one 5-million gallon tank is based on the cost estimate for four $1.25 \mathrm{Mgal}$ tanks to the $3 / 5$ power, but does not include operating or D\&D costs.

14 Raw score was selected by a consensus of the Decision Support Board.

15 Calculation of the weighted score is performed by the equation: (Raw Score) $=$ (Weighting Factor) $*$ (Weighted Score) $/ 5$.

$\begin{array}{lll}\mathrm{AB} & =\text { authorization basis. } & \mathrm{CH}-\mathrm{TRU}=\text { contract-handled transuranic. } \\ \mathrm{ARF} & =\text { airborne release fraction. } & \mathrm{D} \mathrm{D}=\text { decontamination and decommissioning }\end{array}$

BDGRE = buoyant displacement gas release event. DNFSB = Defense Nuclear Facilities Safety Board.

DNFSB $=$ Defense Nuclear Facilities Safety Board. $\quad$ LAW

complexant concentrate.
DST $\quad=$ double-shell tank.

$\begin{aligned} & =\text { Hanford Advisory } \\ & =\text { low-activity waste. }\end{aligned}$
$\mathrm{PT} \quad=$ pretreatment.

$\begin{aligned} \text { SST } & =\text { single-shell tank } \\ \mathrm{TF} & =\text { tank farms. }\end{aligned}$
WFE $\quad$ wiped-film evaporator.

WTP $=$ Waste Treatment and Immobilization 
RPP-RPT-45825

Revision 0

APPENDIX D

TANK-BY-TANK MATRIX

D-i 
Tank Matrix

\begin{tabular}{|c|c|c|c|c|c|c|c|c|c|c|c|c|c|c|}
\hline \multirow[b]{2}{*}{ Tank } & \multirow{2}{*}{$\begin{array}{l}\text { Current Level } \\
\text { (kgal) }^{1}\end{array}$} & \multirow{2}{*}{$\begin{array}{l}\text { Supernatant } \\
\text { Liquid } \\
\text { (kgal) }^{1}\end{array}$} & \multirow{2}{*}{$\begin{array}{l}\text { Sludge } \\
\text { (kgal) }^{1}\end{array}$} & \multirow{2}{*}{$\begin{array}{l}\text { Saltcake } \\
\text { (kgal) }^{1}\end{array}$} & \multirow{2}{*}{$\begin{array}{l}\text { Restricted Space } \\
\text { (kgal) }\end{array}$} & \multirow[b]{2}{*}{$S p G^{2}$} & \multirow{2}{*}{$\begin{array}{c}\text { Raise Level to 454" } \\
\text { (kgal) }\end{array}$} & \multicolumn{3}{|c|}{$\begin{array}{l}\text { Concentrate to Specific Gravity } \\
\text { (total volume kgal) }\end{array}$} & \multicolumn{3}{|c|}{$\begin{array}{l}\text { Total kgal available when } \\
\text { concentrated to: } \\
\text { (incremental volume saved) }\end{array}$} & \multirow{2}{*}{$\begin{array}{l}\text { Alternatives } \\
\text { to using } \\
\text { DSTs for } \\
\text { emergency } \\
\text { storage }\end{array}$} \\
\hline & & & & & & & & 1.43 & 1.5 & 1.7 & 1.43 & 1.5 & 1.7 & \\
\hline Options: & & & & & & & & & & & & & *** Option & \\
\hline AN-101 & 576 & 545 & 0 & 31 & & 1.22 & 104.5 & 310 & 271 & 202 & 266 & 39 & 69 & \\
\hline AN-102 & 1049 & 895 & 0 & 154 & 111 & 1.41 & 104.5 & 1007 & 888 & 678 & & & & \\
\hline AN-103 & 960 & 474 & 0 & 486 & 200 & 1.48 & 104.5 & 1015 & 941 & 811 & & & 130 & \\
\hline AN-104 & 1048 & 605 & 0 & 443 & 112 & 1.40 & 104.5 & 1006 & 927 & 789 & & & 138 & \\
\hline AN-105 & 1124 & 588 & 0 & 536 & 36 & 1.42 & 104.5 & 1110 & 1030 & 889 & & & 141 & \\
\hline AN-106 & 782 & 427 & 338 & 17 & & 1.16 & 104.5 & 514 & 492 & 453 & 268 & 22 & 39 & \\
\hline AN-107 & 1089 & 859 & 0 & 230 & 71 & 1.43 & 104.5 & 1089 & 969 & 758 & & & & \\
\hline AP-101 & 1112 & 1112 & 0 & 0 & & 1.40 & 0.0 & 1034 & 890 & 635 & 78 & 145 & 254 & \\
\hline AP-102 & 1081 & 1053 & 28 & 0 & & 1.37 & 0.0 & 934 & 807 & 585 & 147 & 127 & 223 & \\
\hline AP-103 & 1237 & 1185 & 0 & 52 & & 1.38 & 0.0 & 1099 & 953 & 695 & 138 & 147 & 257 & \\
\hline AP-104 & 448 & 430 & 0 & 18 & & 1.41 & 0.0 & 428 & 371 & 270 & 20 & 57 & 101 & \\
\hline AP-105 & 1137 & 1032 & 0 & 105 & & 1.40 & 0.0 & 1065 & 931 & 695 & 72 & 134 & 236 & \\
\hline AP-106 & 1136 & 1136 & 0 & 0 & & 1.21 & 0.0 & 555 & 477 & 341 & 581 & 78 & 136 & \\
\hline AP-107 & 1106 & 1106 & 0 & 0 & & 1.24 & 0.0 & 617 & 531 & 379 & ${ }^{3}$ & 86 & 152 & \\
\hline AP-108 & 1244 & 1132 & 0 & 112 & & 1.42 & 0.0 & 1218 & 1063 & 791 & 26 & 155 & 272 & \\
\hline AW-101 & 1131 & 735 & 0 & 396 & 29 & 1.47 & 104.5 & 1199 & 1087 & 890 & & & 197 & \\
\hline AW-102 & 105 & 56 & 49 & 0 & & 1.23 & 104.5 & 79 & 75 & 67 & 3 & & & \\
\hline AW-103 & 1090 & 770 & 280 & 40 & & 1.24 & 104.5 & 750 & 690 & 584 & 340 & 60 & 106 & \\
\hline AW-104 & 1063 & 809 & 97 & 157 & & 1.36 & 104.5 & 931 & 836 & 670 & 132 & 95 & 166 & \\
\hline AW-105 & 411 & 163 & 248 & 0 & & 1.06 & 104.5 & 271 & 268 & 262 & 140 & 3 & 6 & \\
\hline AW-106 & 1129 & 848 & 0 & 281 & & 1.21 & 104.5 & 695 & 637 & 535 & 3 & & & \\
\hline AY-101 & 692 & 587 & 105 & 0 & & 1.10 & 247.5 & 242 & 222 & 189 & 450 & 19 & 34 & \\
\hline AY-102 & 917 & 766 & 151 & 0 & 83 & 1.31 & 247.5 & 703 & 626 & 490 & & & & \\
\hline AZ-101 & 985 & 933 & 52 & 0 & & 1.23 & 247.5 & 551 & 481 & 359 & & & & \\
\hline AZ-102 & 920 & 815 & 105 & 0 & & 1.22 & 247.5 & 522 & 464 & 361 & 3 & & & \\
\hline SY-101 & 1106 & 851 & 0 & 255 & & 1.13 & 104.5 & 512 & 476 & 413 & 594 & 36 & 63 & \\
\hline SY-102 & 556 & 353 & 203 & 0 & & 1.12 & 104.5 & 302 & 288 & 264 & 254 & 14 & 24 & \\
\hline SY-103 & 738 & 381 & 0 & 357 & 422 & 1.49 & 104.5 & 791 & 730 & 624 & & & 107 & \\
\hline & & & & & & $\begin{array}{l}\text { Total space made available } \\
\text { (kgal): }\end{array}$ & 1672 & - & - & - & 3507 & 1217 & 2850 & 1265 \\
\hline
\end{tabular}

1 TWINS, 2009, Tank Waste Information Network System, queried September 2009, [Tank 241-AN-101 and Tank 241-AY-101 Best Basis Inventory data], http://twins.pnl.gov/twins.htm. As reported in RPT-5541-PR-0002, Rev. 1.

Evaporator campaigns to be performed on tanks AW-102, AW-106, AP-107, and AZ-102 in existing baseline plan.

- CC Tanks

$$
\begin{aligned}
& \text { - CC Tanks } \\
& \text { - Group A Tanks }
\end{aligned}
$$

Grapostions

- Hot Commissioning Tank 


\section{APPENDIX E}

\section{SENSITIVITY ANALYSIS CASES}


Sensitivity Case 1: $50 \%$ Weight on Cost and Schedule

\begin{tabular}{|c|c|c|c|c|c|c|c|c|c|c|c|c|c|c|c|c|c|c|}
\hline \multirow[b]{2}{*}{ Criteria } & \multirow[b]{2}{*}{ Measures } & \multirow{2}{*}{$\begin{array}{c}\text { Weighting } \\
\text { factor }\end{array}$} & \multicolumn{2}{|c|}{$\begin{array}{c}\text { Raise waste levels in } \\
\text { nine non-aging waste } \\
\text { DSTs }\end{array}$} & \multicolumn{2}{|c|}{$\begin{array}{c}\text { Concentrate waste in } \\
15 \text { DSTs at } 242-\mathrm{A} \\
\text { Evaporator to } 1.43 \\
\mathrm{~g} / \mathrm{ml} \\
\end{array}$} & \multicolumn{2}{|c|}{$\begin{array}{c}\text { Raise waste levels in } \\
\text { three aging waste } \\
\text { DSTs }\end{array}$} & \multicolumn{2}{|c|}{\begin{tabular}{|l|} 
Raise waste level and \\
concentrate waste in \\
AY-102 to $1.43 \mathrm{~g} / \mathrm{ml}$ \\
\end{tabular}} & \multicolumn{2}{|c|}{$\begin{array}{l}\text { Use restricted } \\
\text { capacity in Group A } \\
\text { Tanks using mixer } \\
\text { pumps }\end{array}$} & \multicolumn{2}{|c|}{$\begin{array}{c}\text { Use restricted } \\
\text { capacity in CC tanks }\end{array}$} & \multicolumn{2}{|c|}{$\begin{array}{l}\text { In-tank evaporation } \\
\text { using dry warm air }\end{array}$} & \multicolumn{2}{|c|}{$\begin{array}{l}\text { Stage sludge waste in } \\
\text { sound SSTs }\end{array}$} \\
\hline & & & \multicolumn{2}{|c|}{$(4.1 .1)$} & \multicolumn{2}{|c|}{$(4.1 .2)$} & \multicolumn{2}{|c|}{$(4.1 .3)$} & \multicolumn{2}{|c|}{ 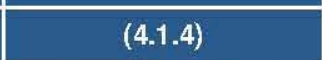 } & \multicolumn{2}{|c|}{$(4.1 .5)$} & \multicolumn{2}{|c|}{$\begin{array}{l}(4.1 .6) \\
\end{array}$} & \multicolumn{2}{|c|}{$(4.1 .7)$} & \multicolumn{2}{|c|}{ (4.1.8) } \\
\hline \multirow{3}{*}{$\begin{array}{l}\text { Safety/Regulatory } \\
\text { Compliance/Stakeholder } \\
\text { Acceptance }\end{array}$} & $\begin{array}{l}\text { Extent to which existing } \mathrm{AB} \text { for } \mathrm{TF} \\
\text { operations will require modification }\end{array}$ & 8 & 5 & 8 & 5 & 8 & 5 & 8 & 5 & 8 & 3 & 4.8 & 5 & 8 & 1 & 1.6 & 1 & 1.6 \\
\hline & $\begin{array}{l}\text { Regulatory agency approval of } \\
\text { modifications to existing } \\
\text { environmental permit(s), or issuance } \\
\text { of new environmental permit(s) }\end{array}$ & 8 & 5 & 8 & 5 & 8 & 5 & 8 & 3 & 4.8 & 5 & 8 & 3 & 4.8 & 3 & 4.8 & 1 & 1.6 \\
\hline & $\begin{array}{l}\text { Stakeholder (e.g., HAB, DNFSB) } \\
\text { and Tribal Nations acceptance }\end{array}$ & 4 & 5 & 4 & 5 & 4 & 3 & 2.4 & 3 & 2.4 & 3 & 2.4 & 3 & 2.4 & 3 & 2.4 & 1 & 0.8 \\
\hline \multirow[t]{3}{*}{ Technical Feasibility } & \multirow{2}{*}{$\begin{array}{l}\text { Estimated volume of recovered tank } \\
\text { space (kgal) }\end{array}$} & & 940 & & 3,500 & & 750 & & 461 & & 799 & & 390 & & 3,300 & & 650 & \\
\hline & & 15 & 5 & 15 & 5 & 15 & 3 & 9 & 3 & 9 & 3 & 9 & 1 & 3 & 3 & 9 & 3 & 9 \\
\hline & Technical maturity & 10 & 5 & 10 & 5 & 10 & 1 & 2 & 1 & 2 & 3 & 6 & 5 & 10 & 5 & 10 & 3 & 6 \\
\hline $\begin{array}{l}\text { Operability and } \\
\text { Maintainability }\end{array}$ & $\begin{array}{l}\text { Ability for facility/process to be } \\
\text { operated and maintained }\end{array}$ & 7 & 5 & 7 & 3 & 4.2 & 5 & 7 & 5 & 7 & 3 & 4.2 & 5 & 7 & 3 & 4.2 & 3 & 4.2 \\
\hline \multirow[t]{6}{*}{ Cost and Schedule } & \multirow{2}{*}{$\begin{array}{l}\text { Total cost (including development } \\
\text { and demonstration, design, } \\
\text { procurement, installation/startup, } \\
\text { operating cost through 2025) }\end{array}$} & & $\$ 5.3 \mathrm{M}$ & & $\$ 23 \mathrm{M}$ & & $\$ 15 \mathrm{M}$ & & $\$ 15 \mathrm{M}$ & & $\$ 55 \mathrm{M}$ & & $\$ 2.2 \mathrm{M}$ & & DNE & & $\$ 81 \mathrm{M}$ & \\
\hline & & 10 & 5 & 10 & 5 & 10 & 5 & 10 & 5 & 10 & 3 & 6 & 5 & 10 & 3 & 6 & 3 & 6 \\
\hline & \multirow[t]{2}{*}{ Cost per gallon of tank space created } & & $\$ 6.00$ & & $\$ 7.00$ & & $\$ 20.00$ & & $\$ 32.60$ & & $\$ 69.00$ & & $\$ 6.00$ & & DNE & & $\$ 125$ & \\
\hline & & 5 & 5 & 5 & 5 & 5 & 3 & 3 & 3 & 3 & 1 & 1 & 1 & 1 & 3 & 3 & 1 & 1 \\
\hline & $\begin{array}{l}\text { Project/activity in existing or } \\
\text { planned facility }\end{array}$ & 8 & 5 & 8 & 5 & 8 & 5 & 8 & 5 & 8 & 5 & 8 & 5 & 8 & 5 & 8 & 5 & 8 \\
\hline & $\begin{array}{l}\text { Implementation schedule (including } \\
\text { development and demonstration, } \\
\text { design, procurement, } \\
\text { installation/startup) }\end{array}$ & 10 & 5 & 10 & 5 & 10 & 5 & 10 & 5 & 10 & 5 & 10 & 5 & 10 & 5 & 10 & 5 & 10 \\
\hline \multirow{6}{*}{$\begin{array}{l}\text { Impact on Waste Feed } \\
\text { Delivery Mission }\end{array}$} & Impact on mix/blend function & 3 & 3 & 1.8 & 3 & 1.8 & 3 & 1.8 & 3 & 1.8 & 3 & 1.8 & 3 & 1.8 & 3 & 1.8 & 3 & 1.8 \\
\hline & $\begin{array}{l}\text { Impact on sample/characterize/ } \\
\text { certify function }\end{array}$ & 3 & 3 & 1.8 & 3 & 1.8 & 3 & 1.8 & 1 & 0.6 & 3 & 1.8 & 3 & 1.8 & 3 & 1.8 & 3 & 1.8 \\
\hline & $\begin{array}{l}\text { Impact on WTP pretreatment } \\
\text { function }\end{array}$ & 3 & 3 & 1.8 & 3 & 1.8 & 3 & 1.8 & 3 & 1.8 & 3 & 1.8 & 1 & 0.6 & 3 & 1.8 & 3 & 1.8 \\
\hline & $\begin{array}{l}\text { Impact on retrieving or returning } \\
\text { waste to processable form }\end{array}$ & 6 & 5 & 6 & 5 & 6 & 5 & 6 & 5 & 6 & 5 & 6 & 3 & 3.6 & 3 & 3.6 & 3 & 3.6 \\
\hline & Sensitivity score: ${ }^{1}$ & 100 & & 97.3 & & 95.2 & & 82.6 & & 79.4 & & 72.1 & & 76.0 & & 71.5 & & 61.9 \\
\hline & Original score: & 100 & & 96.4 & & 93.6 & & 78.8 & & $\mathbf{7 4 . 4}$ & & 70.8 & & 72 & & 68 & & 57.2 \\
\hline
\end{tabular}

1 Calculation for the Sensitivity Score for a $50 \%$ weight on cost and schedule was performed using the following equation:
(Sensitivity score $)=100 *[((0.5 *$ ((sum of safety/regulatory compliance/stakeholder acceptance scores) $+($ (sum of technical feasibility scores $)+($ sum of operability and maintainability scores) $+($ (sum of impact on waste feed delivery mission scores $)) / 67)+$ . * $^{*}$ (sum of cost and schedule scores) $/ 33$ )] 
Sensitivity Case 2: Impact of Waste Feed Delivery Mission

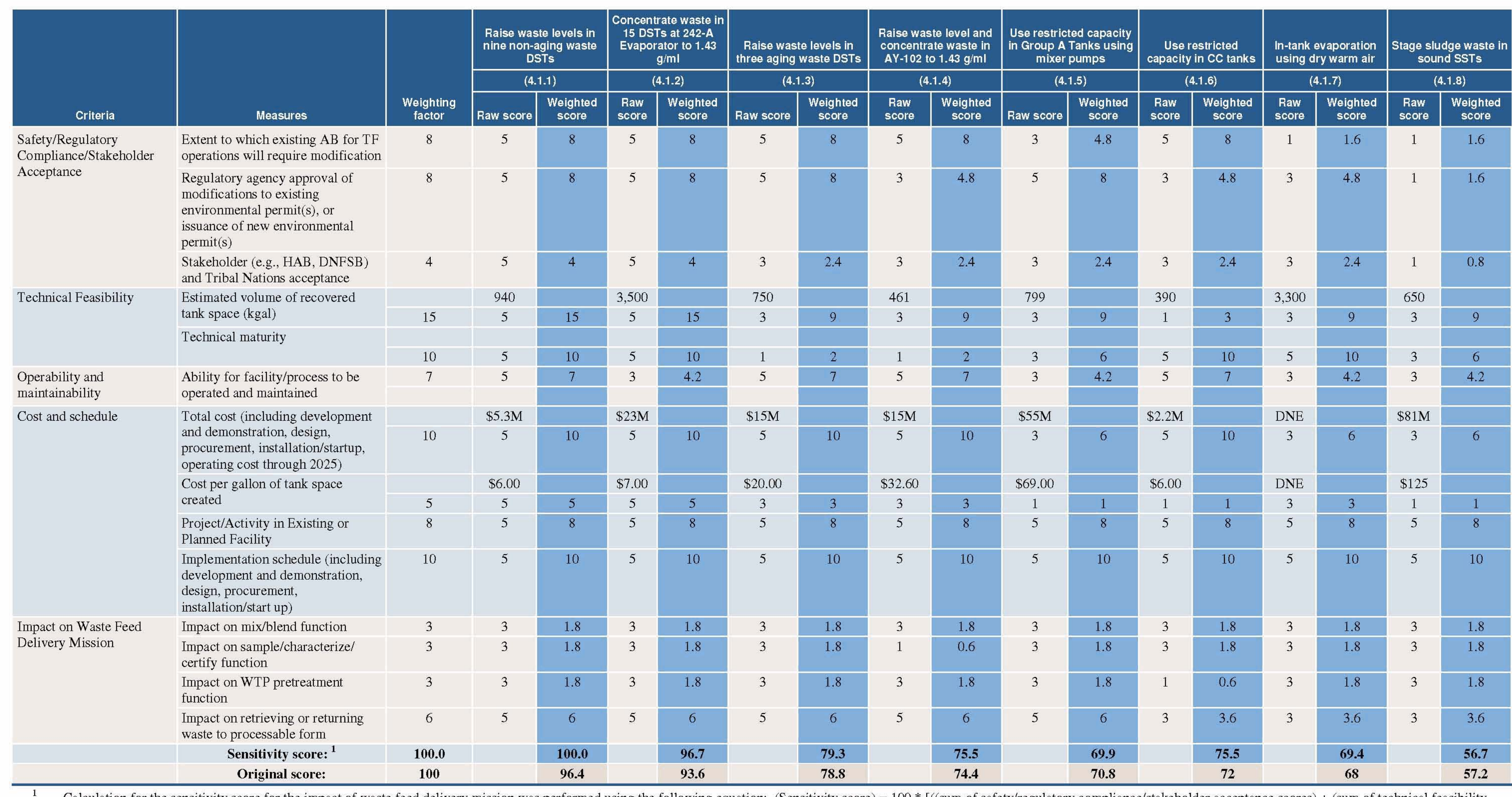

Calculation for the sensitivity score for the impact of waste feed delivery mission was per
scores) + (sum of operability and maintainability scores) + (sum of cost and schedule scores)/ 855$]$ 
Sensitivity Case 3: Impact of Cost and Schedule

\begin{tabular}{|c|c|c|c|c|c|c|c|c|c|c|c|c|c|c|c|c|c|c|}
\hline \multirow[b]{3}{*}{ Criteria } & \multirow[b]{3}{*}{ Measures } & \multirow[b]{3}{*}{$\begin{array}{c}\text { Weighting } \\
\text { factor }\end{array}$} & \multirow{2}{*}{\multicolumn{2}{|c|}{$\begin{array}{c}\begin{array}{c}\text { Raise waste levels in } \\
\text { nine non-aging waste } \\
\text { DSTs }\end{array} \\
\text { (4.1.1) }\end{array}$}} & \multirow{2}{*}{\multicolumn{2}{|c|}{\begin{tabular}{|c|}
$\begin{array}{c}\text { Concentrate waste in } \\
15 \text { DSTs at } 242-\mathrm{A} \\
\text { Evaporator to } 1.43 \\
\mathrm{~g} / \mathrm{ml}\end{array}$ \\
(4.1.2) \\
\end{tabular}}} & \multirow{2}{*}{\multicolumn{2}{|c|}{$\begin{array}{c}\begin{array}{c}\text { Raise waste levels in } \\
\text { three aging waste } \\
\text { DSTs }\end{array} \\
(4.1 .3) \\
\end{array}$}} & \multirow{2}{*}{\multicolumn{2}{|c|}{\begin{tabular}{|c|}
$\begin{array}{c}\text { Raise waste level and } \\
\text { concentrate waste in } \\
\text { AY-102 to } 1.43 \mathrm{~g} / \mathrm{ml}\end{array}$ \\
(4.1.4) \\
\end{tabular}}} & \multirow{2}{*}{\multicolumn{2}{|c|}{$\begin{array}{c}\begin{array}{c}\text { Use restricted } \\
\text { capacity in Group A } \\
\text { Tanks using mixer } \\
\text { pumps }\end{array} \\
\text { (4.1.5) } \\
\end{array}$}} & \multirow{2}{*}{\multicolumn{2}{|c|}{$\begin{array}{c}\begin{array}{c}\text { Use restricted } \\
\text { capacity in CC tanks }\end{array} \\
\text { (4.1.6) } \\
\end{array}$}} & \multirow{2}{*}{\multicolumn{2}{|c|}{$\begin{array}{c}\begin{array}{c}\text { In-tank evaporation } \\
\text { using dry warm air }\end{array} \\
(4.1 .7)\end{array}$}} & \multirow{2}{*}{\multicolumn{2}{|c|}{\begin{tabular}{|c|}
$\begin{array}{c}\text { Stage sludge waste in } \\
\text { sound SSTs }\end{array}$ \\
(4.1.8) \\
\end{tabular}}} \\
\hline & & & & & & & & & & & & & & & & & & \\
\hline & & & Raw score & $\begin{array}{c}\text { Weighted } \\
\text { score }\end{array}$ & $\begin{array}{l}\text { Raw } \\
\text { score }\end{array}$ & $\begin{array}{l}\text { Weighted } \\
\text { score }\end{array}$ & $\begin{array}{l}\text { Raw } \\
\text { score }\end{array}$ & $\begin{array}{l}\text { Weighted } \\
\text { score }\end{array}$ & $\begin{array}{l}\text { Raw } \\
\text { score }\end{array}$ & $\begin{array}{l}\text { Weighted } \\
\text { score }\end{array}$ & $\begin{array}{l}\text { Raw } \\
\text { score }\end{array}$ & $\begin{array}{c}\text { Weighted } \\
\text { score }\end{array}$ & $\begin{array}{l}\text { Raw } \\
\text { score }\end{array}$ & $\begin{array}{l}\text { Weighted } \\
\text { score }\end{array}$ & $\begin{array}{l}\text { Raw } \\
\text { score }\end{array}$ & $\begin{array}{l}\text { Weighted } \\
\text { score }\end{array}$ & $\begin{array}{l}\text { Raw } \\
\text { score }\end{array}$ & $\begin{array}{l}\text { Weighted } \\
\text { score }\end{array}$ \\
\hline \multirow{3}{*}{$\begin{array}{l}\text { Safety/Regulatory } \\
\text { Compliance/Stakeholder } \\
\text { Acceptance }\end{array}$} & $\begin{array}{l}\text { Extent to which existing } \mathrm{AB} \text { for } \mathrm{TF} \\
\text { operations will require modification }\end{array}$ & 8 & 5 & 8 & 5 & 8 & 5 & 8 & 5 & 8 & 3 & 4.8 & 5 & 8 & 1 & 1.6 & 1 & 1.6 \\
\hline & $\begin{array}{l}\text { Regulatory agency approval of } \\
\text { modifications to existing } \\
\text { environmental permit(s), or issuance } \\
\text { of new environmental permit(s) }\end{array}$ & 8 & 5 & 8 & 5 & 8 & 5 & 8 & 3 & 4.8 & 5 & 8 & 3 & 4.8 & 3 & 4.8 & 1 & 1.6 \\
\hline & $\begin{array}{l}\text { Stakeholder (e.g., HAB, DNFSB) } \\
\text { and Tribal Nations acceptance }\end{array}$ & 4 & 5 & 4 & 5 & 4 & 3 & 2.4 & 3 & 2.4 & 3 & 2.4 & 3 & 2.4 & 3 & 2.4 & 1 & 0.8 \\
\hline \multirow[t]{4}{*}{ Technical Feasibility } & \multirow{2}{*}{$\begin{array}{l}\text { Estimated volume of recovered tank } \\
\text { space (kgal) }\end{array}$} & & 940 & & 3,500 & & 750 & & 461 & & 799 & & 390 & & 3,300 & & 650 & \\
\hline & & 15 & 5 & 15 & 5 & 15 & 3 & 9 & 3 & 9 & 3 & 9 & 1 & 3 & 3 & 9 & 3 & 9 \\
\hline & \multirow[t]{2}{*}{ Technical maturity } & & & & & & & & & & & & & & & & & \\
\hline & & 10 & 5 & 10 & 5 & 10 & 1 & 2 & 1 & 2 & 3 & 6 & 5 & 10 & 5 & 10 & 3 & 6 \\
\hline $\begin{array}{l}\text { Operability and } \\
\text { maintainability }\end{array}$ & $\begin{array}{l}\text { Ability for facility/process to be } \\
\text { operated and maintained }\end{array}$ & 7 & 5 & 7 & 3 & 4.2 & 5 & 7 & 5 & 7 & 3 & 4.2 & 5 & 7 & 3 & 4.2 & 3 & 4.2 \\
\hline \multirow[t]{6}{*}{ Cost and schedule } & \multirow{2}{*}{$\begin{array}{l}\text { Total cost (including development } \\
\text { and demonstration, design, } \\
\text { procurement, installation/startup, } \\
\text { operating cost through 2025) }\end{array}$} & & $\$ 5.3 \mathrm{M}$ & & $\$ 23 \mathrm{M}$ & & $\$ 15 \mathrm{M}$ & & $\$ 15 \mathrm{M}$ & & $\$ 55 \mathrm{M}$ & & $\$ 2.2 \mathrm{M}$ & & DNE & & $\$ 81 \mathrm{M}$ & \\
\hline & & 10 & 5 & 10 & 5 & 10 & 5 & 10 & 5 & 10 & 3 & 6 & 5 & 10 & 3 & 6 & 3 & 6 \\
\hline & \multirow[t]{2}{*}{ Cost per gallon of tank space created } & & $\$ 6.00$ & & $\$ 7.00$ & & $\$ 20.00$ & & $\$ 32.60$ & & $\$ 69.00$ & & $\$ 6.00$ & & DNE & & $\$ 125$ & \\
\hline & & 5 & 5 & 5 & 5 & 5 & 3 & 3 & 3 & 3 & 1 & 1 & 1 & 1 & 3 & 3 & 1 & 1 \\
\hline & $\begin{array}{l}\text { Project/Activity in Existing or } \\
\text { Planned Facility }\end{array}$ & 8 & 5 & 8 & 5 & 8 & 5 & 8 & 5 & 8 & 5 & 8 & 5 & 8 & 5 & 8 & 5 & 8 \\
\hline & $\begin{array}{l}\text { Implementation schedule (including } \\
\text { development and demonstration, } \\
\text { design, procurement, } \\
\text { installation/startup) }\end{array}$ & 10 & 5 & 10 & 5 & 10 & 5 & 10 & 5 & 10 & 5 & 10 & 5 & 10 & 5 & 10 & 5 & 10 \\
\hline \multirow{6}{*}{$\begin{array}{l}\text { Impact on Waste Feed } \\
\text { Delivery Mission }\end{array}$} & Impact on mix/blend function & 3 & 3 & 1.8 & 3 & 1.8 & 3 & 1.8 & 3 & 1.8 & 3 & 1.8 & 3 & 1.8 & 3 & 1.8 & 3 & 1.8 \\
\hline & $\begin{array}{l}\text { Impact on sample/characterize/ } \\
\text { certify function }\end{array}$ & 3 & 3 & 1.8 & 3 & 1.8 & 3 & 1.8 & 1 & 0.6 & 3 & 1.8 & 3 & 1.8 & 3 & 1.8 & 3 & 1.8 \\
\hline & $\begin{array}{l}\text { Impact on WTP pretreatment } \\
\text { function }\end{array}$ & 3 & 3 & 1.8 & 3 & 1.8 & 3 & 1.8 & 3 & 1.8 & 3 & 1.8 & 1 & 0.6 & 3 & 1.8 & 3 & 1.8 \\
\hline & $\begin{array}{l}\text { Impact on retrieving or returning } \\
\text { waste to processable form }\end{array}$ & 6 & 5 & 6 & 5 & 6 & 5 & 6 & 5 & 6 & 5 & 6 & 3 & 3.6 & 3 & 3.6 & 3 & 3.6 \\
\hline & Sensitivity score: ${ }^{1}$ & 100.0 & & 100.0 & & 100.0 & & 93.9 & & 93.9 & & 75.8 & & 87.9 & & 81.8 & & 75.8 \\
\hline & Original score: & 100 & & 96.4 & & 93.6 & & 78.8 & & 74.4 & & 70.8 & & 72 & & 68 & & 57.2 \\
\hline
\end{tabular}

1 Calculation for the sensitivity score for the impact of cost and schedule was performed using the following equation: (Sensitivity score) $=100 *$ [(sum of cost and schedule scores)/33]. 


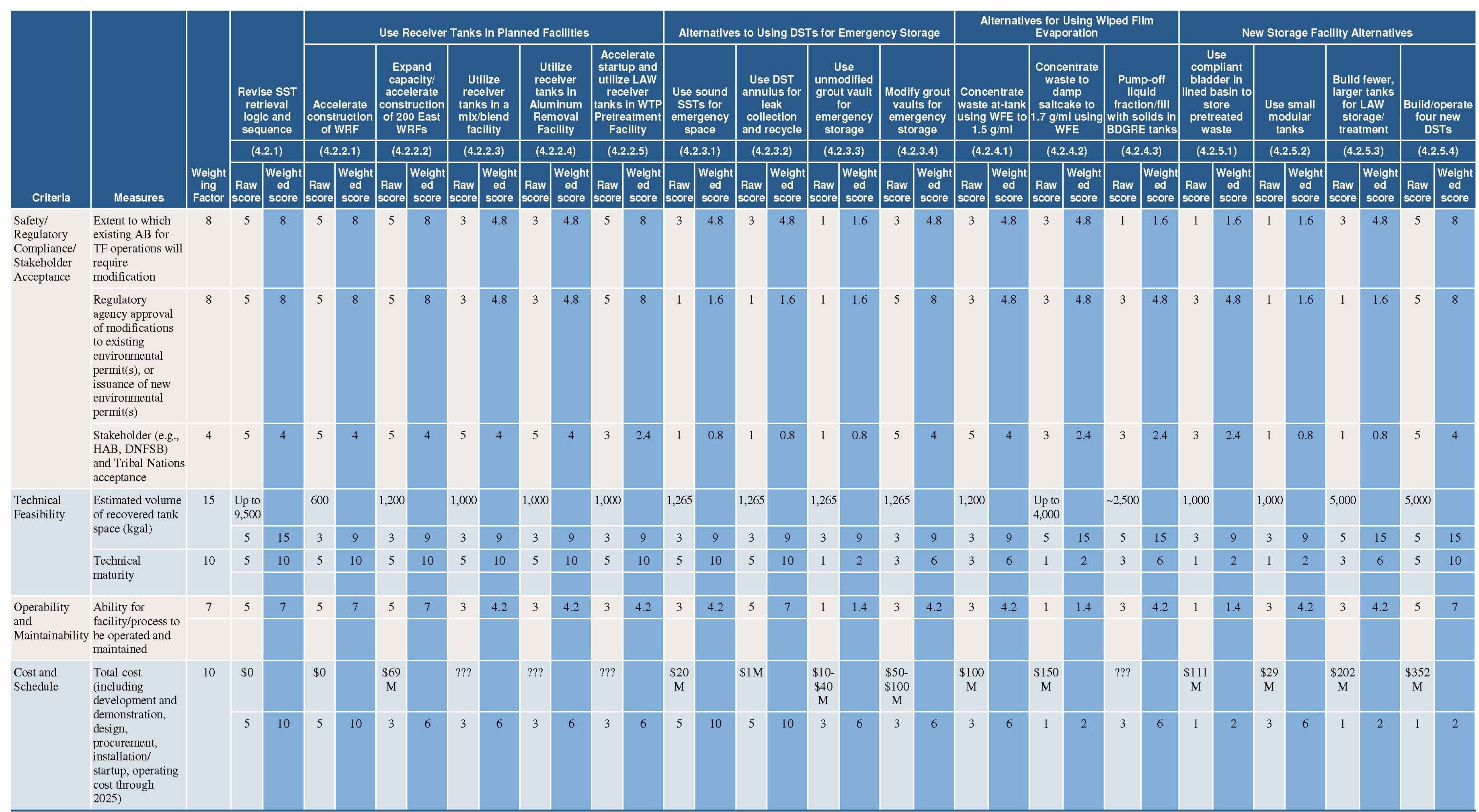




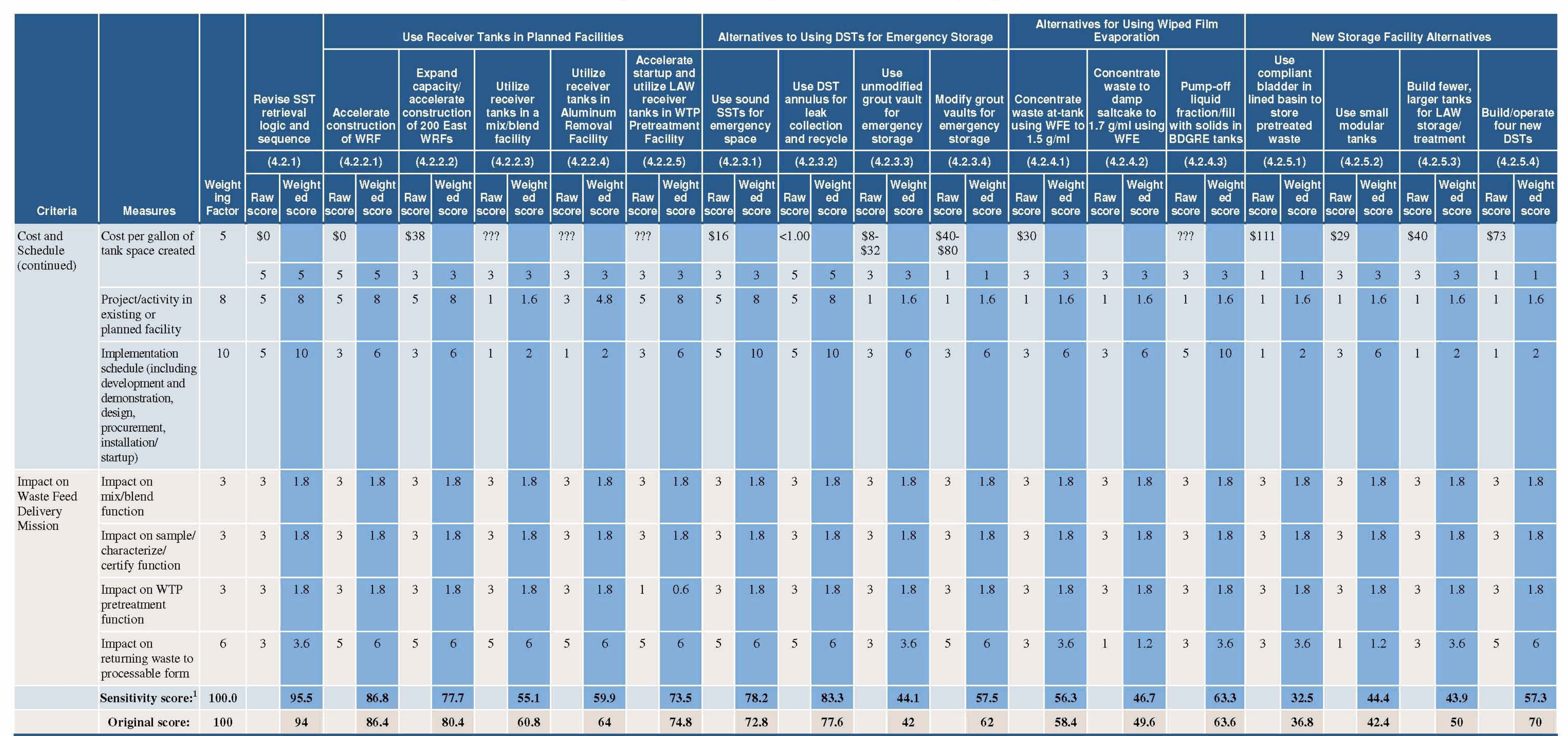

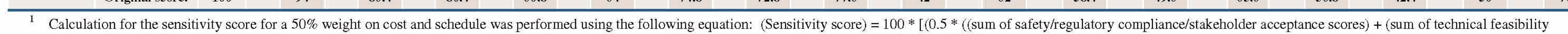
scores) + (sum of operability and maintainability scores) + (sum of impact on waste feed delivery mission scores) $) / 67)+(0.5 *$ (sum of cost and schedule scores) $/ 33)]$ 


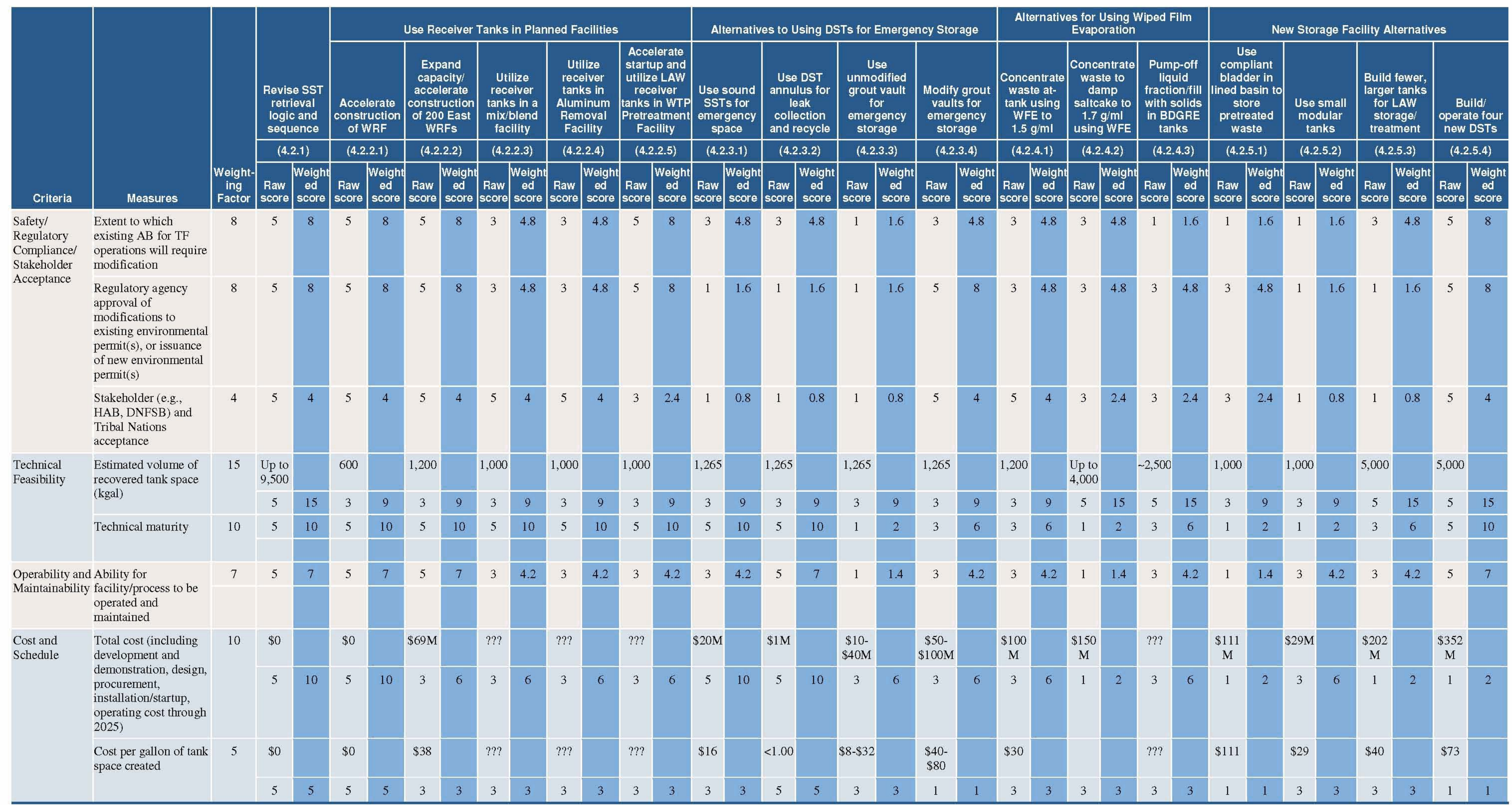




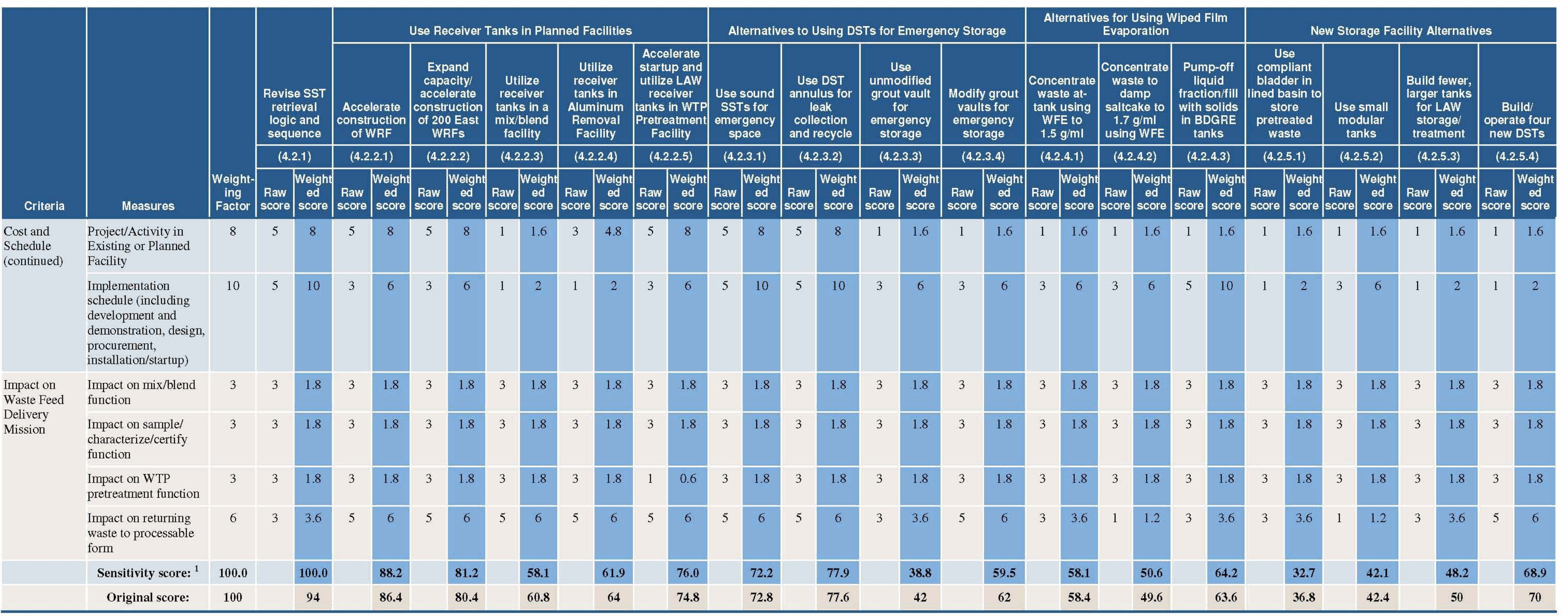

1 Calculation for the sensitivity score for the impact of waste feed delivery mission was perfor
scores) $+($ (sum of operability and maintainability scores $)+($ (sum of cost and schedule scores) $) / 85$ ] 


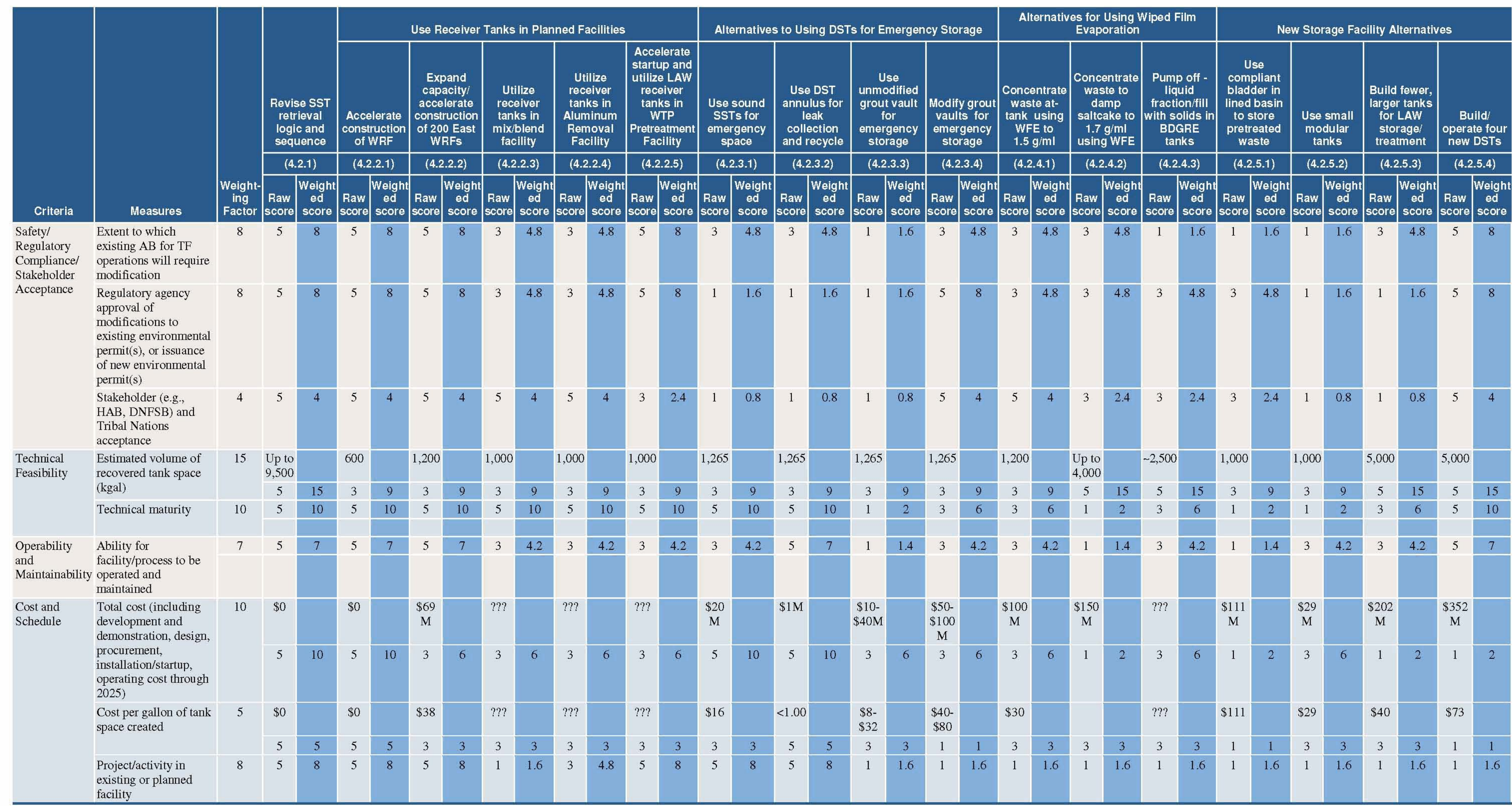




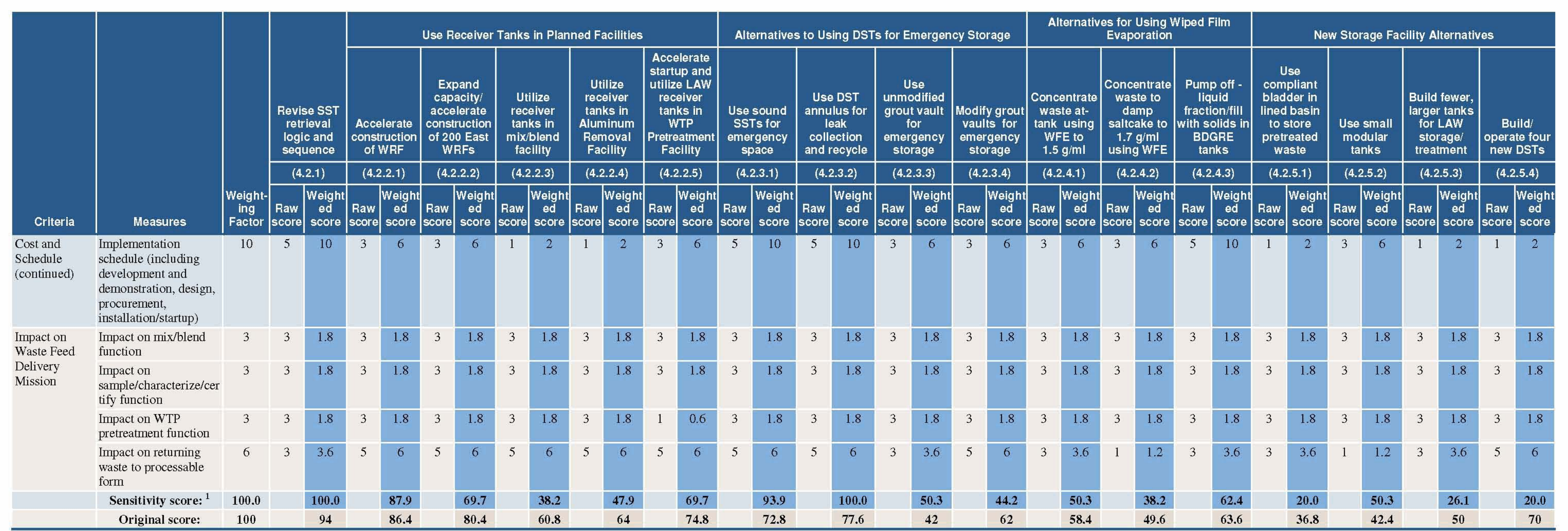

1 Calculation for the sensitivity score for the impact of cost and schedule was performed using the following equation: (Sensitivity score) $=100 *[$ (sum of cost and schedule scores)/33] 


\section{APPENDIX F}

\section{SUMMARY OF DECISION SUPPORT BOARD MEETINGS}




\section{SUMMARY OF DECISION SUPPORT BOARD MEETINGS}

The Decision Support Board was convened a total of eight times in support of the Tank Space Alternatives Analysis initiative between February 16 and March 10, 2010. Those meetings are summarized as follows:

1. Kick-off Meeting (Tuesday, February 16, 2010) - reviewed and revised criteria, measures, definitions, and weightings as proposed in the RPP-PLAN-45168, Tank Space Options Decision Plan; brainstormed potential tank space options, in addition to those already identified in the RPP-7702, Tank Space Options Report (Rev. 1)

2. Alternatives Evaluation Meeting \#1 (Wednesday, February 17, 2010) - initiated evaluation of options that could potentially be implemented in the near-term (2011 2015)

3. Alternatives Evaluation Meeting \#2 (Thursday, February 18, 2010) - completed evaluation of near-term options; initiated evaluation of options that could potentially be implemented in the long-term (2015 - 2020)

4. Alternatives Evaluation Meeting \#3 (Tuesday, February 23, 2010) - completed evaluation of individual options; initiated evaluation of combinations of near-term and long-term options that could potentially be recommended for implementation by the TOC

5. Alternatives Evaluation Meeting \#4 (Wednesday, February 24, 2010) - met with seven subject matter experts, representing operations (2), nuclear safety, regulatory compliance, projects, the wiped-film evaporation technology/project, and RPP system modeling to review results of evaluations and provide subject matter experts feedback and input

6. Alternatives Evaluation Meeting \#5 (Friday, February 26, 2010) - reviewed input from subject matter experts and revised evaluations as appropriate; developed graphics to support recommended near-term and long-term options; finalized report outline

7. Table Top Review Meeting \#1 (Monday, March 8, 2010) - initiated review of draft RPP-45825, Tank Space Alternatives Analysis Report

8. Table Top Review Meeting \#2 (Wednesday, March 10, 2010) - completed review of draft report; finalized graphics to support recommended near-term/long-term options. 
APPENDIX G

DECISION SUPPORT BOARD MEMBER BIOS 


\section{DECISION SUPPORT BOARD MEMBER BIOS}

A Decision Support Board (DSB) was selected to identify, evaluate, and recommend options that could potentially be implemented by the Tank Operations Contractor (TOC) to allow continued and uninterrupted single-shell tank (SST) retrievals to support the waste feed delivery mission, while the Waste Treatment and Immobilization Plant (WTP) construction and startup is proceeding. The selected members of the DSB have over 175 years of combined Hanford-related experience. Brief biographical summaries of DSB members are provided below.

Nicholas W. Kirch (Washington River Protection Solutions LLC [WRPS]) - Mr. Kirch has more than 29 years of Hanford-related experience with the prime contractor responsible for operation of the Hanford tank farms. During that time, he has managed technical organizations responsible for the resolution of tank safety issues, including flammable gas generation, retention and release, organic-nitrate reactions, and high radiolytic decay heat. He is currently the engineering manager for organizations responsible for developing near-term operating plans for waste transfers and evaporator campaigns, and for long-term mission modeling in support of strategic planning. Mr. Kirch has a degree in chemical engineering from Iowa State University.

P.S. (Steve) Schaus (Consultant) - Mr. Schaus has more than 35 years of experience supporting U.S. Department of Energy (DOE) and Department of Defense projects and programs, including 30 years of Hanford-related experience. He has supported a number of Hanford-specific (e.g., tank waste remediation system) and DOE complex-wide (e.g., New Production Reactor) strategic and long-range planning initiatives, and the identification, evaluation, and selection of technologies for retrieving, treating, and disposing of nuclear waste. He also managed the High-Level Waste Program Office that provided technical and programmatic support to DOE Headquarter/EM-30 for four years. Since retiring in 2006, Mr. Schaus has been an independent contractor, consulting on several different projects, including the tank farm interim pretreatment system and the TOC's Recovery Act pre-planning activities. Mr. Schaus has a master's degree in metallurgical engineering from Columbia University and a master's degree in business administration from George Washington University.

Dennis J. Washenfelder (WRPS) - Mr. Washenfelder has more than 40 years of Hanford-related experience in operations, engineering, laboratory operations, and project management. He has worked on the Hanford 200 Area nuclear fuels reprocessing, plutonium metal and oxide production, fission product processing, and tank waste storage and treatment facilities. His tank farm experience includes 18 years in operations management of the 200 Area tank farm processes, startup of the 241-AN and 241-AW doubleshell tank (DST) farms, and process and design engineering. He is currently the engineering manager for Technical Integration, Central Process Engineering, and DST and SST Integrity. Mr. Washenfelder has a degree in chemistry from Washington State University.

Stephen A. Wiegman (Consultant) - Mr. Wiegman has over 40 years of experience in the development and safe operation of electrical power systems, defense nuclear production facilities, and nuclear/mixed waste management. His experience includes 30 years working on Hanford-related projects with prime contractors, as a consultant, and as a DOE employee. He has technical expertise in environmental compliance, nuclear safety, emergency response, facility planning, life-cycle baseline management, and technology development. He has successfully represented major projects to the public and regulatory agencies. He has managed SST technology programs, long-range Hanford site clean-up planning, and environmental and safety organizations. He also served as a Senior Technical Advisor for the DOE Office of River Protection (ORP). Mr. Wiegman has a degree in civil engineering from California Polytechnic Institute. 
Donald W. Wodrich (Consultant) - Mr. Wodrich worked on the Hanford Site for 50 years, including 36 years with prime contractors, 6 years with DOE-ORP, and 8 years as a consultant to DOE-ORP. During this time, he managed technical organizations involved in program management, program planning, technical integration, conceptual design, process design, equipment development, construction, and safety analysis. These activities have primarily been for the safe storage, retrieval, treatment, and immobilization of the high-level radioactive tank waste. He also has experience in nuclear spent fuel reprocessing and plutonium processing. Mr. Wodrich visited the former USSR in the $1990 \mathrm{~s}$ as a member of the United States fact-finding delegation on environmental restoration/waste management and a chemical explosion in a radiochemical plant. He has also visited numerous nuclear sites in Europe and the United States. Mr. Wodrich has a degree in mechanical engineering from Montana State University and is a registered professional engineer in the state of Washington. 